UNIVERSIDAD NACIONAL DE LA PLATA

FACULTAD DE HUMANIDADES Y CIENCIAS DE LA EDUCACIÓN SECRETARÍA DE POSGRAdo

\title{
Incidencia de un Programa de Alfabetización Familiar
}

Evaluación de actitudes y conocimientos sobre el mundo letrado en niños de sectores populares

\section{María Noel Guidali Leunda}

Tesis para optar por el grado de Magíster en Escritura y Alfabetización

Directora Ana María Kaufman

Universidad Nacional de La Plata

La Plata, 30 de agosto de 2013 
Dedico este trabajo a los niños, maestros y familias de la escuela 71.

Ellos impulsaron mi búsqueda. 
Agradecimientos

Cuando un trabajo como este concluye se toma conciencia de que todo tuvo que ver para que ocurriera. Los primeros afectos, los primeros cuentos, mis maestras, mi familia, la que la vida me dio y la que luego elegí. Pero debo destacar y agradecer especialmente a mi madre, que me inscribió en magisterio mientras decidía qué quería ser en la vida. A mi padre, que me hizo incansablemente curiosa. A mis alumnos, que me señalaban lo que debía aprender para poder enseñarles. A las maestras de las escuelas que intervinieron en el estudio, por apostar con nosotros en la mejora de los aprendizajes de los niños.

Al flaco, que como siempre estuvo y está conmigo en la lucha, y a mis hijos, a los cinco.

A mi directora, militante de la generosidad y entrega. ¿Cómo retribuir el honor de haber sido su alumna?

Finalmente a la otra Cuenta, compañera incondicional, con quien porfiadamente creemos que la lectura permite no solo pensar en otros mundos posibles sino tomar posición y actuar para lograrlos. 


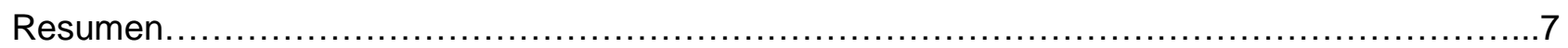

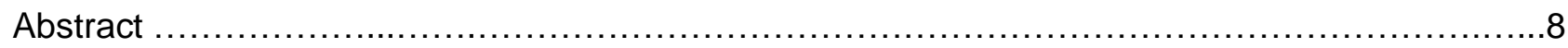

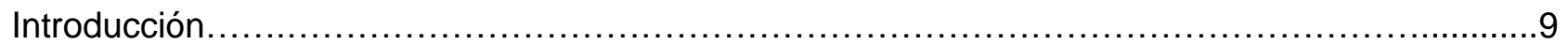

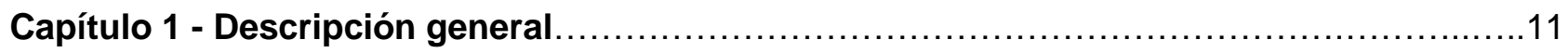

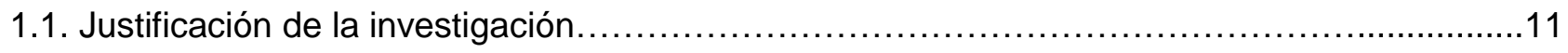

1.2. Descripción del Programa de Alfabetización Familiar Cuenta Quien Cuenta......................13

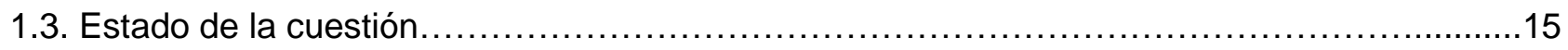

1.3.1. Estudios sobre la vinculación entre la intervención familiar y la formación del niño

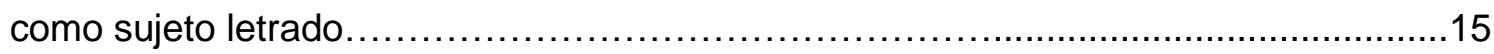

1.3.2. Programas y experiencias de alfabetización familiar...............................28

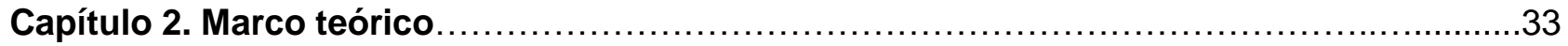

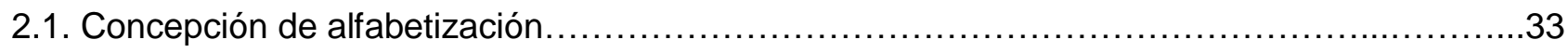

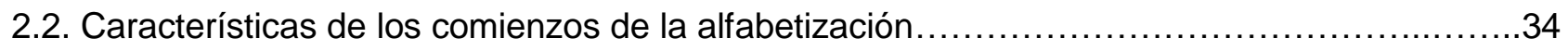

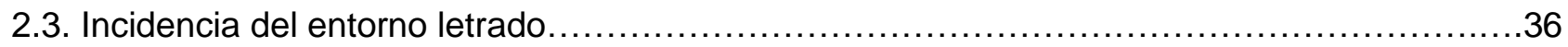

2.4. Situaciones didácticas que favorecen la formación de los niños como lectores y productores

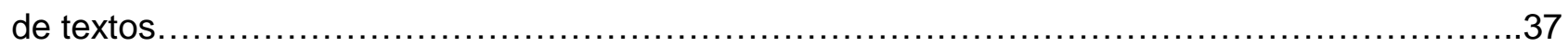

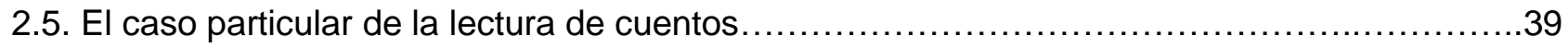

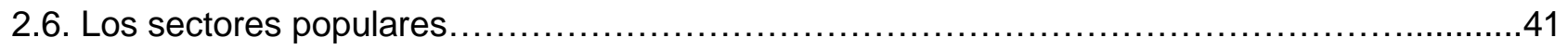

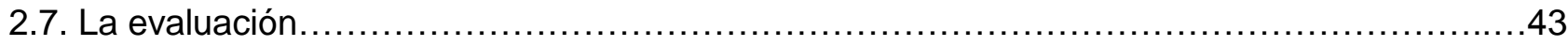

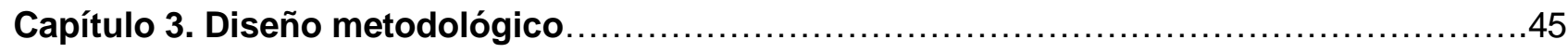

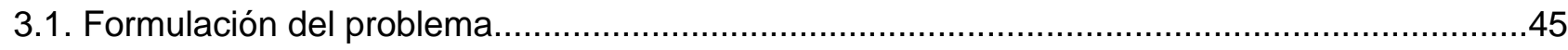

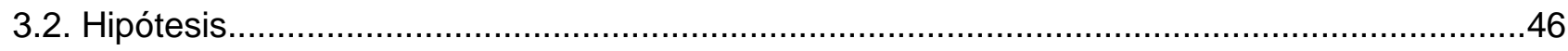

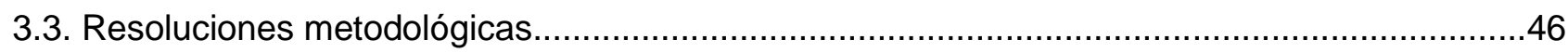


3.3.1. Población seleccionada: características del grupo experimental y del grupo control47

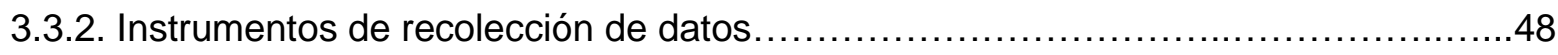

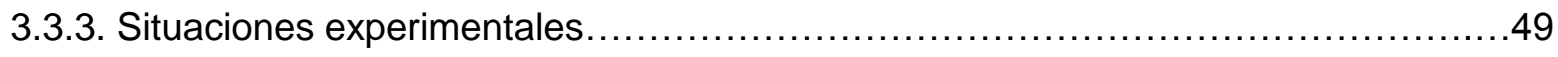

3.3.4. Etapas de procesamiento de los datos obtenidos.....................................50

Capítulo 4.Descripción de las situaciones experimentales, categorías de análisis y

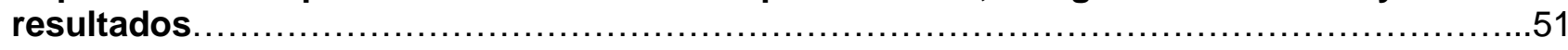

4.1. Situación 1 -Encuesta a los adultos participantes del Programa Cuenta Quien Cuenta...........51

4.1.1. Análisis de los datos personales de los participantes...................................54

4.1.2. Análisis de su relación con la cultura letrada..............................................54

4.2. Situación 2 - Exploración y contacto de los niños con los libros..............................................56

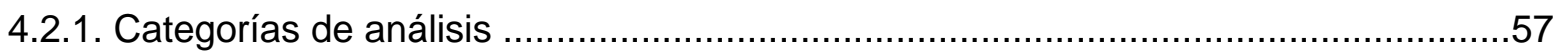

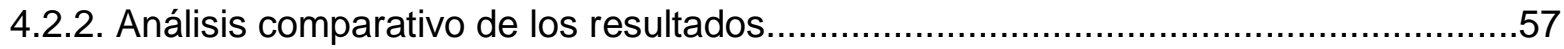

4.3. Situación 3 - Renarración oral de cuentos..........................................................................

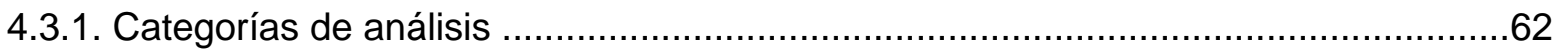

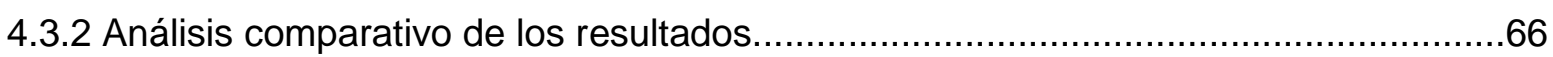

4.4. Situación 4- Escritura del nombre propio.......................................................................70

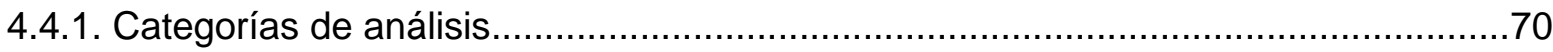

4.4.2. Análisis comparativo de los resultados.............................................................70

4.5. Situación 5 - Escritura de palabras: conocimiento del sistema de escritura...............................72

4.5.1. Categorías de análisis.................................................................................

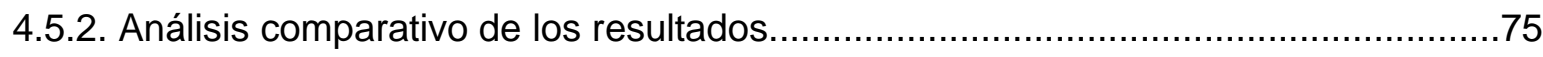

4.6. Situación 6 - Lectura de palabras: uso de estrategias lectoras...............................................77

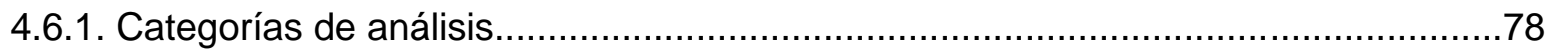

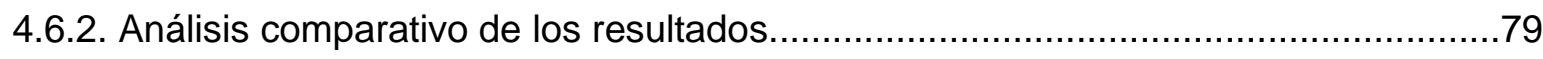

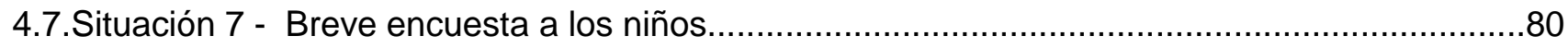

4.7.1 Análisis comparativo de los lectores con que cuentan los niños................................8

4.7.2. Análisis comparativo del caudal de cuentos conocidos..........................................82

4.7.3. Análisis comparativo del conocimiento de los títulos de los cuentos ........................83 
Síntesis de los resultados obtenidos.

Reflexiones finales .89

Referencias bibliográficas

\section{ANEXOS}

ANEXO 1 Situación 2. Cuentos seleccionados para la: Renarración de cuentos

ANEXO 2 Desgrabaciones de los relatos orales de cuentos

ANEXO 3 Situación 3. Distribución de los datos sobre estructura narrativa y recursos literarios correspondientes al Grupo 1 y 2

ANEXO 4 Situación 4. Distribución de los datos sobre escrituras correspondientes al Grupo 1 y 2

ANEXO 5 Situación 7. Distribución de los datos sobre Quién lee al niño; qué títulos recuerda y cuántos correspondientes al Grupo 1 y 2

ANEXO 6 Descripción del Módulo 4 del Programa Cuenta Quien Cuenta (componente metodológico). 


\section{Resumen}

El propósito de esta investigación cualitativa es indagar, a través de un estudio descriptivointerpretativo, la eventual incidencia de un Programa de Alfabetización Familiar en la inclusión de los niños en la cultura escrita al ingresar al primer año escolar. Para esto se evaluarán ciertas actitudes vinculadas con el tipo de contacto que establecen los hijos de algunos participantes con la cultura de los libros y los conocimientos construidos acerca del sistema de escritura y del lenguaje escrito, como así también el desarrollo de estrategias lectoras.

Se parte del análisis del Programa de Alfabetización con la Familia "Cuenta Quien Cuenta", iniciado en el año 2006 en Paysandú, Uruguay, destinado a padres, madres y otros referentes familiares de niños hasta 5 años de edad, pertenecientes a contextos de alta vulnerabilidad económica, social y cultural. El programa tiene una duración de cuatro meses, en los se desarrollan doce talleres. En estos espacios se leen cuentos, se comparten pistas sobre cómo promover la lectura frecuente y la conversación sobre libros y cuentos en el hogar, se compaginan libros y, sobre todo, se insiste en la revalorización del rol de los asistentes como primeros agentes alfabetizadores de sus hijos. Al finalizar el período de intervención, cada hogar cuenta con alrededor de dieciséis libros de cuentos como material de lectura.

El relevamiento realizado sobre otros programas y experiencias de este tipo puso de manifiesto que, en general, están centrados en la descripción del seguimiento realizado y en la socialización de registros anecdóticos, no incluyendo publicaciones que den cuenta de la evaluación de sus efectos en cuanto a los conocimientos de los niños.

Por esa razón, esta investigación procura aportar un conjunto de herramientas que permitan iniciar un camino tendiente a focalizar indicadores que permitan evaluar más específicamente los alcances de las acciones realizadas.

Palabras clave: alfabetización familiar, evaluación, lectura, escritura. 


\section{Abstract}

The purpose of this qualitative research is to investigate, by means of a descriptive-interpretive approach, the potential impact of a Family Literacy Program on the inclusion of children in the written culture when they enter the first grade of primary school. This Family Literacy Program assesses the knowledge built up by some participants' children upon the writing system, as well as about their possibilities for storytelling and the form of contact they have established with books.

It starts from the analysis of the program "Cuenta Quien Cuenta" (It Matters Who Tells the Story), launched in 2006 in Paysandú, Uruguay, which is directed to parents and other family members that act as significant role models for children under 5 years old living under highly vulnerable economic, social and cultural conditions. This program is compounded by twelve workshops where stories are read, clues about how to promote discussions on books and stories at home are given, and books are elaborated. These workshops emphasized on the revalorization of the role of the participants as primary agents the children's literacy. At the end of the intervention period, each household has twelve story books as reading materials.

This research attempts to appoint a systemic observation on children's initial literacy, considering that participation in social practices of reading and writing is the inescapable way to forming readers and writers who could have access through these practices to the necessary metalinguistic reflecting levels.

In the survey conducted on other programs and experiences of this type, generally they focus on the description of the monitoring and socialization of anecdotal records, not finding publications that account for the evaluation of their effects in terms of knowledge of the children.

For that reason, this research seeks to provide a set of tools to start a path tending to focus indicators to assess more specifically the scope of the actions taken.

Key words: family literacy, evaluation, reading, writing. 


\section{Introducción}

Esta tesis pretende evaluar algunos conocimientos sobre el lenguaje escrito y el sistema de escritura, el contacto con la cultura de los libros y las estrategias lectoras desarrolladas por los hijos de algunos participantes de un Programa de Alfabetización con la Familia.

Este trabajo trata de encontrar evidencias de la incidencia de la alfabetización familiar en el posicionamiento del niño como lector y escritor al momento de enfrentarse a la enseñanza formal del lenguaje escrito. Por lo tanto procura identificar y describir qué conocimientos tienen esos niños, que permanecieron inmersos en un entorno alfabetizador a través de la lectura frecuente de cuentos por parte de adultos, al ingresar a la escuela.

La investigación se ha desarrollado en el marco de la Maestría de Escritura y Alfabetización de la Universidad Nacional de la Plata, organizada por la Facultad de Humanidades y Ciencias de la Educación durante el período 2011-2012.

El documento que se presenta a continuación está organizado en cuatro capítulos.

En el Capítulo 1 se describe el Programa de Alfabetización con la Familia Cuenta Quien Cuenta y se despliegan argumentos sobre la importancia de su evaluación. Seguidamente se expone el relevamiento de estudios sobre la vinculación entre la intervención familiar y formación del niño como sujeto letrado y se comentan algunos programas educativos de Argentina, Chile, Brasil, Colombia, España y Francia que pretenden intervenir en ese sentido.

El Capítulo 2 se exponen algunas nociones teóricas en cuanto a los conceptos clave que integran y atraviesan el estudio, vinculadas con:

- la comprensión del fenómeno de la alfabetización, en su más amplio sentido;

- el proceso de alfabetización inicial;

- el modelo didáctico correspondiente a una perspectiva constructivista desarrollado en los últimos años en la República Argentina;

- la concepción vygostkiana del lenguaje como construcción social;

- la noción de familia como entorno alfabetizador; 
- la importancia de la lectura de cuentos a los niños;

- la caracterización de los sectores populares a los que pertenecen los participantes del Programa;

- la conceptualización sobre evaluación a la que adhiere este trabajo.

En el Capítulo 3 se presenta el diseño metodológico de la investigación, en el que se especifica la formulación del problema y las hipótesis centrales, se describe el conjunto de decisiones metodológicas tomadas, se delimita la muestra seleccionada -un grupo experimental y otro control- y se presentan las situaciones experimentales utilizadas para evaluar los conocimientos de los niños y sus familias.

En el Capítulo 4 se describen detalladamente esas situaciones experimentales, las categorías de análisis y los resultados. En primer lugar se puntualiza el proceso de relevamiento de datos y procesamiento de la información obtenida. Luego se ilustran los resultados en tablas y gráficos correspondientes a cada situación experimental y por último se analizan los resultados.

Finalmente, se presentan las conclusiones de esta investigación. 


\section{Capítulo 1.}

\section{Descripción general}

\subsection{Justificación de la investigación}

Desde una perspectiva etnográfica se considera al aprendizaje de la lectura y la escritura como una práctica social donde la relación con el libro y la lectura, como objetos culturales, es generada en alta medida por el contexto más próximo al niño, su familia. Este primer ambiente que propicia el desarrollo lingüístico, cognitivo y social infantil tiene implicancia directa en el aprendizaje escolar en general y en el aprendizaje del lenguaje escrito en particular.

Un considerable número de investigaciones ha demostrado que la participación de los padres y madres en situaciones de lectura en el hogar es un factor relevante para ayudar a mejorar el desempeño lector de sus hijos (Flouri y Buchanan, 2004; Burgess, Heath, 1983; Primavera, 2000). Sin embargo, las características de los programas de intervención a nivel familiar son diversas y no siempre cuentan con un fundamento teórico y/o práctico consistente, que permita evaluar sus logros. Hasta el momento, no se han relevado experiencias que comparen sus datos con un grupo control, a fin de poder atribuir los resultados observados a la intervención realizada (Wasik, Dobbins y Herrmann, 2002; De Bruin-Parecki y Krol-Sinclair, 2005). Por otra parte, los casos que presentan alguna evaluación de los resultados de la intervención a nivel familiar suelen ser limitados o inconsistentes (Goldenburg, 2002).

Esta investigación se propone evaluar la incidencia del Programa de Alfabetización con la Familia "Cuenta Quien Cuenta", coordinado por la maestra Mabel De Agostini y la autora de esta tesis.

El Programa surgió en el año 2006 y continúa desarrollándose todavía. En el año 2005 la Inspección Departamental de Escuelas de Paysandú, Uruguay había constatado que el 25\% de los alumnos que cursaban primer año de Educación primaria en las escuelas públicas habían repetido el año. Asimismo, se tomó en consideración otro dato importante, aportado por las autoridades municipales que gestionaban los Centros Comunitarios de Educación Infantil donde concurren niños de 0 a 5 años: el $36 \%$ de las madres de los niños que asistían a estos centros no 
había completado el ciclo de Educación primaria y el 72\% de las mismas manifestaba ausencia de materiales de lectura en el hogar.

El modelo socioeducativo de intervención que propone el Programa se estructura a partir de los saberes, creencias y potencialidades que las familias de contextos vulnerables tienen en torno a la lectura y la escritura y del valor social y cultural que le atribuyen a estas prácticas.

En el momento de diseñar el Programa se tuvo en cuenta el consenso que existe entre los investigadores respecto de la importancia que tiene la lectura de cuentos para el desarrollo del lenguaje y el aprendizaje de la lectura y la escritura (Payne, Whitehurst et al., 1994; Wasik \& Bond, 2001). Lamentablemente, no todos los entornos cercanos al niño - el hogar y la escuela proporcionan siempre experiencias de calidad y cantidad. Los niños de sectores más empobrecidos tienen en general un contacto muy limitado con libros de cuentos (Adams, 1990; Snow, Burns \& Griffin, 1998; UNICEF, 1990; Wells 1988).

Las experiencias de alfabetización de los niños previas a su ingreso a la escuela constituyen uno de los factores más importantes para comprender las causas de algunas de las dificultades que manifiestan muchos niños provenientes de familias de contextos de pobreza para aprender a leer y escribir. En función de ello se concibió el Programa mencionado aspirando a que se constituyera como una propuesta alternativa que invitara a los adultos a leer cuentos en forma sistemática a sus hijos.

El objetivo general apunta a generar procesos de equidad e inclusión cultural y a favorecer el fortalecimiento de la calidad de la educación de las poblaciones en situación de vulnerabilidad a través de involucrar a las familias en el proceso de alfabetización de sus hijos. En este sentido Judith Kalman (2003:38) afirma que el acceso a las prácticas sociales depende, en gran medida, de la posibilidad de participar en su uso con personas que las conocen y utilizan. El Programa Cuenta Quien Cuenta (en adelante, el Programa o CQC), propone el acceso a la cultura escrita como un proceso social donde la interacción entre padres e hijos es condición necesaria para aprender a leer y a escribir.

Al momento de su diseño, el Programa debía contemplar la distribución de libros para dar mayores posibilidades a los referentes familiares de participar en eventos de la lengua escrita; entendiendo por ello aquellas situaciones en la que el sujeto se posiciona frente a otros lectores y escritores (Kalman, 2001). 


\subsection{Descripción del Programa de Alfabetización Familiar Cuenta Quien Cuenta}

El Programa pretende sensibilizar e involucrar activamente a las familias participantes en el proceso de apropiación del lenguaje escrito por parte de sus hijos. Procura así mismo facilitar a los niños oportunidades para que vivencien el uso social de la lectura en el seno de su familia. Consta básicamente de alrededor de doce Talleres que se realizan con frecuencia semanal a los que asisten padres -o adultos de referencia- de niños cuyas edades oscilan entre cero y cinco años. En dichos talleres se aproxima a los adultos a la lectura de cada cuento a través de dinámicas y estrategias que inciden en la comprensión y producción de textos escritos; se reflexiona sobre las implicancias sociales y familiares de los relatos que se leen -a cuyos efectos se seleccionan específicamente cuentos que abordan temáticas tales como la cuestión del género, la resolución de conflictos, la tolerancia, la identidad, la discriminación, la comunicación entre padres e hijos, la importancia de la educación y la diversidad-; y se hacen actividades de compaginación de libros de cuentos con ilustraciones de los propios padres. La familia se compromete, asimismo, a leer a sus hijos a sus hijos durante la semana y antes del encuentro siguiente el cuento abordado en el taller. Una vez finalizado el Programa, los participantes aceptan el reto de organizarse para extender la experiencia a la comunidad, a través de, por ejemplo, maratones de cuentos en instituciones educativas del barrio, exposiciones de las colecciones de libros elaborados, lecturas de cuentos en las bibliotecas barriales o dramatizaciones de cuentos destinadas a los niños del centro educativo, escuelas públicas, salas de espera de policlínicas pediátricas, etc.

Sustancialmente el Programa identifica, por un lado, la importancia de la lectura frecuente de cuentos a los niños como forma de aproximarse a la cultura escrita y, por otro, centra su accionar directamente en los referentes adultos, destacando las posibilidades que el vínculo familiar proporciona a estos acercamientos. El nombre del Programa, Cuenta Quien Cuenta, intenta poner de manifiesto que en estos primeros aprendizajes en torno al lenguaje escrito vale, para el niño, quién lo acerca a este.

Este Programa se implementó entre los años 2007 y 2012 en cuarenta y seis centros educativos urbanos, suburbanos y rurales- desarrollándose 460 talleres en los que participó un promedio de 18 referentes familiares por institución, llegando a un total de 828 familias involucradas en el mismo. De esta manera, considerando el número promedio de tres hijos por familia, se estima un alcance del Programa a más de 2484 niños, cuyas edades oscilan entre uno y doce años.

Cabe mencionar que CQC fue uno de los trece finalistas del Concurso de Experiencias de innovación socioeducativa en América Latina y el Caribe, organizado por CEPAL en 2009 en Guatemala. Seguidamente se exponen algunas de las apreciaciones que la Lic. Liliana La Rosa, 
evaluadora de las Naciones Unidas enviada a Uruguay, vertió en relación a las cualidades del Programa. En este sentido expresó:

Este Programa incluye diferentes buenas prácticas que juntas dibujan la innovación en la gesta del proyecto. Para ello se han utilizado los conceptos de la educación popular y el constructivismo para dar a luz una propuesta metodológica que pone a disposición de madres y padres, que viven en situación de exclusión, libros y lecturas para leer con sus hijos en el hogar.

Es relevante señalar que el Programa empodera a los padres, madres y tutores que participan, pues la metodología lúdica y participativa con que se implementa, permite compartir saberes, intereses, dificultades e interrogantes, poniendo como eje de la reflexión la ficción del relato y las vivencias personales. De esta manera los padres y madres son convocados a leer y a compartir la lectura de diversos cuentos que despiertan su interés por conectarse con sus hijos e hijas pequeñitos y ayudarlos a desarrollar su imaginación. Los padres aprenden un instrumento para "ser padres" y leer con sus hijos, educarlos. Esto es muy relevante, todos los relatos de los padres y madres participantes se centran en que se "engancharon con la lectura sin darse cuenta", encontraron una forma de estar más cerca de sus hijos e hijas, pues ahora "todo el tiempo nos buscan para que les leamos". Agosto 2009. CEPAL.

Dada la valoración que diversos actores e instituciones nacionales e internacionales realizaran del Programa, consideramos de fundamental importancia poder evaluar si las características particulares del mismo -promoción de la apropiación de la lectura y la escritura en los referentes familiares participantes; revalorización del rol como agentes alfabetizadores de sus hijos; facilitación de la generación de escenarios ${ }^{1}$ de lectura en el hogar; dotación de materiales de lectura- podían tener alguna incidencia sobre el aprendizaje formal del lenguaje escrito de los niños cuyas familias habían participado del Programa. Para ello decidimos encarar una investigación que contemplara la puesta a prueba de situaciones evaluativas para acceder a los saberes de estos niños al iniciar primer año de educación primaria.

\footnotetext{
${ }^{1}$ Escenarios de lectura: "Definiremos la escena de lectura como el lugar donde se realiza y materializa la escritura como práctica social de comunicación. Estas escenas, para ser tales, deben evidenciar los siguientes componentes: los actores -quién o quienes están interviniendo en ese lugar-, las finalidades o propósitos -para qué se lee, estas escenas son explícitas o simbólicas-, los espacios -o sea el marco espacial en que se lee-, los tiempos -frecuente, periódica, casual-, los modos de lectura -silenciosa o en alta voz-, y por último, los soportes materiales". Cucuzza, H. R. (1998).
} 


\subsection{Estado de la cuestión}

La revisión bibliográfica en este campo se realizó con el fin de reunir evidencias halladas por otros estudios en torno a la importancia de la familia como primer ambiente letrado del niño y acceder a la manera en que esa importancia era evaluada. Las numerosas y diversas investigaciones enfatizan la incidencia de la alfabetización del contexto familiar en el rendimiento escolar de los niños, pero en ningún caso se especifica cómo se evaluó dicho impacto.

Con el mismo objetivo -relevar alternativas de evaluación- se revisaron experiencias y programas que tienen como finalidad el involucramiento de la familia en el proceso inicial de alfabetización de sus hijos. Particularmente la búsqueda estuvo focalizada en encontrar un conjunto de herramientas que establecieran indicadores para así poder evaluar los saberes de los niños cuyos padres participaron de planes y programas- al iniciar el primer año de educación primaria. Tampoco las experiencias y programas incluyen en sus informes instrumentos de evaluación que respondan al interés de esta investigación.

\subsubsection{Estudios sobre la vinculación entre la intervención familiar y la formación del niño como sujeto letrado}

Estudios recientes definen las prácticas de alfabetización familiar como aquellas acciones que realizan los padres, madres u otros miembros de la familia encaminadas a la adquisición de los procesos de lectura y escritura iniciales. Esta perspectiva evidencia que el aprendizaje del individuo no se da de manera aislada, sino que resulta de las interacciones sociales, donde el primer espacio social es la familia, y en ella se tejen las interacciones que posibilitan las prácticas letradas.

Al respecto, Vigotsky (1979) señala:

... esas personas cercanas física y afectivamente a los niños, son quienes los conducen a avanzar en el aprendizaje de nuevos significantes. Esta relación adquiere una característica transferencial, en la medida en que incentiva el desarrollo cognitivo a partir del traspaso de conocimientos, capacidades y estrategias de quienes lo poseen (padres) a quienes van a poseer (hijos). Las prácticas alfabetizadoras familiares son un vivo ejemplo de ello. 
Algunas indagaciones sociológicas y experiencias pedagógicas desarrolladas en diversos contextos locales e internacionales vinculadas con la alfabetización inicial permiten identificar ciertas prácticas de lectura de los niños dentro y fuera de la escuela. Valorar los ambientes donde hoy leen y escriben los niños, reconocer sus razones, sus temáticas y jerarquizar el aporte que significan las lecturas heredadas es parte de la construcción colectiva en la formación de lectores.

En este sentido, algunos estudios de la Sociología de la Lectura posibilitan comprender más cabalmente las particularidades que presentan las familias de medios populares y la influencia de las mismas en los procesos de alfabetización. Estos trabajos brindan aportes en relación con los diversos aspectos que pueden explicar el fenómeno de la alfabetización, plantean debates en torno a la formulación de políticas educacionales o propuestas pedagógicas y formulan interrogantes interesantes en torno a las posibilidades que la práctica de la lectura tiene de ser transmitida entre generaciones. Por ejemplo, Ana María de Oliveira Galvão (2001) se pregunta: “¿Cuáles son las diferencias internas en los medios populares susceptibles de justificar variaciones, a veces considerables, en la escolaridad de los niños?".

Estos estudios también indagan las relaciones que se establecen entre la alfabetización de los niños y el nivel de lectura de sus padres, la presencia de materiales escritos y los usos de la lectura y la escritura por parte de la familia. Desde esta perspectiva uno de los factores que explicarían la formación de lectores se vincula con la trasmisión generacional. Los datos analizados por de Oliveira Galvão generan interrogantes orientadores en este campo: ¿La lectura es un bien que se hereda o se da?, ¿El gusto de la lectura es adquirido gracias a que el niño está inmerso en un contexto familiar lector?

Michele Petit (2005) afirma que la lectura es un arte que más que enseñarse se transmite en un cara a cara. Para que un niño se convierta en lector es importante la familiaridad física temprana con los libros y la posibilidad de manipularlos para que no lleguen a investirse de poder. La importancia de ver a los adultos leyendo con pasión está en los relatos de los lectores. Pero, ¿y en los hogares donde esto no ocurre? La autora reconoce que el gusto por la lectura depende, en gran medida, del interés que los padres expresan por los libros y de los intercambios precoces que la madre, padre o la abuela tuvieron con el niño. Petit señala que en ausencia de estos escenarios es fundamental la intervención de las acciones de las políticas públicas focalizadas en promover los acercamientos significativos entre los niños, los libros y la lectura.

Un estudio cualitativo sobre cómo las prácticas de lectura y escritura de padres de familia mexicanos influyeron en el desarrollo de la alfabetización de sus hijos -que fue llevado a cabo originariamente por Christopher Vance (2005) como parte de un programa más amplio acerca de 
la Construcción Social de los Lectores de México y dirigido por los co-autores Patrick H. Smith y Luz A Murillo- puso de manifiesto el beneficio de que la familia modele el placer por la lectura con regularidad. Dicha investigación destacó también la importancia de la incorporación de los padres en el acercamiento de los niños a la cultura escrita, ya que la mayoría de los estudios conocidos hasta la fecha se focalizaban en la influencia de las madres en la adquisición de la lectura y la escritura de sus hijos. Luego de casi un año y medio de trabajo se obtiene como dato que tres de cuatro estudiantes del estudio del caso que eran calificados por su maestra como excelentes lectores procedían de hogares con un ambiente fuertemente letrado.

Florez, R. Restrepo, M. y Schwanenflugel, P. (2009) identifican la convergencia de, fundamentalmente, dos elementos importantes para que tenga lugar la alfabetización temprana considerada como un proceso que reúne un conjunto de conocimientos que los niños desarrollan sobre el lenguaje escrito antes de su instrucción formal en los primeros años de la escuela primaria. Por un lado, el incremento de los conocimientos de los niños mediante los procesos que enriquecen su aprendizaje y, por otro, la capacidad de los adultos del entorno del niño para promover experiencias significativas que lo acerquen a estos conocimientos.

Algunos relevamientos exhaustivos de la literatura conceptual e investigativa evidencian que existe una serie de prácticas que favorecen el desarrollo de los fundamentos del alfabetismo y reducen la posibilidad de que los niños presenten dificultades en el aprendizaje de la lectura cuando ingresen a primer año de educación primaria.

Estas prácticas dirigidas a niños de educación inicial, y sobre las cuales existe un amplio consenso relacionado con su calidad y alta capacidad para construir el andamiaje inicial del desarrollo que garantizaría el éxito de los niños en el aprendizaje de la lectura (Florez, R.; Restrepo, M.; Schwanenflugel, P. 2009), se denominan prácticas universales de alta calidad y sus principales componentes son:

a) Lectura de cuentos. Esta actividad está relacionada con el incremento de habilidades del lenguaje abstracto en niños de edad preescolar (Van Kleeck, Gillam \& Hamilton, 1997) y con el aumento del vocabulario (Wells, G., 1981). Involucrar a los niños en experiencias que promuevan la lectura y la interacción alrededor de los cuentos les proporciona tanto conocimiento como habilidades necesarias para tener éxito en el aprendizaje de la lectura (Valdez - Menchaca \& Whitehurst, 1992);

b) Ambiente impreso. Las interacciones entre los niños y entre los niños y el adulto con los materiales impresos permiten avanzar en la interpretación de representaciones simbólicas (Davidson, 1996). 
c) Relaciones orientadas hacia el alfabetismo. Varias investigaciones han demostrado que tanto la frecuencia como la calidad de la lectura compartida de libros en el hogar están asociadas con la calidad de las relaciones entre padres e hijos (Wade \& Moore, 1993; Bus, 1994). Estos niños participan con mayor frecuencia de experiencias de lectura en las que comparten con sus padres el interés por determinados libros.

d) Compromiso Familiar. Los padres generan ambientes que apoyan el alfabetismo a través de la lectura compartida de libros y del aprovechamiento de situaciones que involucran a los niños en actividades relacionadas con la lectura y la escritura (Whitehurts \&Lonigan, 1998). La frecuencia, así como la calidad de las interacciones que ocurren alrededor de ella, desempeñan papeles importantes en el alfabetismo inicial.

Sandra Hincapié Tamayo desarrolló una indagación sobre las Prácticas alfabetizadoras familiares de Medellín, Colombia (2011). El estudio pretendió impulsar la continuidad de investigaciones que vinculen las relaciones familiares y los procesos de lectura y escritura como forma de contribuir en la búsqueda de respuestas a las problemáticas específicas de la educación, como lo es la repitencia, la deserción escolar y el bajo rendimiento académico.

Numerosos estudios focalizados en la relación alfabetización - pobreza, describen algunas variables que se presentan con mayor regularidad en aquellos niños menores de cinco años y que viven en condiciones de pobreza. Estos parecen tener mayores probabilidades de presentar: bajo desarrollo de habilidades lingüísticas (Hart \& Risley, 1995; Wells, 1981); menor vocabulario receptivo y expresivo (Graves \& Brunetti, 1982; White \& Graves, 1990) y menor desarrollo de conceptos relacionados con el alfabetismo (Dixon \& Smith, 1995).

Ni la condición de pobreza por sí misma, ni las diversas capacidades que los niños pueden presentar, se relacionan directamente con los bajos desempeños. Más bien, como señalan Peralta de Mendoza y Salsa (2004), los estilos de interacción padre - hijo, los factores ambientales del hogar, el acceso a materiales impresos, las prácticas de lectura, la calidad y el alcance de las conversaciones que se sostienen en el hogar, estarían condicionando positivamente las posibilidades de que el niño aprenda con éxito el lenguaje escrito.

El bajo desempeño que presentan los niños, entonces, está estrechamente relacionado con las diferencias de oportunidades entre ellos. Los niños que llegan a la escuela sin experiencias significativas relacionadas con el conocimiento alfabético demuestran logros iniciales más bajos que los de sus pares cuyos antecedentes socio-familiares han sido ricos en esas experiencias. Los logros de la lectura, las diferencias tempranas entre los menores permanecen relativamente estables durante la educación básica y las diferencias entre los "buenos" y los "pobres" lectores 
llegan a ser mayores, en términos absolutos, a medida que transcurren los años, Scarborough, $\mathrm{H}$. (2002). En consecuencia, los niños en contacto con experiencias significativas han aprendido mucho acerca de la función del lenguaje escrito, de su forma y contenido y han comenzado a desarrollar actitudes positivas hacia la lectura (Clay, M. 1979; Purcell-Gates,V. 1996).

En este sentido José Joaquín Brunner (2010), investigador chileno, desarrolla un trabajo que gira en torno al vínculo entre la socialización lingüística en el hogar, el capital cultural heredado y el rendimiento escolar o logros de aprendizaje. Este autor se interroga sobre cuáles son los factores determinantes del aprendizaje y cuál es su incidencia en la generación de resultados. Explora las variables que componen el efecto cuna e identifica las brechas que se producen tempranamente en la vida de los individuos en el desarrollo cognitivo, el lenguaje y aspectos socioemocionales, antes de ingresar al sistema educacional. Luego indaga, más específicamente, respecto de las posibles influencias del medioambiente sobre el desarrollo del lenguaje y comenta la evidencia sobre brechas de rezago en niños de sectores socialmente vulnerables.

Brunner destaca que desde la publicación del Informe Coleman en el año 1966, se amplió el consenso la relación entre los resultados escolares de los alumnos y sus antecedentes familiares. Vale la pena recordar los términos con las cuales el propio Informe presenta este hallazgo. Entre sus conclusiones destaca: a) que el trasfondo familiar (family background) se vincula estrechamente con el logro escolar; b) que la intensidad de este vínculo entre familia y logro no disminuye a lo largo de los años de escolarización; y c) que el porcentaje relativamente menor de variación de resultados entre escuelas indicaría el escaso efecto escuela sobre el logro de los estudiantes.

Pues bien, si el efecto cuna da cuenta de una proporción significativa del rendimiento de los alumnos- más de un 50\% - ¿qué contribución hace el denominado efecto escuela? Coleman en su estudio reportó que entre 5\% y 9\% de la varianza total del logro individual de aprendizaje de los alumnos se debía a variables de escuela únicamente. Magnitudes de este mismo orden, en torno a un $10 \%$, han sido confirmadas por múltiples estudios a lo largo de las siguientes décadas.

También Echevarría, K. (2007) sostiene que es fundamental el papel de los padres en la formación de los niños como lectores, aunque a veces resulta difícil pensar una actividad que incluya la participación de los padres en un proceso institucional de lectura. A pesar de ello, algunas escuelas pertenecientes a la zona norte del conurbano de la ciudad de Buenos Aires, Argentina, han trabajado con las familias de los niños de Nivel Inicial y de la Educación Primaria Básica en talleres donde se reflexiona tanto en torno a la propia biografía lectora de los padres 
como a la importancia de los adultos referentes del niño en el acercamiento al libro y a la lectura en forma afectiva.

Por otra parte Cecilia Beuchat (1990), considera esencial que los padres puedan tomar real conciencia del valor de la lectura y de la lectura en voz alta ya que es una actividad que prepara a los niños para el aprendizaje lector.

La investigación desarrollada por de Luna Villalón (2009) sobre el hogar como contexto sociocultural de prácticas de lectoescritura de inmigrantes mexicanos en Canadá, otorga gran importancia a conocer tanto las prácticas de lectura y escritura en el hogar como al desarrollo de ese tipo de prácticas en el ámbito escolar.

Según Felipe Alliende (1983) la familia es la principal promotora en la formación de sus hijos como lectores cuando además de contarles historias comienzan a leérselas. Aquí se entra de lleno en el comportamiento lector. Al leerles cuentos se utiliza una serie de características del lenguaje que no se dan en la lengua hablada. En el lenguaje escrito el léxico, las estructuras morfosintácticas y la organización de los textos no coinciden totalmente con el lenguaje oral. La utilización del lenguaje escrito apela constantemente a un vocabulario que el niño no maneja en la vida diaria. El niño es puesto a prueba de entender palabras y estructuras lingüísticas que usa la comunidad más amplia que su familia. Los padres tienen dos papeles fundamentales en la formación de sus hijos como lectores: primero, ser co-lectores con ellos y segundo, modelando actos de lectura. Los niños se convertirán en lectores habituales si ven que sus padres leen y sacan provecho de la lectura.

Se han considerado también los aportes de la investigación que desarrollaron Díaz, J.; Martínez, I.; López, K. (2006) sobre los componentes cognitivos de los padres en relación con las habilidades lectoras de sus hijos. Los resultados permiten apoyar la hipótesis de que la intervención de los padres, al colaborar con el desarrollo de las habilidades lectoras de los niños a través de diversos procesos cognitivos, sirve para fomentar la lectura.

No hay lugar a dudas de que el contexto familiar es un factor significativo en la formación temprana de los hábitos escolares, entre ellos la lectura. Morrison, T. y Cooney, B. (2009) investigaron algunos patrones que estarían interviniendo en el desarrollo de habilidades, como lo son las actividades de lectura en conjunto entre padres e hijos, para mediar la influencia sociocultural a través de la familia. 
La lectura de un libro entre padres e hijos es un importante intercambio verbal que contribuye al desarrollo de habilidades lectoras; así como la forma en que los padres leen el libro con sus hijos tiene resultados positivos en el interés infantil por la lectura (De Temple, J. M. 2001). Se pueden identificar algunos componentes comunes que comparten aquellos padres que adjudican importancia a la adquisición del hábito lector de los niños:

1) importancia otorgada a la lectura en su vida o trabajo: los padres destacan la lectura como algo necesario para la vida;

2) frecuencia de lectura: alto número de ocasiones,

3) calidad de los materiales de lectura: los padres eligen libros y revistas que consideran un aporte al desarrollo de sus hijos,

4) modelamiento de la lectura: los padres se convierten en ejemplos cuando leen ante sus hijos,

5) preguntas sobre la lectura: conversaciones de los padres y los hijos propiciando la reflexión e indagando posibles alternativas de acción de los personajes frente a los eventos de un relato,

6) fundamentación de la lectura: los padres exponen los argumentos necesarios para que sus hijos comprendan la relevancia de la actividad de leer.

Esta investigación destaca insistentemente la participación activa y constructiva de los padres en el desarrollo de las habilidades lectora de sus niños.

En una investigación internacional sobre el campo de la lectura en familia, (Train, B. 2006), que analiza tanto el desarrollo de las habilidades lectoras en los miembros de la familia como el proceso de compartir lecturas entre ellos, sugiere que al momento de diseñar un programa de alfabetización en familia deberían considerarse tres componentes: alfabetización para niños, alfabetización para los padres y una guía para los adultos sobre cómo estimular las habilidades de lectura y escritura de sus hijos. Advierte que la carencia del lenguaje temprano y de experiencias de lectura pueden tornarse barreras al momento de aprender formalmente el lenguaje escrito.

En el Estudio de la Evaluación de Impacto de la Educación Inicial en el Uruguay, realizado por la Administración Nacional de Educación Pública en 1999, se describe un relevamiento sociolingüístico destinado a conocer el desarrollo del lenguaje de niños de cuatro años inscriptos en jardines y escuelas públicas, centrándose especialmente en los niños provenientes de hogares en situación de pobreza. Este relevamiento incluyó una encuesta sociocultural a la familia que recogió información sobre las características sociales, las prácticas culturales en el hogar, las percepciones de las madres sobre la Educación Inicial y el vínculo del hogar con el lenguaje escrito. 
Una fuerte conclusión que se deriva de este estudio muestra que niños pertenecientes a estratos considerados de riesgo que cursaron dos años de Educación inicial, no muestran diferencias significativas con otros que cursaron solo uno, en cuanto al comportamiento alcanzado en el área del lenguaje y en el área cognitiva al finalizar el primer año escolar. Frente a esto, las autoras de la investigación (Susana Mara et al) proponen dos opciones para lograr disminuir el fracaso en primer año en los sectores de riesgo. Una de ellas tiene que ver con la posibilidad de iniciar más precozmente la escolarización (a los tres años de edad) y la otra está dirigida a fomentar la intencionalidad pedagógica a los efectos de potenciar el desarrollo del área del lenguaje. Este estudio señala: Por último no debe olvidarse la necesidad de incorporar a los padres en el proceso de enseñanza -aprendizaje de sus hijos, involucramiento que aún no se ha logrado y menos aún en los contextos desfavorecidos como los analizados en este estudio.

Basil Bernstein (1993) sostiene que el entorno que rodea al niño de los grupos menos favorecidos, está caracterizado por un tipo de lenguaje, que denomina "código restringido", que tiene particularidades fuertemente unidas a lo contextual. Define a los códigos como principios que regulan los sistemas de significación, adquiridos de forma tácita, que seleccionan e integran modos de actuación. Distingue el código "restringido" del código "elaborado". El código "elaborado" no depende del contexto, es universalista y es empleado por las clases acomodadas.

En las instituciones educativas, los poseedores del código elaborado superan a los estudiantes provenientes de la clase trabajadora, que fracasan en sus estudios en un proceso de selección no natural, sino arbitrario y naturalizado. El contenido de la forma pedagógica, según Bernstein, actúa de forma selectiva sobre los estudiantes, profundizando las relaciones de desigualdad entre las clases sociales.

El problema parece estar radicado, no en la cantidad de palabras sino en el uso de ese vocabulario, el tipo de pensamiento que elaboran. Al respecto Jerome Bruner (1988) señala que no existen diferencias en la cantidad de lenguaje que poseen los niños de diferentes clases sociales, la diferencia está en el uso: en la forma en que la familia y la subcultura influyen sobre el uso.

Las investigaciones realizadas que ponen el foco en los grupos de niños que han podido aprender a leer y escribir tempranamente, identifican que estos niños provenían generalmente de hogares de clase media en los que los padres les leían con frecuencia y participaban junto con ellos de situaciones de lectura y escritura que demandaban atención y ayuda de los adultos. La constatación de que la diferencia de experiencias en el hogar podían afectar diferencialmente los 
logros posteriores de los niños en la escuela primaria promovió el diseño e implementación, fundamentalmente en Estados Unidos, de programas tales como "Parents as Teachers", "Home Instruction Program for Preschool Youngsters", "Parent Child Development Program" cuyo fin último era atender al desarrollo de la alfabetización de aquellos niños que no tienen acceso a la lectura y la escritura en su medio familiar.

Arnold, D. S. y Whitehurst, G. J. (1994) realizaron un estudio que buscó conocer las prácticas de alfabetización familiar, la interacción entre padres e hijos y cómo estas prácticas promueven el adecuado acercamiento a los procesos de lectura y escritura. Esta investigación se realizó con el objetivo de analizar cómo cada familia tiene sus propias expresiones para alfabetizar y observar las interacciones que se generan entre padres e hijos. Para medir esta interacción se aplicó una encuesta de prácticas alfabetizadoras a las familias. La muestra que se utilizó fueron 89 familias pluriétnicas: 47 familias nativas de Holanda, 23 de Surinám y 19 familias de Turquía. Se halló en esta investigación que la alfabetización en el hogar es multifacética; por lo tanto, se concluye que la alfabetización potencia la enseñanza, mediada por factores emocionales que facilitan la cooperación entre padres e hijos, para afirmar que la alfabetización en el hogar mejora las interacciones emocionales y que éstas fortalecen los procesos de enseñanza en la escuela.

Leseman, P. (1998) tuvo como objetivo observar las prácticas de alfabetización en la familia y como estas prácticas son predictoras del desempeño en la lectura inicial. Se manejaron variables como la interacción padre-hijo, vocabulario utilizado en las familias, codificación de palabras y su comprensión. Para esta investigación se utilizó la observación de las prácticas alfabetizadoras familiares que fue realizada utilizando como instrumentos el inventario de prácticas educativas, entrevistas y la escala de cualificación socioemocional de Edison (1996). La muestra fue de 89 familias inmigrantes y se concluyó que las prácticas de alfabetización en la familia posibilitaron un mejor desempeño en la lectura y un incremento en su vocabulario.

El mismo autor realizó en el 2008 una investigación donde evaluó el nivel de eficiencia que logran los niños en sus habilidades de lectura. En este estudio hace una correlación entre las habilidades de lectura y los procesos de alfabetización familiar en niños de preescolar y primaria básica. Delimitó una muestra de 165 niños de primer grado y tuvo en cuenta algunas variables como la edad de ingreso a la escuela y el número de años cursados en preescolar. Como instrumento de recolección de datos se utilizó el Inventario de Ejecución Académica de Macotela, Bermúdez y Castañeda (2003), que preestablece algunas características de las habilidades de lectura en silencio y voz alta, como así también describe indicadores de comprensión de la lectura. La medición de las habilidades de lectura no fue satisfactoria; se encontró baja motivación por la lectura; un nivel bajo de comprensión de los textos leídos y un bajo repertorio léxico que estaba 
acompañado por ausencia de prácticas de lectura en el hogar. Por estas razones este estudio concluye recomendando se fortalezcan los programas de alfabetización familiar al igual que la realización de observaciones de las prácticas de alfabetización en los hogares.

Una reciente investigación (Yubero, S; Larrañaga E., 2010) sobre la vinculación entre el valor de la lectura y el comportamiento lector aporta que "el acercamiento a la lectura no suele producirse de forma espontánea" por lo que resulta imprescindible que el entorno donde se encuentra el niño valore el tiempo de lectura y se comporte como un buen modelo de comportamiento lector. Los resultados de la socialización lectora confirman que los lectores, básicamente, se hacen en casa, con acompañantes lectores y con los padres como modelo. Aún así, el que los padres sean lectores no garantiza hijos lectores, pero es una buena cimentación en la formación del niño como tal porque los lectores frecuentes se encuentran, en porcentajes elevados, inmersos en contextos familiares lectores.

En su estudio sobre los "poco lectores", Joelle Bahloul (2002) señala que la lectura es una práctica social que da origen a interacciones e intercambios sociales y que en el individuo se remonta a la historia familiar y a la formación educativa. Esta práctica social propicia la creación de algunos sistemas de disposiciones, en términos de Bourdieu, entendiéndose por tales al conjunto de preferencias distintas, con una lógica específica, que se configuran en primera instancia en el contexto familiar donde tiene lugar un proceso de inmersión en un ambiente que enseña algo.

Piacente, T., Marder, S., Resches, M., y Ledesma, R. (2006) realizaron un estudio donde comparan el contexto alfabetizador que se presenta en los hogares de familias pobres y de familias con mejores recursos. Su objetivo central era examinar características y prácticas alfabetizadoras relacionadas con el desarrollo de habilidades y conocimientos prelectores en los niños. Se utilizó una muestra compuesta por 208 madres pertenecientes al estrato sociocultural y económico bajo y 50 madres de estrato medio bajo con el fin de identificar la presencia y ausencia de prácticas alfabetizadoras en ambos grupos y los recursos utilizados para alfabetizar. También se indagaron los hábitos lectores maternos, las actividades de escritura más habituales y las producciones de dibujos de los hijos antes de su escolarización formal. Los instrumentos utilizados fueron entrevistas semiestructuradas para la recolección de los datos demográficos y un formulario de evaluación del contexto alfabetizador.

Las conclusiones generales a las que arribaron aluden a que las prácticas alfabetizadoras familiares se presentan con menor frecuencia en las familias pertenecientes a estratos bajos y que las utilizadas corresponden casi en exclusividad a la enseñanza de las letras del nombre. 
El mismo autor y Tittarelli, A.M. (2009) realizaron un estudio sobre la lectura dialógica de cuentos y las características de la interacción según el estrato social de pertenencia, con el propósito de evaluar la disponibilidad de recursos que favorecen la lectura de cuentos destinada a niños. Los datos fueron recogidos de una muestra de madres alfabetizadas, 50 de estrato social bajo y 50 de estrato medio. Los resultados obtenidos muestran diferencias significativas, a saber: en el grupo de familias de estrato social medio era habitual la lectura conjunta de libros entre padres e hijos, mientras que en el grupo de familias pobres se observó la presencia de un porcentaje menor de este tipo de prácticas. De todos modos, en los casos en que compartían algunas situaciones de contacto con cuentos, a pesar de contar con pocos materiales escasos, las prácticas eran adecuadas, incluyendo conversaciones sobre las imágenes y los textos.

En el estudio realizado por Whitehurst, G. J. (1992) se halló una correlación significativa entre las prácticas alfabetizadoras, el nivel de educación de las madres, la motivación de los hijos y la producción de textos escritos y orales y el dibujo. Tal como era de esperarse, se encontraron diferencias entre ambos grupos de madres de acuerdo al estrato, siendo de mejor calidad y mayor frecuencia las prácticas de alfabetización en el estrato más favorecido.

Bernard Lahire (1997) al ser consultado sobre el mundo escolar responde: “...allí se encuentran las primeras grandes desigualdades. Los niños de los ambientes más desprovistos de recursos culturales y escolares, con padres que no tienen título y que pueden ser en algunos casos analfabetos, suelen tener experiencias dolorosas en la escuela. Porque lo que descubren en ese universo rara vez confirma lo que ellos han adquirido hasta ese momento en su familia”. Esta afirmación autoriza a pensar en la importancia de la incidencia en el contexto familiar para mejorar el tránsito de estos niños al ámbito escolar.

En oportunidad del Seminario "Historia y Sociología de la Alfabetización en Brasil: indicadores, discursos y prácticas" el Profesor Antônio Augusto Gomes Batista comentaba la existencia de un nexo o relación entre el capital cultural familiar y la construcción de disposiciones favorables a la cultura escrita, pero advertía sobre la necesidad de comprender cómo se establece esa relación que estaría facilitando la transmisión de saberes. Gomez Batista señalaba: "los estudios sociológicos actuales buscan aprender como la familia se moviliza para asegurar esa trasmisión para garantizar el éxito escolar de los hijos".

Los estudios de Wells, G. (1985) dejan en evidencia la existencia de fuertes relaciones entre el ambiente familiar y el resultado escolar obtenido vinculado a los conocimientos sobre lo impreso, la familiaridad con el lenguaje escrito y las actitudes positivas hacia la escritura. Este autor 
concluye que el acercamiento al lenguaje escrito y el gusto por la lectura se aprenden en los brazos del padre.

Guevara, Y., Rugerio, J., Delgado, Hermosillo, A. y López, A. (2010) desarrollaron un estudio con la finalidad de evaluar el grado de desarrollo de las habilidades lingüísticas antes de ingresar a la escuela en relación con la alfabetización emergente y el ambiente de alfabetización de sus hogares. Como conclusión de este trabajo se pudo establecer que las madres no tienen claro su rol como agentes educativos.

Por otra parte, diversos estudios han identificado un conjunto de barreras o dificultades para la colaboración entre las familias y las escuelas (Pena, D. 2000). Entre estas barreras se menciona la falta de interés y apoyo de los padres a la vida escolar de sus hijos (Feuerstein, 2000), la pobreza (Taylor y Pearson, 2004), el bajo nivel educativo de los padres (Vernon-Feagans, Scheffiner, Miccio y Manlove, 2002), las tensiones entre los padres y la escuela (Martiniello, 1999), y la falta de conocimiento de los mecanismos que favorecen el que los padres se involucren en la educación de sus hijos en las instituciones escolares. Otra dificultad en este sentido proviene de las creencias de muchos maestros de que los padres de sectores pobres no entienden o no pueden seguir indicaciones o actividades que les sugieran para apoyar a sus hijos en sus tareas escolares, por lo que no inician el contacto con los padres para que éstos participen del aprendizaje de los niños, y si realizan alguna actividad que involucre a los padres ésta no es constante ni sistemática (Pena, 2000).

La investigación realizada por Antônio Augusto Gomes Batista y Vera Masagão Ribeiro, sobre la distribución del acceso a la cultura escrita en Brasil evidencia interesantes variables que permiten comprender la relación entre el nivel de alfabetismo y las prácticas de lectura y escritura de los escolares. Entre dichas variables aparecen como relevantes el nivel de lectura de los padres, la presencia de materiales escritos en el hogar, los usos de la lectura y la escritura por parte de la familia.

Otra perspectiva, inaugurada por Brice-Head en 1983, de corte etnográfico denominada constructivismo social considera el aprendizaje de la lectura y la escritura como una práctica social, donde la relación con el libro y la lectura se remonta al ambiente familiar de la primera infancia. Tiene en cuenta la contribución de la comunidad más próxima al niño como primer ambiente de desarrollo lingüístico, cognitivo y social y sus implicaciones en el aprendizaje escolar, en particular en la alfabetización. 
El aporte de la perspectiva socio-constructivista hace referencia al hecho de que la alfabetización no puede considerarse por fuera de los contextos culturales, históricos y sociales en que se desarrolla. Cobran particular importancia las posibilidades que el niño tenga de participar de las prácticas letradas que tengan lugar en su hogar. Las interacciones sociales entre los adultos, los niños y los textos escritos hacen más probable que se construya el vínculo con la lectura y los libros. Durante las actividades de lectura compartida el padre, madre o adulto referente asume la función de mediador entre el texto y el niño quien aún no es lector ni escritor autónomo (Hiebert, E., \& Raphael, T. 1996). Leer cuentos en voz alta, hablar acerca de los textos impresos de circulación social, escribir listas de compras, marcar con el nombre las pertenencias del niño son algunas prácticas que facilitan el acercamiento del niño al mundo de la cultura letrada.

En este apartado se trató de destacar a la familia como la comunidad en la que las personas adquieren los aprendizajes vitales que más adelante resignificarán en el entorno social y la escuela. Aprender significativamente, según Isabel Solé (1982), corresponde a atribuir significado al material de aprendizaje, lo que se logra a partir de aprendizajes alcanzados anteriormente. Por ello, cuánto más rica en elementos y relaciones es la estructura cognoscitiva de un alumno, más posibilidades tiene de aprender significativamente nuevos contenidos. De allí que todas las estrategias de lectura que han de presentarse a la hora de desarrollar un programa de promoción de lectura necesariamente han de partir de actividades que tomen en cuenta los aspectos que son significativos para la población a la que están dirigidas. Por ello, involucrar a los adultos significativos de los niños, objeto de la promoción en el desarrollo de las actividades y relaciones que ésta contempla, sobreviene en beneficios al aportar motivación y confianza que para el escolar resulta trabajar con las personas que le han acompañado a protagonizar los distintos aprendizajes logrados.

A pesar de la existencia de múltiples estudios que vinculan la precariedad del lenguaje escrito de los niños de contextos de pobreza con el ambiente familiar del cual provienen, varias indagaciones sociológicas contemporáneas han cuestionado las visiones deterministas al evidenciar, con respaldo estadístico, que muchas personas de medios populares a quienes se les preveía un destino natural como no lectores se tornaban lectores (Lahire, B. 1997:34).

Sintetizando, la mayoría de los estudios consultados adjudican al contexto familiar un papel fundamental en la formación temprana de lectores y muchos de ellos enfatizan la estrecha relación que existe entre las prácticas de los adultos de la familia y I desempeño escolar de sus hijos. Sin embargo, ninguno incluye datos precisos acerca de cuáles serían los indicadores de la influencia de esas prácticas en el ámbito familiar y cómo evaluar esos efectos en los niños. 


\subsubsection{Programas y experiencias de alfabetización familiar}

El presente trabajo analiza también ciertas experiencias y programas relevantes que algunos países han realizado en este sentido, como Argentina, Chile, España, Francia y Colombia.

El Programa de alfabetización Oscarcito es un programa de intervención pedagógica elaborado por un equipo de investigadoras del Consejo Nacional de Investigaciones Científicas y Técnicas de la Argentina -CONICET-. Tiene como objetivo promover el desarrollo lingüístico y cognitivo de la infancia en situación de pobreza extrema en el medio familiar y en los jardines de infantes a los que asisten los niños.

Las acciones con las familias tienen lugar a través de tres líneas de trabajo convergentes: la elaboración de materiales interculturales -libros infantiles- para promover la alfabetización en los hogares; la realización de talleres de formación con las familias y el seguimiento de la implementación del programa. Los libros infantiles elaborados se organizaron en una colección denominada En la casa de Oscarcito. Es una serie de ocho libros que recuperan la vida cotidiana de los niños de los barrios. Las actividades que se incluyen en los libros están destinadas a que los niños y su madre o padre interactúen entre sí y con el lenguaje. El Programa destaca la importancia de que el acceso de los niños a la alfabetización se produzca con sus familias y en sus hogares aunque, cabe señalar que su perspectiva teórica no es coincidente con la que propone Cuenta Quien Cuenta -objeto de estudio de la presente investigación- ya que cada libro plantea actividades para identificar y escribir letras y palabras; reconocer los sonidos que forman las palabras; establecer correspondencias entre letras y sonidos; desarrollar la motricidad a través del trazado y de pintar ilustraciones; estimular la categorización de objetos y de acciones en base a criterios temáticos, espacio - temporales, funcionales y taxonómicos.

Otro programa argentino, en este caso vigente, es el denominado Primeros Años. El mismo es de cobertura nacional y se desarrolla en el ámbito del Consejo Nacional de Coordinación de Políticas Sociales producto de un convenio firmado, en noviembre del año 2005, entre los Ministerios de Desarrollo Social, de Salud, y de Educación de la Nación con el compromiso de llevar adelante una política pública orientada a favorecer el desarrollo de las niñas y niños de 0 a 4 años. Este programa pretende generar condiciones familiares, comunitarias e institucionales para promover el desarrollo infantil, desde un abordaje integral, a partir de la construcción de entornos contenedores y protectores de los derechos de niñas y niños. El módulo "Leer es contagioso: un encuentro con los libros" tiene como cometido promover experiencias colectivas de lectura junto a las familias y la comunidad. Se propone tender puentes para que el encuentro con los libros de niños y adultos sea cotidiano a través de diversas estrategias que pretenden asegurar el acceso a los libros, generar el intercambio de libros entre los participantes y provocar momentos de lectura 
compartida tanto en el centro comunitario como en el hogar. Lamentablemente no se ha publicado ningún dato sobre los resultados obtenidos.

Ana Siro (2005), en el artículo "Leer entre la escuela y la familia, una posibilidad abierta por los niños" analiza una experiencia de trabajo con familias de una zona rural a partir de diferentes propuestas de lectura generadas desde la escuela que se llevó a cabo en el marco del Proyecto de Capacitación Docente para Sectores Rurales del Gran La Plata ${ }^{2}$ desarrollado desde 1995 hasta 1997, en un sector rural cercano a la ciudad de La Plata (Capital de la Provincia de Buenos Aires - Argentina). Involucró cuatro establecimientos de E.G.B. y uno de Nivel Inicial. Su propósito central fue desarrollar estrategias de acción tendientes a mejorar la calidad de la enseñanza en general y de la lengua escrita en particular, en un sector socioeconómico desfavorecido. Alcanzó a 524 niños entre 3 y 14 años y a sus familias. Veinticuatro docentes participaron durante dos años en una capacitación sistemática. Una de las iniciativas desarrolladas consistía en la grabación de cassettes de textos de la biblioteca institucional. Para esta actividad se seleccionaban textos, especialmente cuentos (narraciones convencionales, antologías de cuentos callejeros) y poesías (piropos, coplas), que se grababan con el propósito de ofrecer un modelo lector para aquellas familias que tenían interés en llevar materiales de lectura a sus hogares pero no disponían entre sus integrantes de ninguno que se animara a leer para todos, porque directamente no sabían leer o tenían dificultades para una lectura fluida y atractiva.

A continuación se analiza el programa Nacidos para Leer: Estimulación lectora en la primera Infancia, llevado a cabo en Chile. Esta iniciativa gubernamental se propone la estimulación lectora en niños socialmente vulnerables, con edades entre los 0 y 4 años, asegurando el acceso a materiales de lectura y favoreciendo el desarrollo cognitivo, mediante estrategias que contemplan la circulación de materiales escritos en el hogar. Este programa surge de instituciones estatales, que coordinan acciones para apoyar y estimular la lectura en niños desde la primera infancia en más de doscientos jardines infantiles a lo largo del país.

Los datos publicados sobre la fase piloto sólo tienen relación con la cobertura y el tipo de material bibliográfico entregado. Según el boletín informativo del Centro Regional para el Fomento del Libro en América Latina y el Caribe (CERLALC) al finalizar el programa cerca de 200.000

\footnotetext{
${ }^{2}$ Este Proyecto fue financiado por Fundación W.K. Kellogg y desarrollado en el marco institucional de la Universidad Nacional de La Plata -Buenos Aires - Argentina. La dirección general estuvo a cargo de la Lic. Ana María Kaufman. El trabajo de campo coordinado por las Prof. Mirta L Castedo y María Claudia Molinari. Las colaboradoras en el trabajo de campo fueron: Prof. Adriana Bello, Prof. Silvia Gurini y Psp. Ana Siro. Durante 1996 se contó con la colaboración de estudiantes avanzadas de la universidad mencionada: Srta. Silvana Casquero y Srta. Flavia Reszes.
} 
personas tuvieron acceso a 100 libros con títulos de excelente calidad, elegidos por un comité de expertos. Del análisis de los materiales dirigidos a las familias y al docente, se desprenden algunos principios pedagógico-didácticos que son transmitidos a las familias y a los docentes, tales como la importancia de educar a los adultos sobre qué y cómo leer en el hogar y la importancia de que los niños tengan con la cultura escrita durante la primera infancia.

Otro programa que pretende impulsar acciones que involucran a las madres y padres en el fomento del hábito lector de sus hijos es la campaña "Leer en familia". Esta fue promovida, a partir de 2008 y hasta la actualidad, por la Consejería de Educación del Gobierno de Extremadura, España, a través del Plan Marco de Apoyo y Fomento de las Bibliotecas Escolares. Su objetivo es comprometer a las familias a compartir un tiempo mínimo de media hora de lectura al día con los más pequeños, durante veinte días al mes y en un período consecutivo de tres meses, acompañándoles y comentando con ellos lo que leen. Aquellas que así lo cumplan recibirán el diploma de familia lectora. La campaña únicamente está dirigida a las familias con hijos que concurren al último curso de Educación Infantil y primer ciclo de Educación Primaria de centros públicos. Las evaluaciones desarrolladas relevaron la opinión de los adultos participantes en cuanto a los aportes que proporcionó la experiencia: mayor desarrollo del gusto por la lectura, fortalecimiento del vínculo entre padres e hijos, incremento de la frecuencia de las interacciones familiares y el aumento del conocimiento de historias por parte de niños y adultos.

La asociación francesa ACCES, (Actions Culturelles contre les Exclusions et les Segregations) propone una estructura orgánica para abordar la formación de lectores, dado que identifica a la lectura y la escritura como procesos que se inician antes de la alfabetización formal y que implican estrechas conexiones entre la etapa del lenguaje oral y la escritura.

Su experiencia de más de veinte años, permite hacer un seguimiento diacrónico del proceso. La propuesta de ACCES conjuga la construcción teórica, desde una perspectiva interdisciplinaria, con un trabajo permanente de investigación-acción, lo cual le ha permitido establecer un diálogo continuo entre teoría y práctica. Esta fundación tiene por objeto, en colaboración con los servicios públicos, poner libros y materiales culturales a disposición de los más pequeños y de sus familias, en ambientes económicamente desfavorecidos. Dicha asociación sostiene que el fracaso escolar y la marginación social resultante de éste no son simples "fatalidades del destino" o anormalidades genéticas sino producto de las carencias, tanto cualitativas como cuantitativas, de las expresiones del lenguaje en el ambiente que rodea a los niños durante sus primeros años de vida. Con el fin de prevenir las futuras exclusiones que los niños puedan padecer más tarde como adultos iletrados, ACCES realiza programas de animación a la lectura y múltiples acciones 
culturales en colaboración con escuelas, bibliotecas y organismos no gubernamentales de su país, apoyándose en las estructuras ya existentes e incitándolas a coordinar acciones. Esa sensibilización, sin ninguna intención de constituirse en enseñanza formal, más tarde permite a los niños abordar en mejores condiciones la adquisición de la lengua escrita. Al dirigirse a los niños pero también a su entorno y al privilegiar los medios más necesitados, busca favorecer un desarrollo armonioso de la personalidad del niño y una mejor inserción en la comunidad a la cual pertenece. Resulta interesante desatacar que el trabajo de ACCES comparte con otras propuestas desarrolladas en Francia la consideración de la lectura como herramienta de inclusión social y cultural.

Esta propuesta se relaciona con otros trabajos centrados en acciones culturales de prevención e investigación como los de Michelle Petit y Geneviève Patte cuya influencia ha resultado particularmente inspiradora en la generación de proyectos similares en el ámbito latinoamericano. Uno de ellos fue el programa regional "Leamos de la mano de papá y mamá", dirigido por Geneviève Patte y desarrollado simultáneamente en Nicaragua, Honduras, Panamá, Venezuela, México y Colombia. Dicho proyecto se propuso la creación de salas de lectura con un acervo básico de libros, que convocaron a la familia y a los niños más pequeños de zonas marginales.

Para documentar los resultados, Fundalectura y el Grupo de Investigación de "Cognición y Lenguaje en la Infancia" de la Universidad Nacional de Colombia realizaron una investigación de seguimiento de la experiencia. El propósito general de dicha investigación fue evaluar el impacto, a corto plazo del programa y, para alcanzar esta meta, se trazaron como objetivos caracterizar las condiciones de vida de los participantes, así como los hábitos de lectura en familia y las prácticas de crianza relacionadas con el lenguaje y la lectura conjunta con el bebé. Para evaluar ese impacto, se aplicó una encuesta inicial y otra de seguimiento seis meses después. Como resultados generales muestran que la lectura compartida desde los seis meses produce una transformación tanto en el adulto como en el niño. Los investigadores manifiestan que los cimientos construidos en esta etapa permiten al niño ingresar a la escuela primaria con buenas bases y actitudes frente al libro y a los diversos materiales escritos. Este dato favorecerá posteriormente su desempeño académico.

Cabe mencionar que el programa descripto considera que la dotación de materiales de lectura constituye una variable fundamental para incrementar las posibilidades de leer en el seno familiar.

En resumidas cuentas las experiencias y programas relevados focalizan sus acciones en cuestiones diversas, aunque todas están destinadas a las familias más alejadas del lenguaje 
escrito -ya sea por condiciones de ruralidad, aislamiento o exclusión social y cultural- y consideran que la inclusión de los niños de sectores populares en el mundo letrado está estrechamente relacionado con determinadas condiciones: las posibilidades de acceso a materiales impresos; contar con el hogar como escenario privilegiado de lectura; la presencia de modelos lectores; leer con frecuencia en la primera infancia y que los adultos de la familia asuman el compromiso de un tiempo de lectura compartida con sus hijos. 


\section{Capítulo 2.}

\section{Marco teórico}

En este marco teórico se exponen algunas precisiones acerca de algunas conceptualizaciones centrales que sustentan el presente trabajo de investigación:

1. la concepción de la alfabetización,

2. las características de los comienzos de ese proceso,

3. la incidencia del entorno letrado en los hogares,

4. la caracterización de situaciones de lectura y escritura que posibilitan que los niños aprendan a leer leyendo y a escribir escribiendo desde edades muy tempranas,

5. el caso particular de la lectura de cuentos,

6. los sectores populares,

7. la evaluación.

\subsection{Concepción de alfabetización}

En primer lugar se aborda el fenómeno de la alfabetización contemplando la multiplicidad de factores que intervienen en este complejo proceso de inclusión en la cultura letrada.

En el Diccionario de Alfabetización de la Asociación Internacional de Lectura (Harris y Hodges, 1995:140) se enumeran más de treinta tipos de alfabetización y se señala que "un consenso sobre una definición única de alfabetización es casi imposible". Por ello existen variadas acepciones respecto de las habilidades de leer, los diversos niveles de comprensión y las dimensiones funcionales, sociales y culturales de la alfabetización. En muchos casos, el término llega a superar el mero conocimiento de la escritura y abarca nuevas competencias. Más aún, la alfabetización es considerada, como lo propone Paulo Freire, como una estrategia de liberación al proporcionar la "capacidad de leer el mundo". Para Franco Firabboni (1985) la alfabetización se define como el proceso cognitivo-creativo de comprensión y reelaboración del universo preceptivosimbólico-lógico-imaginativo, producto de la cultura de una determinada etapa histórica.

Algunos diccionarios de lengua castellana, incluido el de la Real Academia, definen a la alfabetización como "acción y efecto de alfabetizar", y a alfabetizar, como "poner por orden las 
letras" o "enseñar a leer", y define al "analfabeto" (del griego "an": sin y "alphabetos") como el que "no sabe leer".

En este tiempo histórico, donde la sociedad accede a una cantidad de información circulante y tiene posibilidades crecientes de acceso a ella, la definición de alfabetización que la concibe como la mera adquisición de las letras que integran el abecedario, se presenta como reduccionista y necesita mayores explicaciones. En este sentido Koichiro Matsuura, (2005), en su rol como Director General de la UNESCO, señaló que "por alfabetización entendemos no sólo la adquisición de un objeto de conocimiento y el desarrollo de habilidades abstractas a toda práctica de lectura y escritura, sino también el proceso de apropiación de los modos de usar ese objeto, que se concreta viviendo en una comunidad particular y participando de las prácticas de la misma."

Estar alfabetizado implica no solo saber leer y escribir, sino reconocer las pautas que establece el contexto social y cultural en que se lee y se escribe y conocer las formas de uso que establece una comunidad. Como sostiene Ana María Kaufman (2007), la alfabetización de los alumnos alude a un proceso en virtud del cual el niño se apropia de las prácticas sociales de lectura y producción de textos que involucran, lógicamente, el conocimiento del sistema de escritura y del lenguaje escrito. David Olson, (1991:351) destaca el papel sustancial que tienen la lectura y la escritura para explicar y comprender el mundo de otra manera y a través de otras representaciones: "El lenguaje se usa para representar el mundo; permite reflexionar sobre el mundo y tomar conciencia de él. La escritura se usa para representar el lenguaje; permite reflexionar sobre el lenguaje y tomar conciencia de él. Aquí es donde la lectura y la escritura inciden en el pensamiento. Al manejar el lenguaje escrito, ya sea al escribirlo o leerlo, se toma conciencia simultáneamente de dos cosas: del mundo y del lenguaje".

Lourdes Molina Simó (1990) señala que "la utilización del término alfabetización hace referencia a la capacitación de comprender los significados producidos por otros y a la vez producir nuevos significados, esto es conocer, interpretar y modificar el ambiente...”.

\subsection{Características de los comienzos de la alfabetización}

En segundo lugar, es importante conceptualizar cuándo comienza el proceso de alfabetización y cuáles son sus características iniciales.

Las investigaciones psicogenéticas dirigidas por Emilia Ferreiro (Ferreiro y Teberosky, 1979), pusieron de manifiesto que el proceso a través del cual se construyen las bases para la 
apropiación de la lengua escrita y el desarrollo de las habilidades de lectura y escritura comienza mucho antes de que el niño ingrese a primer grado y un maestro se pare frente a él para enseñarle. Esas investigaciones relevaron ideas originales de los niños que preceden a los aprendizajes escolares.

El aprendizaje de la lectura y escritura se concibe como un proceso complejo, un logro cultural, social, cognitivo y linguístico, que se desarrolla durante toda la vida y permite la formación de usuarios competentes de la lengua escrita. A una edad temprana el niño utiliza inteligentemente sus esquemas de conocimiento para apropiarse de los objetos y elementos de su cultura.

En el paradigma vigostkiano subyacen dos principios fundamentales sobre la lectura. Por un lado, el que las competencias de lectura son indispensables para ganar acceso y participar en la sociedad. Por otro, que se pueden desarrollar simultáneamente con el lenguaje oral, si las condiciones sociales lo estimulan. Por ende, si la lectura es un componente significativo en los patrones de interacción social de los niños y las niñas pequeños, ejerce un influjo beneficioso en la alfabetización temprana. Además, provee ventajas para la inserción del aprendiz en la cultura dominante mediante la apropiación de la lengua escrita (Vygotsky, 1978).

Este argumento reviste una pertinencia particular para los niños de niveles socioeconómicos bajos, a quienes en ocasiones se les dificulta satisfacer las expectativas escolares (Whitehurst G.J., Lonigan C.J.,1998).

Las ideas de Vigostky han sido retomadas por varios investigadores contemporáneos que abogan por una reconceptualización transformadora de la lectura emergente -María Eugenia Dubois (1987)-. Como resultado ha surgido un enfoque de alfabetización que recalca los aspectos socioculturales, psicolingüísticos y cognoscitivos inherentes al aprendizaje de la lectura - Noam Chomsky (1978), Emilia Ferreiro (1999), William Labov, (2001). El nuevo enfoque redefine la lectura como un proceso sociolingüístico desde los primeros años de la niñez temprana. Además, lo enmarca en un espacio cultural e histórico, reconociendo que la familia es el primer núcleo social donde surgen oportunidades para aprender sobre la lectura en actividades en la que la lengua escrita se usa con propósitos sociales auténticos.

Desde una perspectiva piagetiana, Ferreiro afirma que todos los objetos a los cuales los adultos dan importancia son objeto de atención por parte de los niños, y que si éstos perciben que las letras y las palabras son importantes para los adultos seguramente van a tratar de apropiarse de ellas. Todas las encuestas coinciden en un hecho muy simple: si el niño ha estado en contacto 
con lectores antes de entrar a la escuela aprenderá más fácilmente a escribir y leer que aquellos niños que no han tenido contacto con lectores. ¿En qué consiste ese saber pre escolar? Básicamente, señala Ferreiro, en una primera inmersión en la cultura letrada haber escuchado leer en voz alta, haber visto escribir, haber tenido la oportunidad de producir marcas intencionales, haber participado en actos sociales donde leer y escribir tienen sentido; haber podido plantear preguntas y obtener algún tipo de respuesta. Estas acciones o prácticas sociales de la lectura estarían facilitando la comprensión de la relación entre las marcas gráficas y el lenguaje. Esta relación, al inicio, continúa Ferreiro, se compone de tres elementos claves en todo escenario de lectura: un intérprete o interpretante, quien lee al niño, un niño y un conjunto de marcas.

\subsection{Incidencia del entorno letrado}

En tercer lugar, es importante remarcar la importancia del entorno social y familiar de los niños, concibiendo la alfabetización como un proceso profundamente social que se inserta en las relaciones sociales, sobre todo en las de los niños con las personas más cercanas de su entorno. Estas personas les sirven de modelo, les ofrecen materiales, crean expectativas y los ayudan a incluirse en la cultura escrita.

En cuanto al entorno alfabetizador de los niños, sin lugar a dudas el proceso de alfabetización depende cada vez más de la coordinación de los aprendizajes que se desarrollan en los diferentes espacios y de las relaciones de las vidas de los niños. Los estudios de alfabetización emergente ya demostraron que la alfabetización se realiza también en la familia, en la calle y otros contextos no escolares con todos los materiales escritos y prácticas letradas que se encuentran en el entorno del niño (Purcell-Gates, 1995; Teale \& Sulzby, 1986) y que cuando las actuaciones educativas inciden directa e indirectamente en todos esos contextos, el entorno alfabetizador se transforma y con él los aprendizajes. La mayoría de los niños que pertenecen a contexto no académicos, forman parte de un contexto cultural diferente al contexto escolar, y los recursos educativos de los que disponen en casa no son del mismo tipo que los que se encuentran en el aula.

Desde la perspectiva del constructivismo social la familia es visualizada como el primer espacio alfabetizador que provoca acciones letradas. En consecuencia este ambiente letrado resultará de algunas condiciones: la disponibilidad de materiales propios de la cultura escrita, el entorno social que enseñe y promueva el hacer uso de ellos y el acceso a las prácticas sociales. Las interacciones de las personas analfabetas con mediadores alfabetizados y con los artefactos escritos jugarán un rol importante en el proceso, irán generando la estructuración de diferentes discursos que posibilitarán poco a poco tomar decisiones y posicionarse en el mundo. 
Así también lo destaca Rosa María Torres (2006) al decir que los programas de "alfabetización familiar" en los países desarrollados, orientan a padres y madres de familia a leer en voz alta a sus hijos todas las noches al acostarles, algo que está vedado a millones de padres y madres en familias pobres, ya porque no saben leer, ya porque no tienen nada que leer a sus hijos, ya porque no tienen luz eléctrica o condiciones mínimas en el hogar, ya porque simplemente la batalla por la supervivencia no deja tiempo ni energías para nada más.

En síntesis: el marco de referencia conceptual de esta investigación concibe el proceso de adquisición del lenguaje escrito como un proceso de construcción social colectivo, en el cual juega un rol preponderante el contexto de mayor o menor alfabetización en que los individuos se desarrollan en edades tempranas y en el que la familia asume un rol central en términos de constituirse como mediador significativo. Las prácticas letradas a que tenga acceso el sujeto lo habilitarán para participar más eficazmente como miembro de su comunidad.

Ya se ha mencionado que para poder participar con solvencia en las prácticas sociales de lectura y escritura que una comunidad produce, los niños deben apropiarse del sistema de escritura y del lenguaje escrito. Estos aprendizajes, afirma Kaufman (2009:23) tienen lugar simultáneamente, desde el comienzo de la alfabetización. Los niños aprenden a leer y a escribir textos, leyendo y escribiendo textos.

\subsection{Situaciones didácticas que favorecen la formación de los niños como lectores y productores de textos}

En cuarto lugar, se toma en consideración una manera particular de caracterizar las situaciones de lectura y escritura que posibilitan que los niños aprendan a leer leyendo y a escribir escribiendo desde edades muy tempranas.

Delia Lerner -como supervisora académica del Documento de Trabajo $N^{\circ} 2$ de Actualización Curricular en Lengua, de la Dirección de Currículum de la Secretaría de Educación de la Municipalidad de la Ciudad de Buenos Aires- expone en el año 1996 una primera organización de las situaciones en que los niños pueden participar de actividades de lectura y escritura. Dichas situaciones fueron denominadas, en esa oportunidad, de la siguiente manera:

- $\quad$ Situaciones en las que el maestro lee para los niños.

- Situaciones en las que los niños leen por sí mismos.

- Situaciones en las que los niños dictan al maestro.

- Situaciones en las que los niños escriben por sí mismos. 
Estas situaciones fueron incluidas posteriormente en el Diseño curricular de la Provincia de Buenos Aires, del año 2008, y las primeras se redenominaron como "los niños escuchan leer al maestro".

Las cuatro situaciones didácticas fundamentales de lectura y escritura fueron propuestas como eje del modelo didáctico que Ana María Kaufman propone en el texto "Leer y escribir: el día a día en las aulas". (Kaufman et al, 2009).

Tal como puede advertirse en el cuadro siguiente, las situaciones fueron denominadas de diferente manera.

\begin{tabular}{|c|c|}
\hline LECTURA & ESCRITURA \\
\hline El niño lee a través del maestro & El niño escribe a través del maestro \\
\hline El niño lee por sí mismo & El niño escribe por sí mismo \\
\hline
\end{tabular}

Consideramos que no se trata solamente de una cuestión nominal sino también conceptual: el niño es el protagonista fundamental de las cuatro situaciones.

No es lo mismo "escuchar leer" que "leer a través de una voz". Es importante que los adultos comprendan que, cuando ellos leen un cuento en voz alta a los niños, son estos últimos quienes están construyendo el sentido del texto, aplicando numerosas estrategias lectoras. "Si leer es comprender un texto escrito, jerarquizar lo más importante y desechar lo accesorio, establecer relaciones entre sus diferentes partes, inferir lo no dicho, el niño pequeño que todavía no domina el sistema de escritura puede conectarse con (y apropiarse de) el lenguaje escrito a través de la voz de otro." (Kaufman et al, 2009 p: 68).

Preservando el protagonismo de los niños en las situaciones didácticas fundamentales, es más adecuada la denominación "el niño escribe a través del maestro" que la de "el niño dicta un texto al maestro". "Si consideramos que escribir es poner las letras sobre el papel, no hay dudas de que en esa situación escribe el maestro. Pero si pensamos que escribir es elaborar un texto y que en esa elaboración vamos a planificar qué contenido vamos a incluir, cómo organizaremos el relato o la exposición, qué recursos usaremos para que el texto produzca el efecto que queremos, qué palabras son más mágicas o más precisas... en ese caso, los que están escribiendo son los niños”. (Kaufman et al, pp: 71,72). 
En cuanto a las situaciones en las que "el niño escribe por sí mismo", las investigaciones de Ferreiro y otros han puesto de manifiesto que en las aulas de educación inicial y de primer año, conviven diferentes modalidades de escritura que constituyen pasos necesarios para la comprensión de nuestro sistema alfabético y que responden a distintas hipótesis que los niños van construyendo para comprender dicho sistema.

Ahora bien, cuando los niños leen por sí mismos, comienzan a explorar el sistema de escritura, integrado por letras, espacios y signos que se combinan de diferentes maneras para representar el lenguaje. Tal como se comentara, los niños escriben de diferentes maneras antes de hacerlo de manera convencional. Esto también vale para la lectura, ya que los pequeños van poniendo en juego diferentes estrategias lectoras (selección de algunas letras como índices para anticipar significados, coordinación de datos del texto con datos del contexto, etcétera) antes de llegar a leer convencionalmente. Estas lecturas no convencionales son verdaderos actos de construcción y atribución de significados.

En esta investigación se seleccionaron tres de esas situaciones para evaluar la incidencia del programa en los saberes de los niños: escribir por sí mismos -, leer por sí mismos y leer a través del maestro. El propósito central de este trabajo consiste en indagar la incidencia del Programa Cuenta Quien Cuenta en los conocimientos y comportamientos letrados de los niños. Cabe remarcar que este Programa ha centrado su estrategia en proponer la generación de escenarios en el hogar que posibilitan, de manera privilegiada, la lectura de los niños a través de los adultos. También es posible que los niños, al estar inmersos en ese universo más letrado que favorecía Cuenta quien Cuenta, hayan podido interactuar con los libros y realizar espontáneamente intentos de lectura por sí mismos. Finalmente, aunque el Programa no proponía a los padres incidir en las escrituras de sus hijos, en la evaluación se incluyó este ítem para detectar si existían diferencias entre el conocimiento de estos niños sobre el sistema de escritura con los saberes de otros niños cuyos padres no tomaron parte de las actividades propuestas (grupo control).

\subsection{El caso particular de la lectura de cuentos}

En general, las familias de las sociedades alfabetizadas desempeñan un papel protagónico en el aprendizaje temprano de la lectura (Dickinson y De Temple, 1998; Fagan y Hayden, 1989, Taylor, 1983). Entre las actividades cotidianas que abordan la lectura con fines prácticos y recreativos, cuya influencia es determinante en la construcción temprana del conocimiento sobre el lenguaje escrito, se destaca la lectura oralizada de cuentos (Durkin, 1966; Many, 1989; Snow y Golfield, 1982). 
Al estudiar el papel de la lectura oral de cuentos en la familia, es necesario explicar la naturaleza de su influencia.

Frente a la complejidad que implica el proceso de aprender a leer y a escribir, Mónica Alvarado y Sofía Vernon (2004) sostienen que es importante que los niños comiencen a familiarizarse con la lengua escrita a través de un proceso de interacción con los materiales escritos y con la ayuda de los miembros formados de una cultura. Este paso supone un auténtico proceso de mediación entre los docentes y los alumnos, hasta que éstos dominan ese conocimiento y pueden actuar de forma autónoma. En este sentido son muy importantes los aportes de Bruner (1991), quien denominó "andamiaje" a este proceso en el que el adulto debe dar sostén a los primeros aprendizajes y retirarse cuando estos estén consolidados. Este autor resalta el valor de la narración oral y su relación con el aprendizaje de la lectura, así como el papel de la cultura y de los instrumentos culturales en el desarrollo de los sujetos.

Ángeles Molina Iturrondo (1999), examinó, en un estudio longitudinal realizado con su hija, el origen y la evolución temprana de las posibilidades de renarración de cuentos, desde su nacimiento hasta el primer grado de la escuela primaria en frecuentes sesiones de lectura oral. Uno de los aspectos analizados fue la naturaleza y la transformación del diálogo y la renarración como vehículo para construir y atribuir significado textual en la lectura oral de cuentos favoritos. La lectura oral de cuentos interactiva y dialogada entre el adulto y el niño, es sin duda una de las formas de lectura no convencional precoz que facilita la construcción temprana de significado textual. El adulto, como lector experto, lee el cuento pero también hace preguntas y genera comentarios sobre la historia y su vinculación con las ilustraciones. La lectura dialógica se constituye en una valiosa estrategia de intervención lingüística que el niño utiliza para interactuar con el lector. En esta situación conversacional el texto oral es el vehículo mediatizador.

Ana María Kaufman y María Elena Rodríguez (2001) describen en su artículo ¿Por qué cuentos en la escuela? algunos de los aprendizajes que tienen lugar cuando los niños narran cuentos. Aprender a narrar, señalan, es una conquista de vital importancia porque implica referir acciones dotadas de intencionalidad y organizar los hechos temporal y causalmente. Los niños, al narrar se van apropiando de las pautas temáticas, estructurales y retóricas propias del relato literario.

Otro estudio que afirma que la lectura de cuentos a los niños facilita la apropiación de las estructuras propias del lenguaje escrito es la tesis doctoral desarrollada por Luz Angélica Sepúlveda Castillo (Barcelona, 2011) El aprendizaje inicial de la reescritura de textos como (re) escritura. Los efectos beneficiosos se atribuyen fundamentalmente a la lectura en voz alta por 
parte del adulto y a la interacción con abundante material escrito. Sepúlveda Castillo señala, asimismo, que el contacto con los libros familiariza al niño con los registros convencionales del lenguaje escrito: fórmulas literarias de comienzo y final de los cuentos, marcadores discursivos, estructuras gramaticales, etc. De todas maneras, la autora destaca que, en los estudios consultados, no se explica cómo se evalúa la influencia de la lectura de cuentos en las apropiaciones infantiles del lenguaje escrito.

Para que un niño recuente un cuento tiene que reconstruirlo cognoscitivamente. Por lo tanto tiene que haber estado en contacto con él de manera recurrente a través de la voz de un adulto antes de intentar leerlo por sí mismo. Según Sulzby, E. (1985), el recuento independiente es un mecanismo de transición entre la supremacía del lenguaje oral como vehículo de atribución de significado en la lectura temprana y predominio del lenguaje escrito en la lectura convencional.

La lectura oral de cuentos entre un adulto y un niño asume un papel preponderante en el enfoque socio-psicolingüístico (Guillaume, G. 1964) ya que esta constituye uno de los antecedentes evolutivos más tempranos de la lectura convencional.

También los trabajos de Christine Pappas y Elga Browne (1987) mostraron que en situaciones de recuento oral de historias conocidas, los preescolares eran capaces de producir textos con las características propias del lenguaje escrito. Simular leer o recontar cuentos no constituyen simples tareas de renarración o de memoria, sino que son situaciones que dan cuenta de un proceso constructivo de apropiación y organización de las formas propias de la experiencia escrita.

En una evaluación destinada a primer ciclo de la escuela primaria se incluye una actividad de reescritura de un cuento tradicional bajo ciertas condiciones: los niños "leen" la historia a través de la voz de su maestro de manera reiterada. El docente tiene en sus manos una versión previamente seleccionada que lee a toda la clase. Los chicos reescriben el cuento enfrentándose con el desafío de explorar los múltiples recursos que les ofrece la lengua para relatar la historia escuchada, sin la tensión de tener que inventar los hechos. La actividad les permite concentrarse en el cómo decir sin necesidad de inventar el qué decir. En ese trabajo se especifica que esa tarea será realizada por niños cuya escritura sea legible sin ninguna aclaración de su parte (Kaufman et al, 2012).

\subsection{Los sectores populares}

Por último, el presente trabajo demanda cierta aproximación al concepto de sectores populares. Este término es extremadamente ambiguo ya que los sectores populares, como cualquier otro 
sector de la población, no constituyen un cuerpo homogéneo, aun cuando posean experiencias y condiciones comunes -de pobreza y dominación- resultantes de un determinado contexto histórico (Julio Pinto, J. y Salazar, G.1999: 97, 98). La diversidad ocupacional, de poder, las tradiciones culturales, la diversidad de ideologías llevan, como señala Luis Alberto Romero (1990:276), a la fragmentación del sujeto. Fragmentación que hace posible la reconstrucción permanente en el entendido que los sujetos no son sino que están siendo, es decir que el sujeto está en permanente construcción.

La noción sectores populares no ha sido definida de manera unívoca en la historiografía, y el concepto popular exige reacomodos y redefiniciones según distintas épocas y lugares. Se trata de un campo de límites fluctuantes, ya que lo que separa a lo popular de lo no popular no se define de una vez para siempre, sino que es el resultado de la dinámica del proceso histórico y, como tal, se desplaza y modifica.

El término describe a un variado universo poblacional que se caracteriza por ser ajeno al mundo del privilegio y del ejercicio del poder. De allí que, por exclusión, podría definírselo como un amplio sector de la sociedad que no disfruta de posiciones dominantes en lo económico, lo político y lo social. En él confluirían, por lo tanto, junto a una gran variedad de oficios y ocupaciones, diversidad de tradiciones culturales, de orígenes étnicos, de riqueza y prestigio, que permiten distinguir diferentes estratos y condiciones.

Hay casi un consenso, en estos últimos tiempos, en tratar los problemas de los sectores populares - desempleo, pobreza, desescolarización - como derivados de la exclusión del mundo del trabajo, de la protección del estado y de las posibilidades de acceso y permanencia en la escuela.

En cuanto al proceso de escolarización, en general, esta población sufre la repetición y el fracaso escolar, especialmente en los primeros años de la enseñanza primaria, cuestión que se vincula a la dificultosa contención de los adolescentes y jóvenes en el sistema educativo.

Un estudio realizado por UNICEF ${ }^{3}$ ha definido algunas dimensiones que miden la calidad de vida y el bienestar de la infancia, más allá de la pobreza o los grados de desarrollo socioeconómico. Los factores más relevantes que se asocian al éxito escolar de los niños se vinculan con: el tiempo que pasan hablando cada día con sus padres; la cantidad de libros que leen y las expectativas acerca de sus posibilidades de desarrollo.

\footnotetext{
${ }^{3}$ UNICEF. Un panorama del bienestar infantil en los países ricos, 2007.
} 
En relación a la revisión de antecedentes en Uruguay, diversos estudios llevados a cabo en la década de los años 90 (CEPAL 1990; CEPAL 1991) demuestran la relación existente entre condiciones de pobreza y bajo rendimiento escolar, fundamentalmente medido por el índice de repetición de los primeros años de Educación Primaria. Actualmente la tasa de repetición en primer año, en las escuelas comunes, se sitúa en el entorno del $7 \%$ de la población nacional que cursa ese grado, agudizándose este porcentaje en aquellas categorizadas como Escuelas APRENDER $^{4}$, la mayoría concentradas en la capital del país y en las zonas suburbanas de las capitales departamentales. Este porcentaje llega a rondar el 20\%. Asimismo cabe mencionar que se advierte un decrecimiento importante en la matrícula, razón por la cual es casi nula la existencia de grupos mayores a veinticinco niños. Actualmente 276 escuelas corresponden a esta categorización de las 2.036 existentes hasta el momento en todo el territorio nacional. Los propósitos centrales de las escuelas APRENDER son: potenciar las actividades educativas que permitan reducir las tasas de repetición, abatir el ausentismo y mejorar los niveles en los aprendizajes; propiciar la consolidación de colectivos docentes que generen Proyectos Educativos relevantes y pertinentes y, por último, mejorar la interrelación con las familias a través de la participación activa de los referentes adultos y el fortalecimiento del vínculo de la escuela con la comunidad.

\subsection{La evaluación}

Por último, se comentará un término que es central en este trabajo: evaluación. La UNESCO, en el Glosario de términos de tecnología de la evaluación, incluye una gran variedad de acepciones sobre esta expresión. Una de ellas la define como un conjunto de operaciones de apreciación, control y medición de los resultados de una estrategia, de un sistema, de un grupo de personas, etc. y como un proceso tendiente a delimitar, obtener y reunir la información útil para juzgar alternativas de decisión, controlar la eficacia de la ejecución de la actividad y juzgar su interés.

Neirotti, N. (2005), señala que de un tiempo a esta parte se ha superado el histórico divorcio entre las metodologías cuantitativas y cualitativas para dar paso a las propuestas "multiplistas" que adoptan enfoques y técnicas de ambos según convenga al objeto a indagar. Esta opción permite atender tanto al proceso como a los resultados. O sea considerar al mismo tiempo la valoración del impacto y la búsqueda de explicaciones sobre los aspectos evaluados. En el caso particular de este trabajo de investigación se utilizará uno de los dos Modelos de comparación propuestos por el

\footnotetext{
${ }^{4}$ Escuelas que cuentan con un modelo de Atención Prioritaria en Entornos con Dificultades Estructurales Relativas, debido a las condiciones socioculturales de la población, el índice de repetición y de desvinculación educativa.
} 
autor: el que trata de la evaluación entre los grupos beneficiarios de un programa y los que no han accedido a él.

En esta investigación se intenta evaluar la incidencia del Programa Cuenta Quien Cuenta en los hijos de algunos participantes, a través de indagar sus conocimientos y prácticas en determinadas situaciones de lectura y escritura al comienzo de su primer año escolar y compararlos con los de los niños cuyos padres no participaron del Programa. 


\section{Capítulo 3.}

\section{Diseño metodológico}

\subsection{Formulación del problema}

La identificación del problema a abordar en esta investigación surge a partir de múltiples cuestionamientos que se refieren fundamentalmente a:

1- ¿Qué modificaciones pueden identificarse en las actitudes y prácticas lectoras de los adultos después de participar en el Programa de Alfabetización Cuenta Quien Cuenta?

2- ¿De qué manera incide la lectura frecuente en los hogares en las características que adopta el contacto de los niños con los libros?

3- ¿De qué manera incide la lectura frecuente en los hogares en el conocimiento del sistema de escritura y del lenguaje escrito así como en el desarrollo de estrategias lectoras que el niño pondrá en juego al ingresar al primer año escolar?

Como se comentara anteriormente, el objetivo general de esta investigación consiste en indagar por un lado, si la alternativa alfabetizadora propuesta por el Programa Cuenta Quien Cuenta incide favorablemente en la inclusión de los hijos de los participantes en el mundo letrado y por otro, identificar y describir qué conocimientos poseen estos niños del lenguaje escrito en general, una vez que sus padres realizaron la experiencia.

Para desarrollar esta indagación, se utilizó un instrumento elaborado por la Directora de esta tesis Lic. Ana María Kaufman y su equipo, que incluye situaciones tendientes a evaluar los conocimientos infantiles, concebidos como procesos, sobre el sistema alfabético de escritura, el lenguaje escrito y la comprensión lectora en primer ciclo de la escuela primaria.

Varios de estos aspectos ya contaban con claves de corrección, es decir, categorías de respuestas esperadas: el conocimiento del sistema de escritura, el uso de estrategias lectoras y la reescritura de un cuento para evaluar aspectos del lenguaje escrito. Como se trata de evaluar niños pequeños, que recién ingresan a primer año, la reescritura de un cuento fue reemplazada 
por la renarración oral del mismo. Una de las ventajas de narrar un cuento conocido, en lugar de crear uno nuevo, es que los niños ya conocen el argumento y pueden centrarse en cómo se narra y no en qué se narra. Asimismo, y como la intención es evaluar el potencial del Programa también en lo que se refiere a la relación con objetos culturales, se incluyó otra situación que permitió apreciar el tipo de contacto que los niños establecen con los libros de cuentos.

Como la situación de renarración oral de cuentos no se ha explorado lo suficiente como para conocer las características que tienen los diferentes momentos de ese proceso constructivo, se planteó la necesidad de elaborar categorías de análisis o claves de respuesta para este ítem.

\subsection{Hipótesis}

Existen diferencias significativas de desempeño escolar entre aquellos niños en cuyos hogares leer y escribir son actividades permanentes -y donde los adultos referentes juegan un rol relevante en la mediación de estos aprendizajes- y aquellos que provienen de un entorno familiar en el cual estas prácticas no son habituales.

Esta investigación parte de la hipótesis de que la participación de las familias en un programa de alfabetización que las involucre activa y sistemáticamente y que a su vez posea algunos de los elementos clave señalados por los autores relevados -lectura de cuentos en voz alta, descontextualización de la temática, interacción dialógica, acceso a material impreso, avances en la alfabetización de los propios adultos participantes, etc- hará más probable que los hijos de las mismas estén mejor posicionados al ingresar a primer año para apropiarse del lenguaje escrito.

\subsection{Resoluciones metodológicas}

Para evaluar la incidencia del Programa CQC en los hijos de los participantes fue necesario tomar una serie de resoluciones metodológicas: la selección de la población a estudiar, el diseño y adecuación de los instrumentos de recolección de datos, los diferentes pasos en el procesamiento de los datos y, finalmente, las decisiones acerca de los procedimientos con los que se analizarían la información obtenida. 


\subsubsection{Población seleccionada: características del grupo experimental y del grupo control}

Si bien la evaluación se focalizó en los hijos de aquellas familias que habían participado del Programa, resultaba interesante comparar esos datos con los de otros niños de similar pertenencia socio-cultural cuyos padres no hubieran asistido al mismo. Por esta razón se incluyó un grupo control, integrado por niños cuyos padres no habían participado del Programa, pero provenían del mismo barrio, concurrían a la misma escuela, asistían al mismo grado, compartían al mismo maestro, con lo cual se garantizaba que estuvieran inmersos en la misma situación de enseñanza.

Para comparar los resultados de los dos grupos fue necesario enriquecer el diseño metodológico de forma tal que permitiera dar cuenta de los posibles conocimientos que unos y otros niños podrían manifestar en situación de leer, escribir y re-narrar cuentos, para lo cual se tomó como referencia uno de los Modelos de comparación propuestos por Cohen y Franco (1991). Estos autores establecen que al momento de realizar una evaluación existe la posibilidad de realizar dos tipos de comparación: a) entre los grupos beneficiarios del programa y los que no han accedido a él; y b) dentro del mismo grupo, a lo largo del tiempo. En esta investigación se optó por utilizar el primero de los métodos comparativos señalados.

Se entrevistaron treinta niños que ingresaban a primer año de escuelas públicas. Quince de ellos son hijos de familias que habían participado del programa Cuenta Quien Cuenta y los restantes quince son hijos de familias que no participaron del mismo. Se seleccionaron cinco escuelas del departamento Paysandú, Uruguay -una urbana, tres suburbanas y una rural categorizadas como escuelas APRENDER-, en función de estar radicadas en las zonas donde residen las familias que participaron del programa mencionado en años anteriores.

Las muestras fueron tomadas durante el primer semestre del año escolar correspondiente a 2011 y la cantidad de niños a entrevistar por aula dependía de la existencia de niños cuyas familias habían participado del programa, es decir si en un aula se hallaban tres niños cuyas familias habían participado del programa se le solicitaba a la maestra que al azar designara la misma cantidad de niños cuyos padres no habían participado del programa para incluirlos en igual proporción a la muestra. 
Las escuelas involucradas en la muestra pertenecen al reciente Programa Escuelas APRENDER, del Consejo de Educación Inicial y Primaria (CEIP) de la Administración Nacional de Educación Pública (ANEP) de Uruguay. Este Programa busca atender integralmente a 276 escuelas de contexto socioculturales críticos con una matrícula de 101.739, lo que representa el 33,3\% de la matrícula total de las escuelas del país. De acuerdo a datos del 2010, las escuelas APRENDER se caracterizan5 por una situación social más compleja que la que se registra en las restantes escuelas comunes.

Una alta proporción de niños tiene madres con niveles educativos de primaria incompleta $(57 \%$ a $31,7 \%)$; pocas madres alcanzan niveles superiores al nivel primario (8, $6 \%$ frente a $25,7 \%)$; muchos niños viven en hogares con al menos una necesidad básica insatisfecha $(32,3 \%$ frente a $14,5 \%$ en escuelas comunes); un porcentaje importante reside en asentamientos (36, $5 \%$ y el 17 , $4 \%$ de los hogares de los niños de estas escuelas presenta desintegración educativa (existencia en el hogar de menores hasta 15 años que no asisten a ningún centro educativo).

Un reciente estudio (Mancebo, M. E. Alonso, C. 2012:14) hace referencia a que los resultados educativos también revelan la complejidad de la realidad de estas escuelas: según datos del 2010 , la repetición total fue del $9,1 \%$ y la de primer grado de $19,2 \%$ (frente a $4,8 \%$ y $9,1 \%$ en las escuelas comunes respectivamente).

Entre los objetivos generales el Programa escuelas APRENDER procura garantizar el acceso, permanencia y sostenimiento de trayectorias escolares personalizadas y de calidad, para mejorar el aprendizaje de todos los niños habilitándolos a participar en la vida social con igualdad de oportunidades. Particularmente intenta mejorar la interrelación con las familias a través de la participación activa de los referentes adultos y del fortalecimiento del vínculo de la escuela con la comunidad.

\subsubsection{Instrumentos de recolección de datos}

Se realizaron observaciones a niños en pequeños grupos -integrados por tres alumnos- y posteriormente entrevistas individuales en las que se indagaron los conocimientos y actitudes que se querían evaluar. Asimismo se incorporaron algunos datos a través de encuestas a los adultos participantes que permitieron conocer con mayor profundidad a la población destinataria del Programa y poseer cierta aproximación a su visión y valoración sobre la lectura y la escritura.

\footnotetext{
${ }^{5}$ Relevamiento de características de las escuelas del Consejo de Educación Inicial y Primaria (2010). Realizado por la División de Investigación, Evaluación y Estadística del CODICEN de la ANEP.
} 
A continuación se incluye un esquema que sintetiza los aspectos a evaluar, las situaciones experimentales consideradas y la modalidad de la indagación en cada uno de los casos.

\subsubsection{Situaciones experimentales}

\begin{tabular}{|c|c|c|}
\hline $\begin{array}{c}\text { SITUACIONES } \\
\text { EXPERIMENTALES }\end{array}$ & ASPECTOS A EVALUAR & MODALIDAD \\
\hline $\begin{array}{l}\text { 1) Encuestas a los adultos } \\
\text { participantes del } \\
\text { Programa }\end{array}$ & $\begin{array}{l}\text { Nivel educativo; presencia de materiales } \\
\text { escritos en el hogar; relevamiento de las } \\
\text { actividades lectoras realizadas con los hijos y } \\
\text { de las dificultades que presentan estas } \\
\text { tareas. }\end{array}$ & $\begin{array}{l}\text { Individual } \\
\text { (Al iniciar y } \\
\text { finalizar su } \\
\text { participación) }\end{array}$ \\
\hline $\begin{array}{l}\text { 2) Exploración y contacto } \\
\text { con libros }\end{array}$ & Actitudes de los niños frente a los libros. & $\begin{array}{l}\text { Pequeño grupo } \\
\text { (Observación y } \\
\text { registro) }\end{array}$ \\
\hline $\begin{array}{l}\text { 3) Renarración de un } \\
\text { cuento }\end{array}$ & $\begin{array}{l}\text { Posibilidad de reconstruir la estructura } \\
\text { narrativa y los recursos literarios de un cuento } \\
\text { conocido. }\end{array}$ & $\begin{array}{l}\text { Individual } \\
\text { (Entrevista. } \\
\text { Método clínico) }\end{array}$ \\
\hline $\begin{array}{l}\text { 4) Escritura del nombre } \\
\text { propio }\end{array}$ & $\begin{array}{l}\text { Conocimiento convencional de la escritura del } \\
\text { nombre propio. }\end{array}$ & $\begin{array}{l}\text { Individual } \\
\text { (Entrevista. } \\
\text { Método clínico) }\end{array}$ \\
\hline 5) Escritura de palabras & $\begin{array}{l}\text { Nivel de conocimiento del sistema de } \\
\text { escritura. }\end{array}$ & $\begin{array}{l}\text { Individual } \\
\text { (Entrevista. } \\
\text { Método clínico) }\end{array}$ \\
\hline 6) Lectura de palabras & $\begin{array}{l}\text { Estrategias lectoras puestas en juego para } \\
\text { identificar palabras escritas. }\end{array}$ & $\begin{array}{l}\text { Individual } \\
\text { (Entrevista. } \\
\text { Método clínico) }\end{array}$ \\
\hline $\begin{array}{l}\text { 7) Breve encuesta a los } \\
\text { niños }\end{array}$ & Acceso a lecturas extraescolares. & Individual \\
\hline
\end{tabular}

La situación 1 se configuró aprovechando los datos obtenidos a partir del Formulario que el Programa aplica a los adultos participantes al comenzar y finalizar cada edición.

Las situaciones 2 y 7 fueron diseñadas a efectos de esta investigación.

Las situaciones 3, 4, 5 y 6 corresponden a la propuesta de Evaluación de los procesos de lectura y escritura elaborados por Ana María Kaufman (2012) y su equipo, aunque es preciso señalar que la situación 3 fue rediseñada tomando como referencia la propuesta original de la autora de reescritura de un cuento conocido. 
Cabe mencionar que en las situaciones 3, 4, 5 y 6 se utilizó, para la obtención de datos, el Método clínico ${ }^{6}$.

Para las respuestas en las situaciones que no corresponden a las encuestas, se establecieron categorías denominadas como A, B y C. En algunas situaciones los datos expresados en A, dan cuenta de que el niño ha adquirido los conocimientos de mayor nivel en el ítem correspondiente. Los datos expresados como $\mathrm{B}$, son indicadoras de una construcción parcial del conocimiento evaluado y las respuestas $C$ evidencia un desempeño que corresponde a un momento muy inicial del proceso constructivo. Para registrar el número de niños que no realizaron la tarea se les adjudicó la sigla NRT.

\subsubsection{Etapas de procesamiento de los datos obtenidos}

Los materiales recabados en la recolección de datos fueron procesados a partir de los siguientes pasos:

a) Sistematizar las respuestas obtenidas en las encuestas a adultos participantes del Programa (Situación Experimental $N^{\circ} 1$ ).

b) Sistematizar los registros de observaciones de las actitudes de los niños en la situación de Exploración y contacto con los libros (Situación Experimental №2).

C) Desgrabar los videos y sistematizar los datos registrados en la situación de Renarración oral de cuentos (Situación Experimental №3).

d) Sistematizar los datos obtenidos en las situaciones de escritura y lectura (Situaciones Experimentales $\mathrm{N}^{\circ} 4,5$ y 6 ).

e) Sistematizar las respuestas obtenidas en las encuestas realizadas a los niños (Situación Experimental $\mathrm{N}^{\circ} 7$ ).

f) Procesar, tabular y graficar la totalidad de los resultados obtenidos.

g) Comparar los resultados obtenidos en los dos grupos de niños evaluados a efectos de identificar eventuales diferencias entre ambos.

\footnotetext{
${ }^{6}$ Este método de investigación es empleado para conocer las concepciones infantiles sobre el mundo. Permite superar el método de pura observación y, sin caer en los inconvenientes del test, alcanzar las principales ventajas de la experimentación. Las respuestas espontáneas están basadas en lo que Piaget denominó como creencias espontáneas o las que el niño posee sin intervención del entrevistador o el adulto (La representation du monde chez l'enfant, 1926).Se diseñan, con este cometido, situaciones experimentales que ponen de manifiesto indicadores que permiten inferir la estructura que se está construyendo.
} 


\section{Capítulo 4.}

\section{Descripción de las situaciones experimentales, categorías de análisis y resultados}

A continuación se describirán pormenorizadamente las situaciones experimentales; se explicitarán las categorías de análisis empleadas y se compararán los resultados de ambos grupos a excepción de la situación experimental $\mathrm{N}^{\circ} 1$ en la que solamente se analizan respuestas de los participantes del Programa CQC. Esta última situación corresponde a una encuesta que se aplicaba en forma sistemática a las familias al inicio y al final del programa. En este caso se compararán las respuestas de los padres antes y después de participar.

\subsection{Situación 1 -Encuesta a los adultos participantes del programa Cuenta Quien Cuenta}

La indagación sobre la creación de posibles escenarios de lectura y escritura en el hogar generados por el Programa implicaría pensar en un abordaje metodológico de corte etnográfico a través de observaciones de los modos de decir y usar la lectura por parte de los adultos participantes. Las limitaciones temporales y de otros recursos impidieron incorporar el mismo a la presente investigación. En este sentido, y considerando de todos modos la importancia de conocer el perfil de los adultos participantes del programa -edad, nivel educativo, el número de hijos, etc.- así como otras cuestiones referidas a las condiciones que pueden afectar el desarrollo de prácticas lectoras, tales como la existencia de materiales de lectura en el hogar y las dificultades más sentidas al momento de querer leer a sus hijos, se decidió aprovechar los datos relevados antes y después del Programa con los adultos participantes. Esta información se recogió en un formulario preestructurado que apuntaba precisamente a recabar la información necesaria y que se incluye a continuación. 


\section{Registro de datos relevantes de los participantes}

Fecha:

Nombre del niño o niña por quien concurre:

Edad:

\section{1) Datos personales del familiar que participa}

Nombre:

Relación con el niño: Padre Madre Hermano/a Tía/o Abuela/o Otra relación
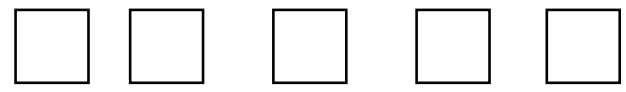

Edad (marcar con una X)

\begin{tabular}{|l|l|}
\hline 18 años o menos & \\
\hline Entre 19 y 30 años & \\
\hline Entre 31 y 45 años & \\
\hline Entre 46 y 60 años & \\
\hline 61 años o más & \\
\hline
\end{tabular}

Nivel educativo (marcar con una X)

\begin{tabular}{|l|l|}
\hline Primaria incompleta & \\
\hline Primaria completa & \\
\hline Secundaria incompleta & \\
\hline Secundaria completa & \\
\hline Terciario & \\
\hline Otros & \\
\hline
\end{tabular}

Número de hijos:

\begin{tabular}{|l|l|}
\hline Entre 0 y 5 & \\
\hline Entre 6 y 12 & \\
\hline 13 años o más & \\
\hline
\end{tabular}

2) Datos generales sobre la cultura letrada

¿Tiene material de lectura en el hogar? Sí NO

¿Cuáles?

¿Qué ha leído usted esta última semana?

¿Cuándo fue la última vez que usted le leyó algo a sus hijos?

¿Qué le leyó?

¿Por qué le leyó?

¿Qué cosas le parece que puede hacer la familia para ayudar a sus hijos a aprender a leer?

¿Qué dificultades encuentra usted para leerles a sus hijos? (marcar con una X)

\begin{tabular}{|l|l|}
\hline Tengo poco tiempo & \\
\hline No sé leer muy bien & \\
\hline Tengo pocas cosas para leerles & \\
\hline Me aburre leer & \\
\hline No tengo dificultad & \\
\hline Otras & \\
\hline
\end{tabular}




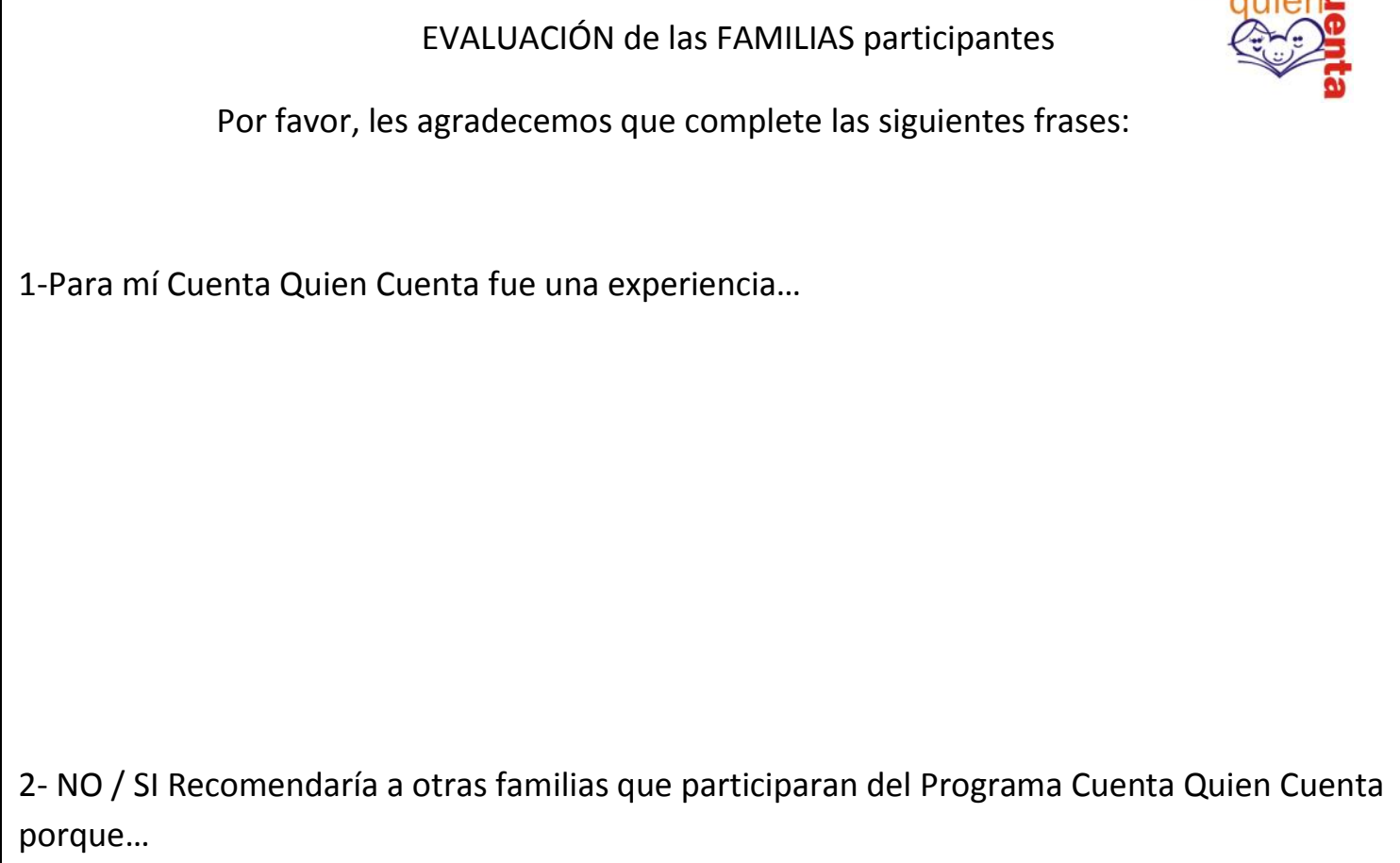

1-Para mí Cuenta Quien Cuenta fue una experiencia...

2- NO / SI Recomendaría a otras familias que participaran del Programa Cuenta Quien Cuenta porque...

3- Creo que la lectura de cuentos en casa... 


\subsubsection{Análisis de la información de la encuesta inicial: datos personales y relación con la cultura letrada}

De acuerdo con el relevamiento de los datos, las principales características de la población destinataria del Programa consignadas en la encuesta inicial son las siguientes:

- Los adultos que participaron del Programa son en su mayoría madres (76\%), abuelas (14\%), en tanto que el $10 \%$ restante estaba integrado por padres, tías, hermanas o vecinas.

- $\quad$ El $86 \%$ se sitúa en un nivel socio-económico muy desfavorecido.

- El $36 \%$ presenta un bajo nivel educativo al no haber completado el ciclo de Educación Primaria.

- $\quad$ El 54\% de los participantes son jóvenes -entre 18 y 29 años-.

- El $42 \%$ manifiesta ausencia de materiales de lectura en el hogar. El 58\% restante comenta que el material que posee consiste en revistas, libros de cuentos y diccionario.

- El $24 \%$ ha leído algo durante la última semana -el 19\% manifestó haber leído el cuaderno viajero del jardín y el 5\% un libro de poesía y el diario-. El 76\% restante manifiesta no haber leído nada.

\subsubsection{Análisis de la información de la encuesta final: relación con la cultura letrada}

Es interesante remarcar la diferencia de las respuestas obtenidas al comienzo y al finalizar el programa respecto de: 1) la significación que otorgan a la lectura en los hogares, 2) la frecuencia con que leen a los niños, 3) los materiales de lectura disponibles, 4) las actividades que realizan con sus hijos para ayudarlos a aprender a leer y a escribir y 5) las dificultades que encuentran para leerles.

A continuación se describirán las identificadas:

1) Consultadas respecto a la significación de la lectura, las familias entrevistadas responden al inicio del programa que leyeron a sus hijos "porque le gusta; para entretenerlos; a requerimiento de los niños; para que duerma"; en tanto que una vez finalizado el programa las respuestas señalan: "porque ahora sabemos que leer a los 
niños los ayuda a que conozcan más palabras; porque es importante que nos vean leer para que tomen el gusto por la lectura; porque van a aprender más fácil en la escuela; porque es una manera de pasar más tiempo con ellos leyendo cuentos". Esto da cuenta de un cambio cualitativo en el valor asignado a leer a sus hijos.

2) Las respuestas evidencian que la frecuencia con que los adultos de la familia leen a sus hijos se eleva significativamente. Al inicio del Programa la mayoría decía no leerles o leerles en escasas ocasiones, mientras que al ser consultados una vez finalizado el Programa el $78 \%$ alude leer a sus hijos casi todas las noches.

3) Materiales: La gran mayoría de las familias, en oportunidad de aplicárseles el formulario al finalizar el Programa, respondieron que ahora cuentan con al menos doce libros de cuentos infantiles y que también han coleccionado otros materiales escritos, como revistas y folletos de índole comercial, que consideran pueden constituir un aporte al momento en que sus hijos frecuenten diversidad de textos.

4) Las respuestas brindadas por las familias al inicio del Programa en cuanto a las actividades que realizan para ayudar a sus hijos a aprender a leer y a escribir se restringen a las siguientes respuestas: "darles hojas para pintar; hacer que los niños copien su nombre; que jueguen con los lápices y los colores".

Sin embargo, una vez finalizado el Programa la gran mayoría manifiesta que para ayudar a sus hijos a aprender a leer y a escribir lo que hacen es: "leer cuentos a mis hijos casi todos los días; leerles lo que la maestra manda en el cuadernito; enseñarles a nombrar las cosas que aparecen en los libros y revistas; volver a contarles el mismo cuento; escribir el nombre de los cuentos; dibujar los personajes; conversar sobre el cuento que le leí y compararlo con otros".

5) En cuanto a la identificación por parte de las familias -al inicio del Programa- de las dificultades que tienen a la hora de leer a sus hijos, estas se refieren mayoritariamente a no tener materiales de lectura, en menor escala a no saber leer muy bien, y, unos pocos mencionaron no tener tiempo. Las respuestas aparecen en orden decreciente según la reiteración hallada. En función de ello, el incremento de la disponibilidad de acceso a materiales de lectura registrado con posterioridad a la participación de los adultos en el Programa -ya señalado en el ítem 3- así como el aumento en el tiempo destinado a la lectura de cuentos -evidenciado en el ítem 2- manifiestan una incidencia positiva de dicha participación en la superación de las restricciones mencionadas. 


\subsection{Situación 2 - Exploración y contacto de los niños con los libros}

Esta situación procura recuperar las maneras en que el lector se relaciona con la lectura. Este comportamiento lector es la manifestación social de la forma en que una persona representa y practica la lectura en el contexto de la cultura escrita que lo acoge (Álvarez, D. 2006).

Se seleccionan tres niños por cada instancia de evaluación. Se les presenta una mesa con aproximadamente diez libros -predominantemente cuentos de literatura infantil- y se los invita a conectarse con los textos con una consigna de este tipo: Estos son unos libros que a mí me gustan mucho. Los dejo acá para compartirlos con ustedes. Vamos a tener un ratito para que puedan verlos bien.

Se registra durante cinco a diez minutos el comportamiento de los niños en la guía de observación que se inscribe debajo, en la que se contempla la duración del contacto, la modalidad del mismo y las oportunidades de socialización entre los niños.

\begin{tabular}{|c|c|c|c|}
\hline & ACTITUDES & Con CQC & Sin CQC \\
\hline \multirow{3}{*}{ 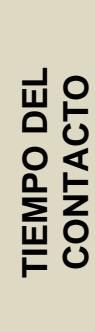 } & Ignora los libros todo el tiempo. & & \\
\hline & $\begin{array}{l}\text { Demora en conectarse con los } \\
\text { libros o lo hace de a ratos. }\end{array}$ & & \\
\hline & $\begin{array}{l}\text { Se conecta todo el tiempo con los } \\
\text { libros. }\end{array}$ & & \\
\hline \multirow{2}{*}{ 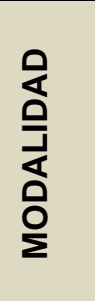 } & $\begin{array}{l}\text { Toma adecuadamente los libros y } \\
\text { los hojea. }\end{array}$ & & \\
\hline & $\begin{array}{l}\text { Toma los libros pero los usa } \\
\text { inadecuadamente. } \\
\text { (Por ejemplo, los apila, hace } \\
\text { construcciones.) }\end{array}$ & & \\
\hline \multirow{2}{*}{ 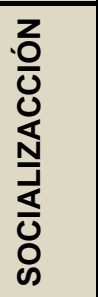 } & $\begin{array}{l}\text { Se conecta con los libros de } \\
\text { manera solitaria. }\end{array}$ & & \\
\hline & $\begin{array}{l}\text { Comparte el contenido u opiniones } \\
\text { con otros. }\end{array}$ & & \\
\hline
\end{tabular}

Como ya fuera señalado, esta situación pretendía observar la manera en que los niños se contactan con los libros, a fin de aproximarnos a qué representación tiene la lectura en su vida. En 
este marco, se tomaron en cuenta tres aspectos a fin de evaluar con mayor precisión las características de ese contacto. La primera variable se refiere al tiempo del contacto. La segunda se vincula con la manera que los niños se vinculan con los libros y la hemos denominado modalidad. La tercera -socialización- tiene relación con la construcción de una comunidad lectora y se manifiesta a partir de la relación que los niños tienen entre sí: si comparten el contenido de los libros o los exploran de manera solitaria.

\subsubsection{Categorías de análisis}

Tiempo del contacto

\begin{tabular}{|l|l|}
\hline A & Se conecta todo el tiempo con los libros. \\
\hline B & $\begin{array}{l}\text { Demora en conectarse con los libros o lo } \\
\text { hace de a ratos. }\end{array}$ \\
\hline C & Ignora los libros todo el tiempo. \\
\hline
\end{tabular}

\section{Modalidad del contacto}

\begin{tabular}{|l|l|}
\hline A & Toma adecuadamente los libros y los hojea \\
\hline B & $\begin{array}{l}\text { Toma los libros pero los usa } \\
\text { inadecuadamente. }\end{array}$ \\
\hline
\end{tabular}

\section{Socialización de la lectura}

\begin{tabular}{|l|l|}
\hline A & Comparte el contenido u opiniones con otros. \\
\hline B & $\begin{array}{l}\text { Se conecta con los libros de manera } \\
\text { solitaria. }\end{array}$ \\
\hline
\end{tabular}

\subsubsection{Análisis comparativo de los resultados}

En la tabla 1 se presentan los resultados encontrados sobre la primera variable. En esta tabla, como en todas las siguientes, se consignan los datos en valores absolutos en el casillero inferior derecho mientras que en el casillero superior izquierdo pueden observarse también los valores porcentuales correspondientes. 
TABLA 1

\begin{tabular}{|c|lc|lc|}
\hline TIEMPO DEL CONTACTO & \multicolumn{2}{|c|}{ Con CQC } & \multicolumn{2}{c|}{ Sin CQC } \\
\hline $\begin{array}{c}\text { A- Se conecta todo el tiempo } \\
\text { con los libros. }\end{array}$ & $87 \%$ & 13 & 8 \\
\hline $\begin{array}{c}\text { B- Demora en conectarse con } \\
\text { los libros o lo hace de a ratos. }\end{array}$ & $13 \%$ & 2 & $33 \%$ & 5 \\
\hline $\begin{array}{c}\text { C- Ignora los libros todo el } \\
\text { tiempo. }\end{array}$ & $0 \%$ & 0 & $14 \%$ & 2 \\
\hline
\end{tabular}

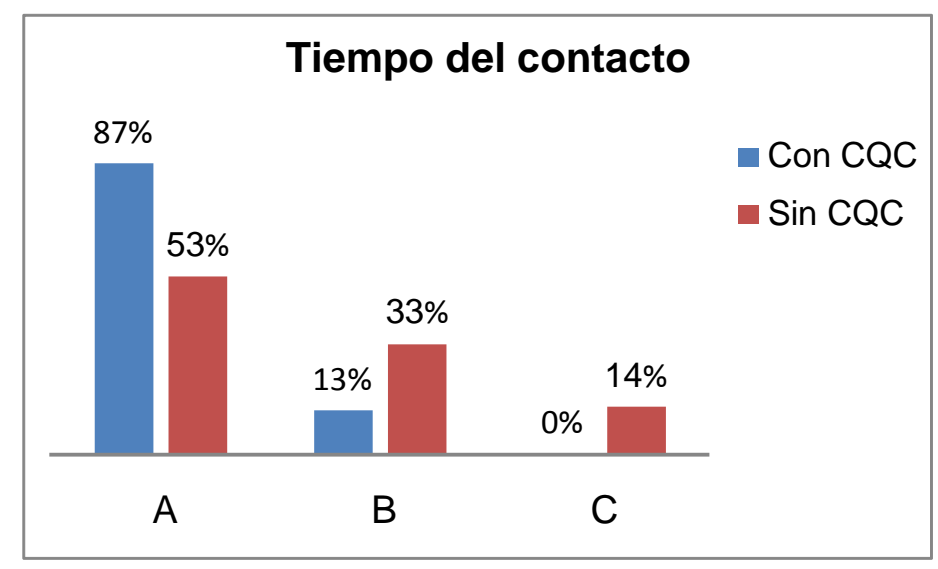

Como puede apreciarse en cuanto al Tiempo de contacto, ningún niño del primer grupo -hijos de padres que participaron del Programa- permaneció indiferente frente a la propuesta de exploración de libros. Trece de los niños lograron conectarse todo el tiempo con los libros, mientras que solo dos de ellos demoraron en tomarlos y, una vez que lo hicieron, el contacto fue intermitente. En cambio, el segundo grupo de niños observados -Sin CQC- se distribuye de la siguiente manera: ocho de ellos se vincularon con los libros todo el tiempo, cinco lo hicieron por lapsos breves y los dos restantes permanecieron indiferentes y no los tomaron en ningún momento.

En la tabla 2 se presentan los resultados del segundo ítem: la manera en que se vincularon con los libros. 
TABLA 2

\begin{tabular}{|c|lc|cc|}
\hline \multicolumn{1}{|c|}{$\begin{array}{c}\text { MODALIDAD DEL } \\
\text { CONTACTO }\end{array}$} & Con CQC & $53 \%$ & \multicolumn{2}{c|}{ Sin CQC } \\
\hline $\begin{array}{c}\text { A- Toma adecuadamente los } \\
\text { libros y los hojea. }\end{array}$ & $100 \%$ & 15 & 8 \\
\hline $\begin{array}{c}\text { B- Toma los libros pero los } \\
\text { usa inadecuadamente. }\end{array}$ & $0 \%$ & 0 & $47 \%$ & 7 \\
\hline
\end{tabular}

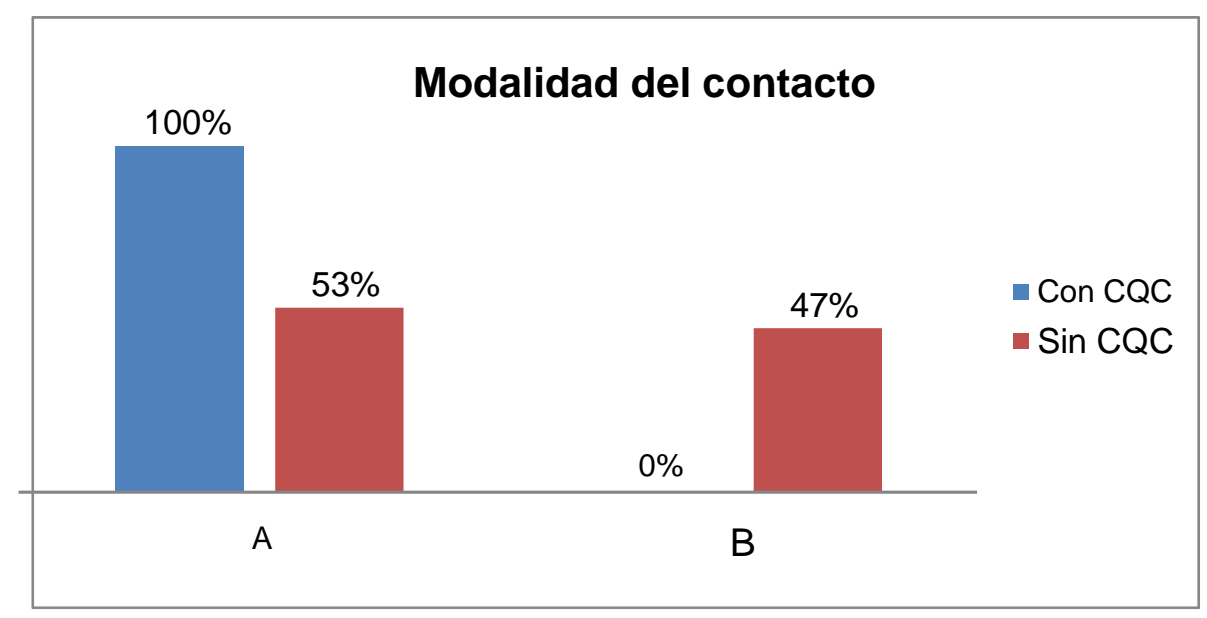

En relación con el segundo indicador -que se refiere a las formas de uso del libro como objeto cultural- puede observarse que la totalidad de los niños cuyos padres participaron del programa tomaban adecuadamente los libros y los hojeaban.

En cuanto al grupo Sin CQC, ocho niños tomaron los libros adecuadamente, mientras que los demás cambiaban de libro rápidamente, retiraban bruscamente los libros de la mesa o se los quitaban a algún compañero que estaba leyendo.

En la Tabla 3 se presentan los resultados del análisis del tercer indicador de esta situación experimental. 
TABLA 3

\begin{tabular}{|c|c|c|c|c|}
\hline $\begin{array}{l}\text { SOCIALIZACIÓN } \\
\text { DE LA LECTURA }\end{array}$ & Con CQC & & & \\
\hline $\begin{array}{c}\text { A- Comparte el contenido } \\
\text { u opiniones con otros. }\end{array}$ & $80 \%$ & 12 & $53 \%$ & 8 \\
\hline $\begin{array}{l}\text { B- Se conecta con los } \\
\text { libros de manera } \\
\text { solitaria. }\end{array}$ & $20 \%$ & 3 & $47 \%$ & 7 \\
\hline
\end{tabular}

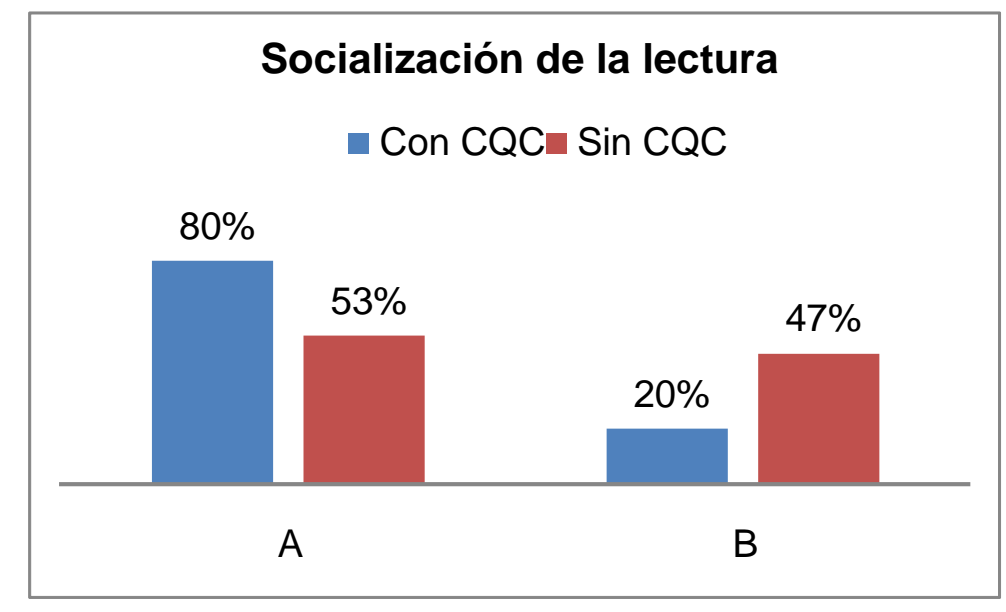

En esta variable -que proporciona datos sobre el uso de la lectura y del libro que hace el sujeto desde su dimensión social- pone de manifiesto que doce niños del grupo Con CQC compartieron el contenido del cuento que estaban leyendo e intercambiaron opiniones con los demás, mientras que solo tres de ellos se vincularon con los libros en forma solitaria.

El comportamiento del segundo grupo difiere significativamente: poco más de la mitad compartió el contenido y opiniones con otros, mientras que el resto se conectó con los libros de manera solitaria.

Podría mencionarse, a manera de conclusión, que esta primera situación experimental puso de manifiesto diferencias interesantes entre ambos grupos, tanto en lo que se refiere al contacto de los niños con los libros como objeto cultural, como en la interacción entre ellos mientras los exploraban. 
El grupo de niños Con CQC se relacionó más tiempo y de manera más pertinente con los libros y entre sí. Manipular un libro, mirar y reconocer las imágenes, comprender la historia, asumir actos de lectura -aprendidos seguramente a partir de modelos cercanos-, elaborar historias propias, conversar sobre la lectura que está realizando, recomendar un libro, fueron algunas de las manifestaciones de estos niños.

\subsection{Situación 3 - Renarración oral de cuentos}

En el marco de esta tesis, decidimos utilizar la situación de renarración de un cuento con la finalidad de obtener indicadores del conocimiento de los niños acerca del lenguaje escrito. Esto se debe a que los niños entrevistados todavía no habían llegado a un nivel de conocimiento del sistema de escritura que permitiera interpretar sus producciones.

Como se explicitó anteriormente, los niños pueden leer por sí mismos o a través de la voz del adulto. En este último caso, ellos pueden ir apropiándose de aspectos del lenguaje escrito antes de dominar cuestiones vinculadas con el conocimiento del sistema de escritura. Una alternativa para evaluar oralmente qué aspectos de los textos literarios maneja un niño es pedirle que cuente un cuento en voz alta. Al igual que en la situación de reescritura mencionada anteriormente, elegimos la situación de renarrar un cuento conocido y no pedirles que inventaran un cuento porque, de esta manera, se libera al niño de tener que inventar un argumento y puede centrarse en aspectos vinculados con la organización del relato.

A dichos efectos se seleccionaron dos cuentos de Keiko Kasza: "El estofado del lobo" y "Choco encuentra una mamá" (ver Anexo 1). Se intentó seleccionar dos textos que no difirieran en el estilo de escritura - de allí la elección de la misma autora- y que tuvieran, dentro de lo posible, tramas que compartieran un nivel equivalente de dificultad. Por otra parte, al tratarse en ambos casos de libros-álbum, ilustrados por su autora, también compartirían la importancia y la calidad del diseño gráfico.

Antes de implementar esta situación, se solicita a la maestra de los niños que les lea los dos cuentos seleccionados, al menos dos veces cada uno, y que los comente en clase. Lo importante es garantizar que los niños hayan entendido la historia para que las dudas sobre el argumento no obstaculicen la renarración. Esa renarración no es utilizada para evaluar la comprensión lectora de los niños sino para poder identificar cómo organiza el relato, con un buen conocimiento de la historia. 
La entrevistadora invitaba a uno de los niños seleccionados a sentarse y le mostraba los cuentos que la maestra había leído previamente, mientras decía:

- ¿Conocés estos cuentos? Me los dio tu maestra y me dijo que se los había leído. Yo no los conozco, ¿qué tal son?, ¿te gustaron?

Luego le solicitaba que eligiera uno y se lo contase. Si el niño presentaba alguna resistencia, el entrevistador lo animaba, insistiendo en que estaba muy interesado en saber de qué trataba el cuento. Las renarraciones fueron filmadas y desgrabadas en todos los casos (ver Anexo 2).

Para analizar los relatos de los niños se seleccionaron algunos parámetros de la evaluación elaborada por Ana María Kaufman y su equipo de investigación para analizar la reescritura de cuentos por parte de niños de escuela primaria (Kaufman, 2012:108). La intención es utilizar aquellos ítems que resulten pertinentes para analizar, en este caso, la renarración oral de cuentos conocidos por parte de niños pequeños.

Se seleccionaron dos parámetros que pueden dar cuenta de ciertas adquisiciones del lenguaje escrito por parte de los niños: la reconstrucción de la estructura narrativa del cuento y el uso de los siguientes recursos literarios: inclusión de las voces de los personajes -diálogos- y léxico utilizado.

\subsubsection{Categorías de análisis}

En lo que se refiere a la estructura narrativa, se intentó identificar los episodios mencionados por los niños en oportunidad de renarrar uno de los cuentos. En particular fue importante evaluar qué episodios incluían al relatar y si los mismos presentaban o no distorsiones.

Las claves de corrección se elaboraron a partir de un listado preestablecido de episodios que configuran el relato de cada uno de los dos cuentos. Los episodios están constituidos por acciones que se encadenan causalmente. En este caso solamente se consideran los episodios nucleares.

En consecuencia, las categorías para evaluar las renarraciones orales de los niños, en este aspecto, fueron las siguientes: 


\begin{tabular}{|l|l|}
\hline A & Cuento que incluye todos los episodios nucleares. \\
\hline B & Cuento que omite o modifica algún episodio nuclear. \\
\hline C & $\begin{array}{l}\text { Fragmentos vinculados con la historia que no llegan a } \\
\text { constituir un cuento. }\end{array}$ \\
\hline
\end{tabular}

A continuación se presentan los listados de episodios de los cuentos utilizados. En cada uno, es considerada válida cualquier opción de las que aparecen entre barras.

Episodios del cuento "El estofado del lobo"

1) El lobo quiere comer y encuentra una gallina.

2) Se le ocurre que es mejor engordarla.

3) Va a su casa, cocina panqueques y los deja en la puerta de la casa de la gallina / Lleva rosquillas / Lleva un pastel / Lleva muchas comidas.

4) Va a la casa de la gallina y se encuentra con que hay muchísimos pollitos / La gallina dice a los pollitos que era el lobo quien les traía las comidas / Los pollitos agradecen al lobo con besos.

5) El lobo decide no comer a la gallina.

Episodios del cuento "Choco encuentra una mamá"

1) Choco sale a buscar una mamá porque vive solo.

2) Encuentra a la señora jirafa, le pregunta si es su mamá y ella responde que no porque es diferente / Choco encuentra a la señora pingüino, le pregunta si es su mamá y ella responde que no porque es diferente / Choco encuentra a la señora morsa, le pregunta si es su mamá y ella responde que no porque es diferente / Encuentra a varios animales que no pueden ser su mamá porque son diferentes.

3) Choco ve a una osa.

4) La osa invita a Choco a su casa a comer pastel con sus hijos.

5) Cuando llegan, la osa le presenta a sus hijos que: eran un hipopótamo, un cocodrilo y un chancho / eran todos diferentes animales.

6) La osa los abraza y Choco se siente feliz porque encontró una madre / se queda vivir con su nueva familia / está feliz con su madre tal como es.

En cuanto a los recursos literarios utilizados, se seleccionaron dos aspectos: la inclusión de las voces de los personajes y el léxico empleado.

Es sabido que los diálogos enriquecen la narración a través del intercambio discursivo entre dos o más personajes que alternan sus voces, su papel de emisores y receptores, emitiendo mensajes. El diálogo, empleado en cualquier tipo de ficción narrativa, es uno de los mecanismos para 
eliminar o limitar la presencia del narrador y potenciar la presencia del personaje, dando más emoción al relato.

Las claves de corrección utilizadas son las siguientes:

\begin{tabular}{|l|l|}
\hline A & $\begin{array}{l}\text { Incluye las voces de los personajes sostenidamente a lo } \\
\text { largo de la narración. }\end{array}$ \\
\hline B & $\begin{array}{l}\text { Incluye las voces de los personajes en muy pocas } \\
\text { ocasiones. }\end{array}$ \\
\hline C & $\begin{array}{l}\text { No incluye las voces de los personajes o bien obtuvo C } \\
\text { en estructura narrativa. }\end{array}$ \\
\hline
\end{tabular}

Como puede observarse, la categoría C corresponden a las renarraciones que no incluyen las voces de los personajes y también las que, aunque incluyan algún diálogo, no constituyen un cuento. Lógicamente, como se están ponderando elementos que enriquecen la calidad de los cuentos narrados por los niños, esto no puede ser tomado en cuenta cuando sus relatos son fragmentos discontinuos que no constituyen un cuento.

En cuanto al léxico, se intentó identificar la presencia de algunas particularidades propias del lenguaje literario que se alejan del uso habitual, que resultan especialmente expresivas y que dan mayor calidad al texto, expresiones empleadas en relación con la función estética del lenguaje.

En consecuencia se utilizaron las siguientes claves de corrección:

\begin{tabular}{|l|l|}
\hline A & $\begin{array}{l}\text { Utiliza privilegiadamente vocabulario y expresiones } \\
\text { propias del lenguaje literario (metáforas, comparaciones, } \\
\text { juegos de palabras, rimas, etcétera). }\end{array}$ \\
\hline B & $\begin{array}{l}\text { Utiliza pocos elementos pertenecientes al vocabulario y } \\
\text { expresiones propias del lenguaje literario. }\end{array}$ \\
\hline C & $\begin{array}{l}\text { No utiliza lenguaje literario o bien obtuvo C en estructura } \\
\text { narrativa. }\end{array}$ \\
\hline
\end{tabular}

A fin de que quede más clara la aplicación de las claves de corrección, transcribiremos a modo de ejemplo, las renarraciones de tres niños - Luisina, Federico y Abigail - con las categorizaciones obtenidas en cada caso. 


\section{"Choco encuentra a su mamá" (Luisina)}

\section{Este es el del pajarito.}

Un pajarito que estaba buscando madre...

Y encontró a una señora jirafa y le dijo a la señora jirafa:

- Señora Jirafa, usted ¿es mi mamá? Porque tiene color amarillo como yo.

Y la señora Jirafa dijo:

- No.

- ¡Hola Pingüino! ¿Tú eres mi mamá? Porque tienes, porque tienes... algunas cosas para volar como yo.

Y la mamá Pingüino dijo:

- No.

- ¡Hola señora ... ¡Hola señora Morsa! ¿Usted es mi mamá? Porque tiene... tiene colita como yo.

Y la señora le dijo que no. Y entonces no encontró una madre que sea de él. Después vio a una señora oso tomando manzanas. $Y$ entonces, le dijo:

- No llores. ¿Por qué estás llorando?

- Porque no tengo mamá.

- Mejor, así te cuidaré.

- Quiero un gran abrazo de mi madre.

Y la mamá oso le dio un abrazo. Y después lo llevó a su casa donde había otros hijos diferentes. Y entonces, fueron cantando por el bosque. Entonces, la mamá... el pajarito y la mamá oso... Y el pajarito le dijo:

- ¿Me contás un cuento?

Y le contó un cuento. Y entonces, la mamá Oso le puso "algo" como un oso. Y después se acariciaron los dos. Entonces, fueron a la casa de la mamá oso. Después se encontraron con los demás hijos. Eran un hipopótamo, un cocodrilo y un chanchito. Y entonces, después, la mamá oso estaba haciendo una torta y los niños jugaban y vivieron felices para siempre.

\section{"Choco encuentra una mamá" (Federico)}

Choco no tenía una mamá y salió a buscar una. Y le preguntó a la señora jirafa:

- Señora Jirafa, ¿usted es mi mamá?

- No, yo no tengo alas como tú, para volar, ni cachetes gordos... tan gordos.

Le preguntó a la señora jirafa... a la señora pingüino... y le dijo:

- Sí, usted tiene alas como yo.

- $\quad$ No, le dijo.

Le preguntó a la señora morsa:

- Usted puede ser mi mamá. Tiene los cachetes gordos como yo.

No la encontró.

Se encontró con la señora oso... estaba juntando manzanas... Choco entonces se puso a llorar porque no tenía una mamá.

La madre los abrazó a todos los hijos. Un cocodrilo, un chancho y un hipopótamo.

\section{"El estofado del lobo" (Abigail)}

El lobo quiere comer a la gallina.

La estaba persiguiendo pero después, no. Se fue a pensar en otra idea.

Hizo unos platillos para la señora gallina. Acá también y acá también. Acá llevó pasteles. Y ahí fue a ver si estaba.

Acá la señora Gallina abrió la puerta y después los pollitos salieron. Y acá preparó galletitas.

Para los pollitos. 
A continuación se vuelcan las categorías de respuestas obtenidas por cada niño, en función de las claves de corrección:

\begin{tabular}{|l|c|c|c|}
\hline & Estructura Narrativa & Diálogos & Léxico \\
\hline Luisina & $\mathrm{A}$ & $\mathrm{A}$ & $\mathrm{B}$ \\
\hline Federico & $\mathrm{B}$ & $\mathrm{B}$ & $\mathrm{B}$ \\
\hline Abigail & $\mathrm{C}$ & $\mathrm{C}$ & $\mathrm{C}$ \\
\hline
\end{tabular}

En lo que respecta a la estructura narrativa de los tres cuentos, está claro que Luisina incluye todos los episodios nucleares, Federico omite los episodios 4 y 5, mientras que Abigail expone fragmentos de la historia que no llegan a constituir un cuento.

En cuanto a los recursos literarios, Luisina introduce las voces de los personajes de manera permanente, reproduciendo el estilo de Keiko Kasza, que hace avanzar la acción a través de esas voces, mientras que Federico inserta diálogos en pocas ocasiones. En relación con Abigail, la niña ya obtuvo $\mathrm{C}$ en la estructura narrativa, de modo que, al no constituir un cuento, no pueden evaluarse los recursos literarios.

Finalmente, en cuanto al léxico empleado puede observarse que Luisina utiliza algunas expresiones propias de los cuentos ("Un pajarito que estaba buscando madre", uso del tuteo y no voseo, "Y vivieron felices para siempre"), al igual que Federico.

\subsubsection{Análisis comparativo de los resultados}

A continuación se presentan los resultados de las renarraciones de los dos grupos (Con CQC y Sin CQC). En primer término se incluyen los datos vinculados con la reconstrucción de la estructura narrativa y, posteriormente, los correspondientes a la inclusión de recursos literarios.

En la Tabla 6 se presenta una síntesis de los resultados de ambos grupos en relación con la estructura narrativa. 
TABLA 6

RESULTADOS DE AMBOS GRUPOS EN ESTRUCTURA NARRATIVA

\begin{tabular}{|l|lc|lc|}
\hline \multicolumn{1}{|c|}{ ESTRUCTURA NARRATIVA } & \multicolumn{2}{|c|}{ Con CQC } & \multicolumn{2}{c|}{ Sin CQC } \\
\hline $\begin{array}{l}\text { A- Cuento que incluye todos los } \\
\text { episodios. }\end{array}$ & $27 \%$ & 4 & $0 \%$ & 0 \\
\hline $\begin{array}{l}\text { B- Cuento que omite o modifica algún } \\
\text { episodio. }\end{array}$ & $46 \%$ & 7 & $13 \%$ & 2 \\
\hline $\begin{array}{l}\text { C- Fragmentos vinculados con la historia } \\
\text { que no llegan a constituir un cuento. }\end{array}$ & $27 \%$ & 4 & $87 \%$ & 13 \\
\hline
\end{tabular}

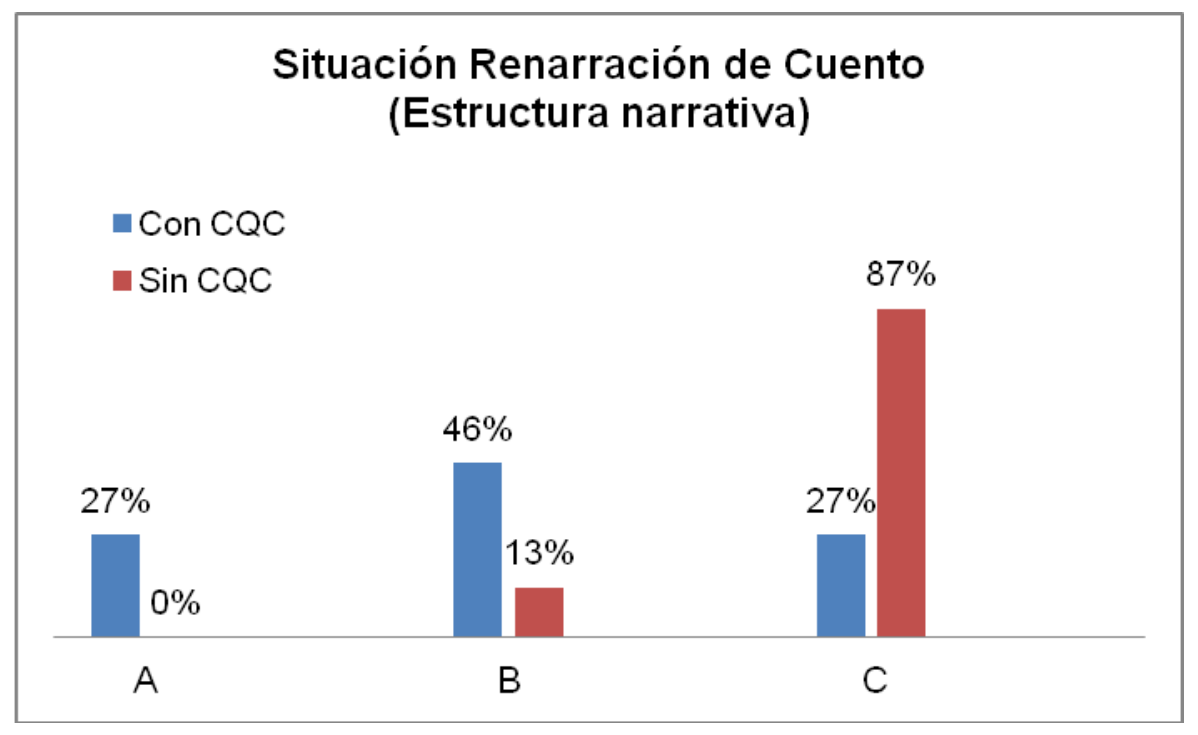

En base a las pautas de corrección establecidas, cuatro niños del primer grupo incluyen al relatar los episodios nucleares (27\%), siete de este grupo omiten y/o modifican más de un episodio en su relato $(46 \%)$ y los cuatro restantes $(27 \%)$ recuperan fragmentos de la historia pero que no llegan a constituir un cuento. Es interesante apreciar que más del $70 \%$ de los niños de este grupo consiguen reconstruir verbalmente un cuento - aunque distorsionen u omitan algún episodio -, situación que prácticamente se invierte en el Grupo 2.

En este segundo grupo de niños -cuyos padres no participaron del Programa de Alfabetizaciónninguno logra incluir todos los episodios nucleares; dos (13\%) omiten o modifican uno de ellos; y trece $(87 \%)$ recuperan fragmentos vinculados con la historia que no llegan a constituir un cuento. 
Es significativo este último porcentaje comparado con el Grupo 1, en el que solamente el 33\% no consigue reconstruir un relato que constituya un cuento.

En la tabla 7 se presenta una síntesis de los resultados de ambos grupos en relación a la inclusión de diálogos en la renarración.

TABLA 7

RESULTADOS DE AMBOS GRUPOS EN INCLUSIÓN DE DIÁLOGOS

\begin{tabular}{|l|ll|lr|}
\hline \multicolumn{1}{|c|}{ INCLUSIÓN DE DIÁLOGOS } & \multicolumn{2}{|c|}{ Con CQC } & Sin CQC \\
\hline $\begin{array}{l}\text { A-Inserta las voces de los personajes } \\
\text { sostenidamente a lo largo de la narración. }\end{array}$ & $27 \%$ & 4 & $0 \%$ & 0 \\
\hline $\begin{array}{l}\text { B-Inserta las voces de los personajes en } \\
\text { muy pocas ocasiones. }\end{array}$ & $20 \%$ & 3 & $7 \%$ & 1 \\
\hline $\begin{array}{l}\text { C- No inserta las voces de los personajes } \\
\text { o bien obtuvo C en estructura narrativa. }\end{array}$ & $53 \%$ & 8 & $93 \%$ & 14 \\
\hline
\end{tabular}

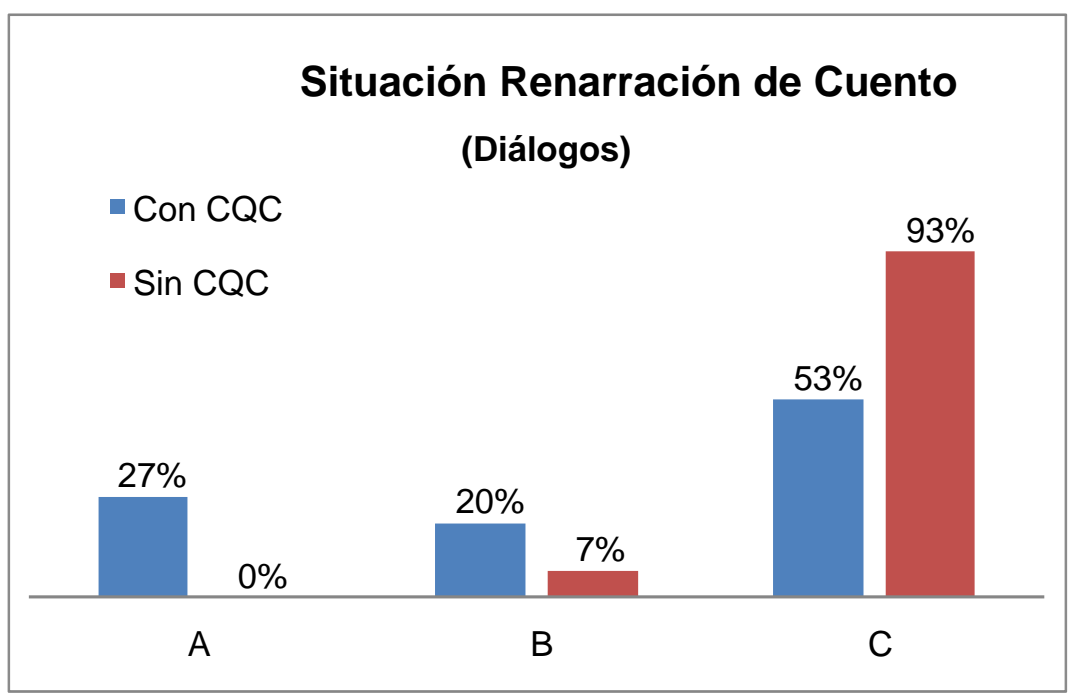


En el Grupo 1, casi la mitad de los niños incluye las voces de los personajes. En el Grupo 2, solo un niño utiliza este recurso y casi la totalidad de la muestra prescinde de él.

Las familias que participaron en el Programa Cuenta Quien Cuenta manifiestan haber leído cuentos a sus hijos con alta frecuencia, lo que hizo posible que los niños se hayan familiarizado con el interjuego entre la voz del narrador y las de los personajes.

En la Tabla 8 se analizan las características del léxico utilizado en las renarraciones.

TABLA 8

RESULTADOS DE AMBOS GRUPOS EN ANÁLISIS DEL LÉXICO UTILIZADO

\begin{tabular}{|c|c|c|}
\hline LÉXICO & Con CQC & Sin CQC \\
\hline $\begin{array}{l}\text { A-Utiliza privilegiadamente vocabulario y } \\
\text { expresiones propias del lenguaje literario } \\
\text { (metáforas, comparaciones, juegos de palabras, } \\
\text { rimas, etcétera). }\end{array}$ & $13 \%$ & $7 \%$ \\
\hline $\begin{array}{l}\text { B-Utiliza pocos elementos pertenecientes al } \\
\text { vocabulario y expresiones propias del lenguaje } \\
\text { literario. }\end{array}$ & $27 \%$ & $0 \%$ \\
\hline $\begin{array}{l}\text { C-No utiliza lenguaje literario. } \\
\text { Obtuvo C en estructura narrativa. }\end{array}$ & $60 \%$ & $93 \%$ \\
\hline
\end{tabular}

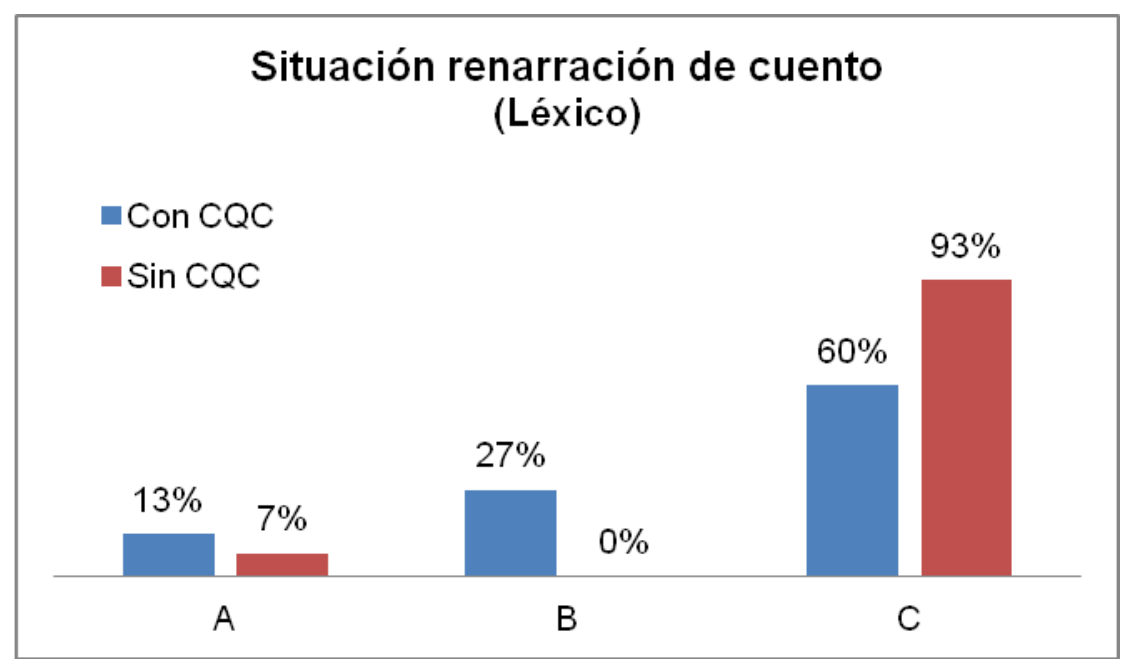


Puede observarse que seis niños, que constituyen el 40\% del Grupo 1 utilizan en mayor o menor medida expresiones propias del lenguaje literario, mientras que los nueve restantes no utilizaron estos recursos en su intento de narración del cuento.

Por su parte, en el Grupo 2 esta última situación se generaliza a catorce niños y solo uno de ellos utiliza un vocabulario característico de los cuentos.

\subsection{Situación 4- Escritura del nombre propio}

Esta situación no se propone conocer los saberes del niño sobre el sistema de escritura, más bien sondear la información con que cuenta este para avanzar en su proceso de aprendizaje del sistema.

En esta situación la entrevistadora solicita al niño que escriba su nombre en la hoja con la finalidad de saber si conoce la escritura convencional del mismo.

\subsubsection{Categorías de análisis}

\begin{tabular}{|l|l|}
\hline A & Escribe correctamente el nombre. \\
\hline B & $\begin{array}{l}\text { Escribe con omisiones, sustituciones o alteración } \\
\text { del orden de las letras. }\end{array}$ \\
\hline C & Escribe de manera no reconocible. \\
\hline NRT & No realiza la tarea. \\
\hline
\end{tabular}

\subsubsection{Análisis comparativo de los resultados}

Los resultados obtenidos pueden visualizarse en la Tabla 10. 
TABLA 10

RESULTADOS DE LA SITUACIÓN “ESCRITURA DEL NOMBRE”

\begin{tabular}{|l|lc|lc|}
\hline \multicolumn{1}{|c|}{ ESCRITURA DEL NOMBRE } & \multicolumn{2}{|c|}{ Con CQC } & \multicolumn{2}{c|}{ Sin CQC } \\
\hline $\begin{array}{l}\text { A- Escribe correctamente el } \\
\text { nombre. }\end{array}$ & $87 \%$ & 13 & $33 \%$ \\
\hline $\begin{array}{l}\text { B- Escribe con omisiones, } \\
\text { sustituciones o alteración del } \\
\text { orden de las letras. }\end{array}$ & $13 \%$ & 2 & $33 \%$ & 5 \\
\hline $\begin{array}{l}\text { C- Escribe de manera no } \\
\text { reconocible. }\end{array}$ & $0 \%$ & 0 & $21 \%$ & 3 \\
\hline \begin{tabular}{l} 
No realiza la tarea. \\
\hline
\end{tabular} & $0 \%$ & 0 & $13 \%$ & 2 \\
\hline
\end{tabular}

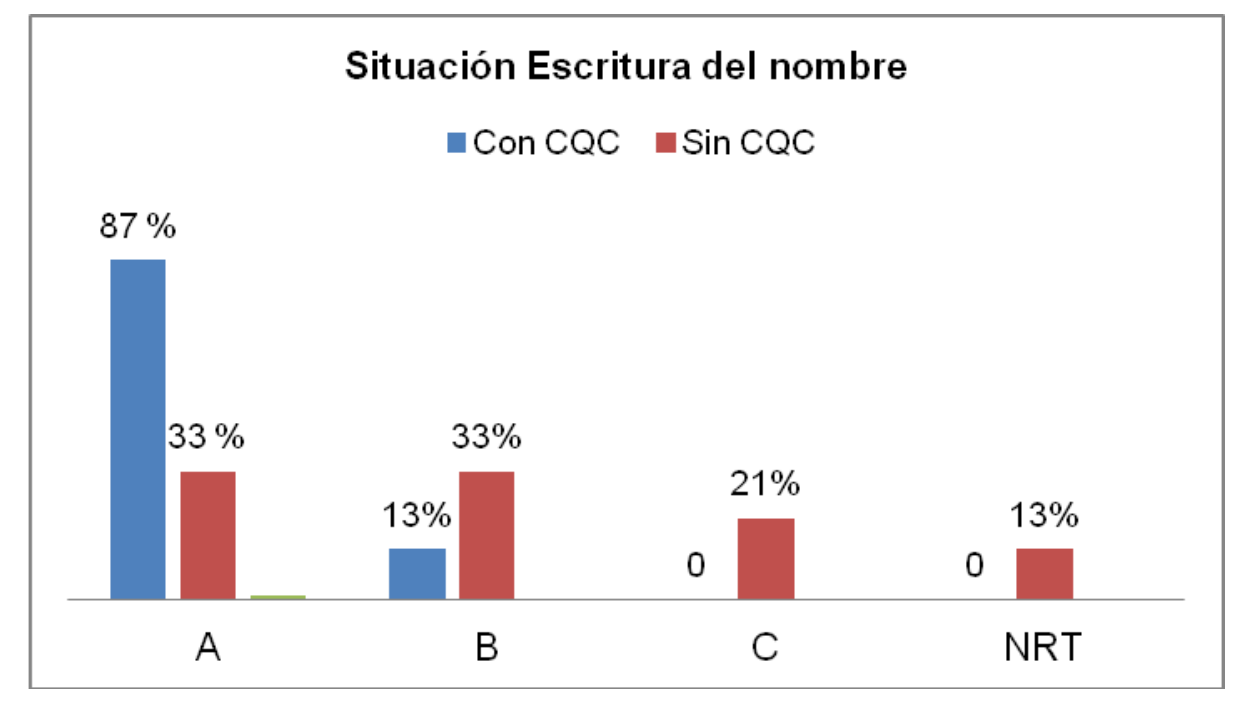

En la evaluación realizada al tercer mes de iniciado el año escolar el $87 \%$ de los niños Con CQC (trece niños) escribía su nombre correctamente y el 13\% restante lo hizo con algunas omisiones.

En el grupo de niños Sin CQC, un 33\% (cinco niños) escribe correctamente su nombre mientras que el $67 \%$ restante se distribuye de la siguiente manera: un $33 \%$ lo escribe con omisiones y distorsiones, el $21 \%$ intenta escribirlo pero lo hace de manera no reconocible, mientras que el $13 \%$ restante (dos niños) no realiza la tarea. 
Estos resultados exponen diferencias significativas entre los dos grupos. El primero evidencia un conocimiento del repertorio de letras que integran su nombre, conocimiento que además implica comprender que las mismas letras, en el mismo orden siempre van a decir lo mismo, lo cual es una información que los niños no saben desde el comienzo y lo aprenden cuando se ponen en contacto con el mundo letrado.

Ese repertorio de letras puede constituir un andamio al que los niños pueden acudir para producir otras escrituras. Por otra parte, el nombre es una pieza de escritura fuertemente impregnada con cuestiones relacionadas con la identidad: es uno de los pocos atributos que no puede graficarse de ninguna manera que no sea la escritura y tiene una fuerte relación con la persona que posee dicho nombre.

\subsection{Situación 5 - Escritura de palabras: conocimiento del sistema de escritura}

La entrevistadora muestra al niño una hoja con imágenes de animales e indaga si los conoce a todos; si el niño dice que no o los denomina mal se le explica que son un canguro, un cerdo, un avestruz, un pingüino, una cebra, una hormiga y un cangrejo. Luego le propone que escriba los nombres de los animales presentados, animándolo a hacerlo, tal como se ha hecho siempre en las investigaciones sobre psicogénesis de la escritura.

Esta situación plantea a los niños la escritura de los nombres de algunos animales cuya escritura no conocen, para evaluar los conocimientos que los niños poseen sobre el sistema alfabético de escritura. Las imágenes fueron seleccionadas para detectar los diferentes niveles de escritura, incluyendo sílabas complejas, tal como se explica posteriormente. Los aspectos ortográficos no fueron contemplados por hallarse los niños indagados al inicio del primer año escolar. 
ESCRIBE LOS NOMBRES DE LOS SIGUIENTES ANIMALES:
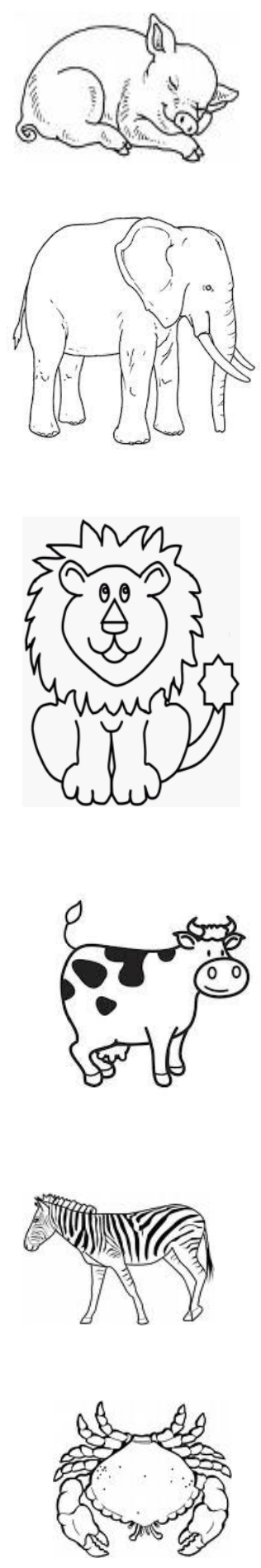


\subsubsection{Categorías de análisis}

Las categorías utilizadas para evaluar el nivel de conceptualización de cada niño respecto del sistema de escritura tomaron en consideración las investigaciones psicogenéticas dirigidas por Emilia Ferreiro (Ferreiro y Teberosky, 1979) que pusieron de manifiesto diferentes aproximaciones de los niños a las características alfabéticas de nuestro sistema: escrituras que no se relacionan con la sonoridad (grafismos primitivos, escrituras sin control de cantidad, escrituras fijas y diferenciadas), escrituras silábicas, silábico-alfabéticas y alfabéticas. Posteriormente, a los niveles originales se agregaron otras escrituras a las que Kaufman (2012:52) denomina "cuasi" alfabéticas. Se trata de escrituras que presentan sustituciones, omisiones, inversiones y agregados, que no son escrituras silábico-alfabéticas como son descriptas en las investigaciones originales de Ferreiro, pero tampoco son estrictamente alfabéticas. Estos problemas aparecen privilegiadamente en las palabras con sílabas complejas (CCV o CVC), tal como se manifiesta en la investigación de Celia Zamudio sobre conciencia fonológica (Zamudio, 2008).

Veamos algunos ejemplos:

$$
\text { STINOSEROTE }
$$

En la palabra RINOCERONTE, el autor omite la letra N en la sílaba "ron". No se toma en cuenta el error de la sílaba anterior porque se trata de una cuestión ortográfica.

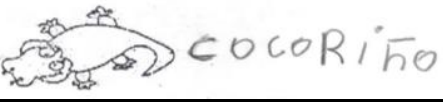

En la sílaba "dri" de la palabra COCODRILO hay una omisión y en la última aparece la sustitución de la letra $L$ por $\tilde{N}$.

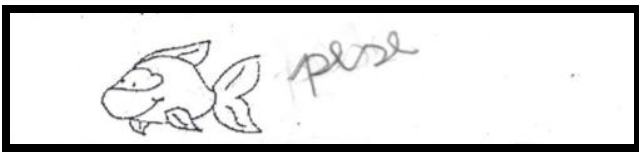

En la palabra PEZ, el niño agrega una letra al final. Como se aclaró anteriormente, no se toman en cuenta las cuestiones ortográficas.

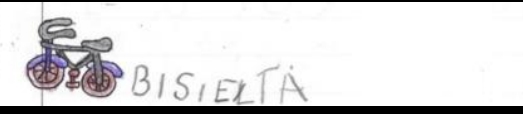

En la sílaba "cle" de la palabra BICICLETA, se omite la letra C y se invierten la $L$ y la $E$. 


\subsubsection{Análisis comparativo de los resultados}

En la Tabla 11, se consignan las escrituras de los dos grupos, agrupadas en las categorías A, B y C: las escrituras A corresponden al nivel alfabético, las B implican diferentes tipos de relación entre la escritura y la sonoridad, mientras que las $C$ corresponden a escrituras que no tienen relación con la emisión oral.

En la Tabla 11 se presenta la distribución de las respuestas de las distintas categorías, en términos absolutos y de porcentaje, correspondientes a los dos grupos.

TABLA 11

RESULTADOS DE LA SITUACIÓN “ESCRITURA DE PALABRAS”

\begin{tabular}{|c|c|c|}
\hline ESCRITURA DE PALABRAS & Con CQC & Sin CQC \\
\hline A- Escrituras alfabéticas. & $33 \%$ & $13 \%$ \\
\hline $\begin{array}{l}\text { B- Escrituras relacionadas con la sonoridad } \\
\text { (cuasi-alfabéticas, silábico-alfabéticas y silábicas). }\end{array}$ & $67 \%$ & $53 \%$ \\
\hline $\begin{array}{l}\text { C- Escrituras que no se relacionan con la } \\
\text { sonoridad. En todos los casos se trata de } \\
\text { escrituras diferenciadas. }\end{array}$ & $0 \%$ & $21 \%$ \\
\hline No realiza la tarea & $0 \%$ & $13 \%$ \\
\hline
\end{tabular}




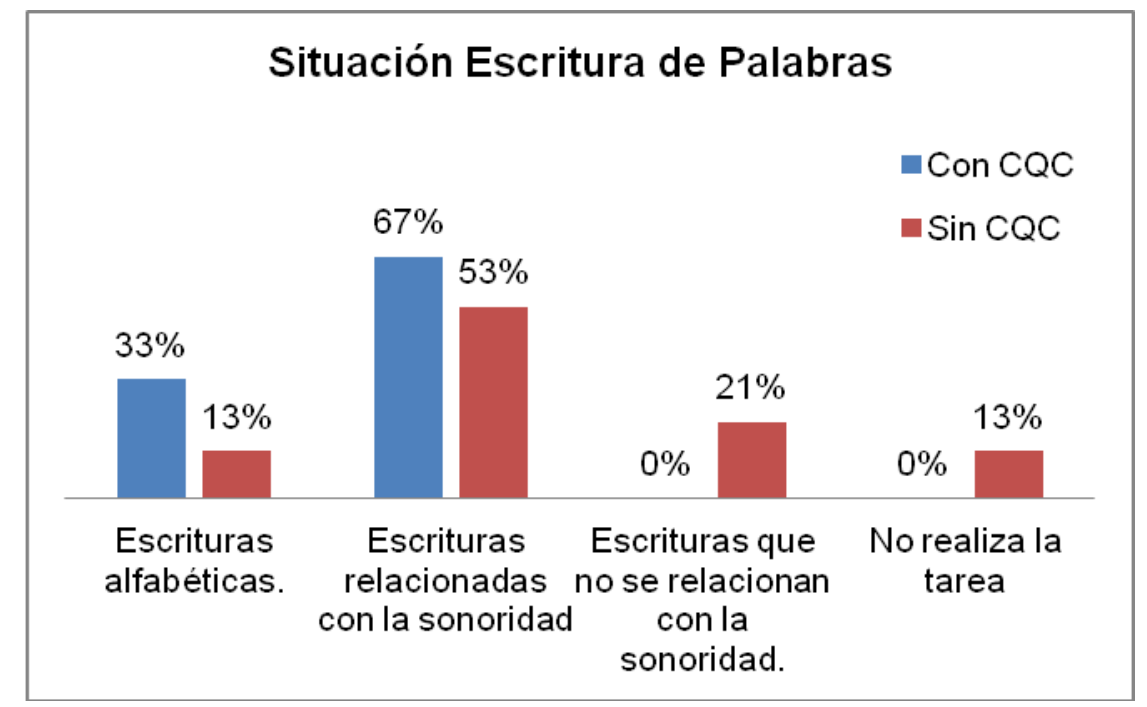

Al igual que en otras situaciones, es dable apreciar diferencias significativas entre los desempeños de ambos grupos.

De manera general se puede decir que el $100 \%$ de los niños del primer grupo relaciona su escritura con los aspectos sonoros del habla mientras que en el segundo grupo lo hace el $67 \%$ de los mismos.

El 33\% de los niños Con CQC tiene escritura alfabética y el 67\% de la misma muestra se distribuye entre escrituras cuasi-alfabéticas, silábico-alfabéticas y silábicas. En el Anexo 4 se incluye la Tabla 11 bis, con el detalle de la distribución de estas escrituras correspondientes a la Categoría B.

En el otro grupo hay una distribución mucho más repartida entre todas las categorías, lo que está mostrando una mayor heterogeneidad entre sus integrantes. El 13\% produce escrituras alfabéticas, el 53\% (8 niños) ya relacionan la escritura con la sonoridad y, a diferencia del Grupo 1 , dos niños no se sintieron en condiciones de realizar la tarea.

Cabe destacar que los niños que ingresan a primer grado relacionando la escritura con la sonoridad tienen muchas mayores posibilidades de acceder a lo que la escuela espera de ellos: que escriban alfabéticamente al finalizar el año. En ese sentido, es probable que los niños del Grupo 2 tengan mayores dificultades que los del primero, ya que deben recorrer un trecho mucho más largo del proceso en un tiempo muy acotado. Los estudios de Ferreiro y Teberosky (1979) evidencian que aunque todos los niños postulan y ponen a prueba sus hipótesis sobre la escritura existe un desfase cronológico importante entre los que pertenecen a sectores socioculturales 
diferentes, en función de mayor o menor posibilidad de contacto con ese objeto de conocimiento. Kaufman (1982:42), entre otros, incorpora los aportes teóricos a experiencias didácticas y sostiene que la ausencia de situaciones alfabetizadoras a edades tempranas no hace más que ampliar la brecha existente entre los niños en cuyos hogares la lectura y la escritura son actividades permanentes y aquellos sectores desfavorecidos que, además de no vivir en un ambiente alfabetizador en lo referente a prácticas y materiales de lectura, ni siquiera cuentan con informantes idóneos en el caso que surgiera alguna inquietud...

Cabe señalar que el Programa CQC está focalizado en la lectura de cuentos y no sugiere a los padres realizar con sus hijos actividades de escritura. Por tanto, si bien los datos obtenidos revelan una correlación positiva entre el nivel de conocimiento del sistema de escritura y la pertenencia a familias que han participado del Programa, sería arriesgado afirmar en este caso que se trate de una correlación causal.

\subsection{Situación 6 - Lectura de palabras: uso de estrategias lectoras}

Esta tarea es muy frecuente en las escuelas. En una columna se presentan imágenes y en otra, los nombres correspondientes ubicados en un orden de aparición diferente de la posición de las ilustraciones. En estos casos, el contexto gráfico permite al alumno saber que esas palabras son los nombres de los objetos y que debe explorar tanto sus características cualitativas (alguna letra conocida), como cuantitativas (extensión de la escritura) para ver cuáles escrituras llega a identificar.

La propuesta incluye un elemento distractor, que consiste en la palabra computadora, que no tiene su correspondiente ilustración. Fue seleccionada en virtud de que comienza y termina con las mismas letras que copa, aunque su extensión es mayor. En cuanto al resto de las palabras, tres de ellas se diferencian en la variedad de letras, tanto iniciales como finales (sombrero, paraguas, $y$ escalera), y otro par (libro y lápiz) está integrado por palabras que comparten inicial y la extensión, pero predomina la diferencia en el resto de las letras. 
1) UNE CON FLECHAS LAS IMÁGENES CON LOS NOMBRES CORRESPONDIENTES.

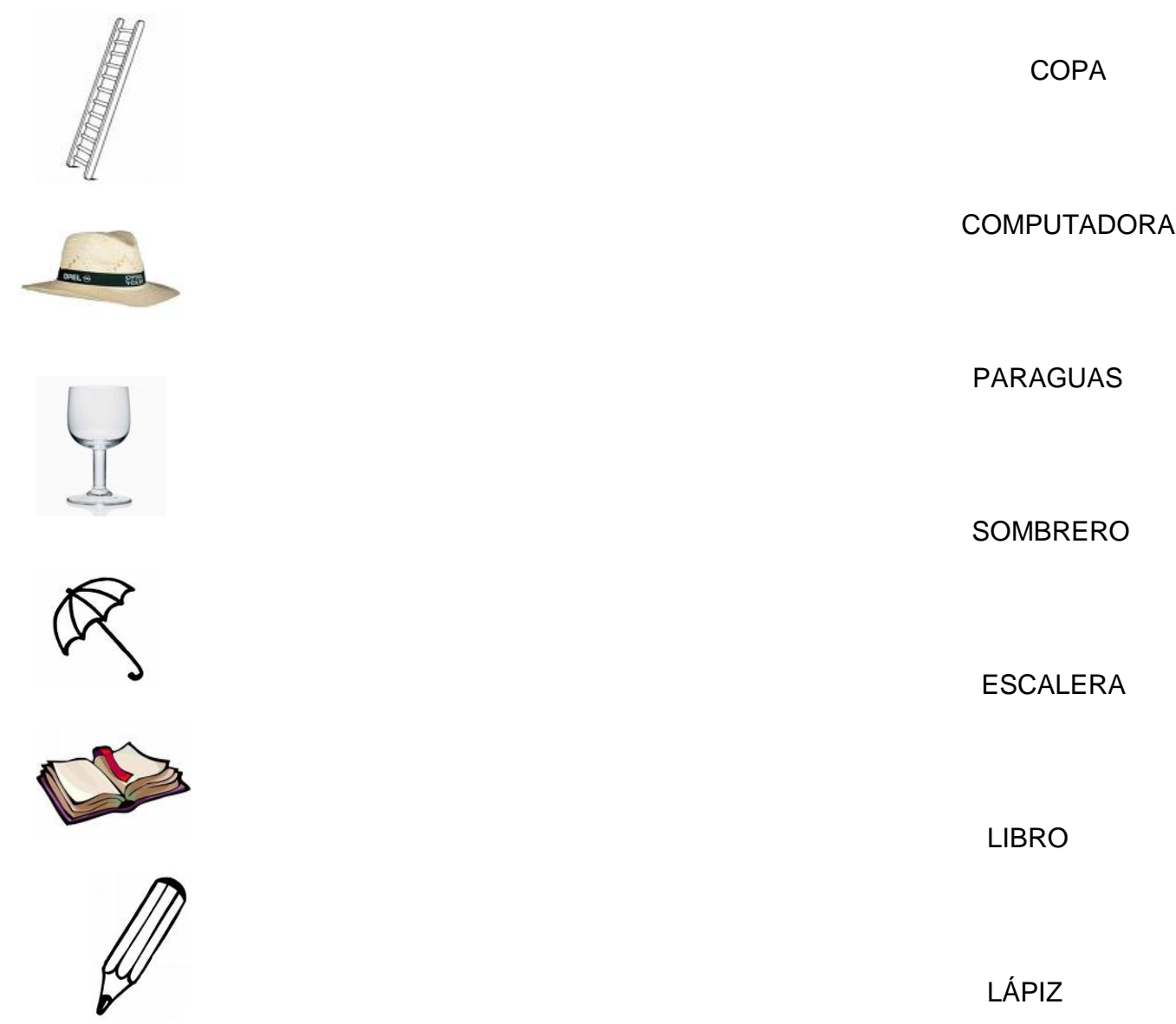

Esta actividad de lectura de palabras pretendía evaluar las estrategias lectoras que ponen en juego pequeños lectores que todavía no leen convencionalmente.

\subsubsection{Categorías de análisis}

\begin{tabular}{|l|l|}
\hline A & $\begin{array}{l}\text { Unen correctamente todos los nombres con sus } \\
\text { imágenes. }\end{array}$ \\
\hline B & $\begin{array}{l}\text { Unen correctamente algunos nombres con sus imágenes } \\
\text { (al menos tres). }\end{array}$ \\
\hline C & $\begin{array}{l}\text { Unen en forma incorrecta la mayoría de los nombres e } \\
\text { imágenes (cuatro o más). }\end{array}$ \\
\hline NRT & No realizan la tarea. \\
\hline
\end{tabular}




\subsubsection{Análisis comparativo de los resultados}

La siguiente tabla presenta los resultados obtenidos por los niños de ambos grupos en esta situación.

TABLA 12

RESULTADOS DE LA SITUACIÓN “LECTURA”

\begin{tabular}{|l|lc|ll|}
\hline \multicolumn{1}{|c|}{ LECTURA } & \multicolumn{1}{c|}{ Con CQC } & \multicolumn{2}{c|}{ Sin CQC } \\
\hline $\begin{array}{l}\text { A- Unen correctamente todos los } \\
\text { nombres con sus imágenes. }\end{array}$ & $80 \%$ & $20 \%$ & 3 \\
\hline $\begin{array}{l}\text { B-Unen correctamente algunos } \\
\text { nombres con sus imágenes (al menos } \\
\text { tres). }\end{array}$ & $20 \%$ & 3 & $27 \%$ & 4 \\
\hline $\begin{array}{l}\text { C-Unen en forma incorrecta la } \\
\text { mayoría de los nombres e imágenes } \\
\text { (cuatro o más). }\end{array}$ & $0 \%$ & 0 & $47 \%$ & 7 \\
\hline $\begin{array}{l}\text { NRT-No realizan la tarea. } \\
\end{array}$ & $0 \%$ & 0 & & 1 \\
\hline
\end{tabular}

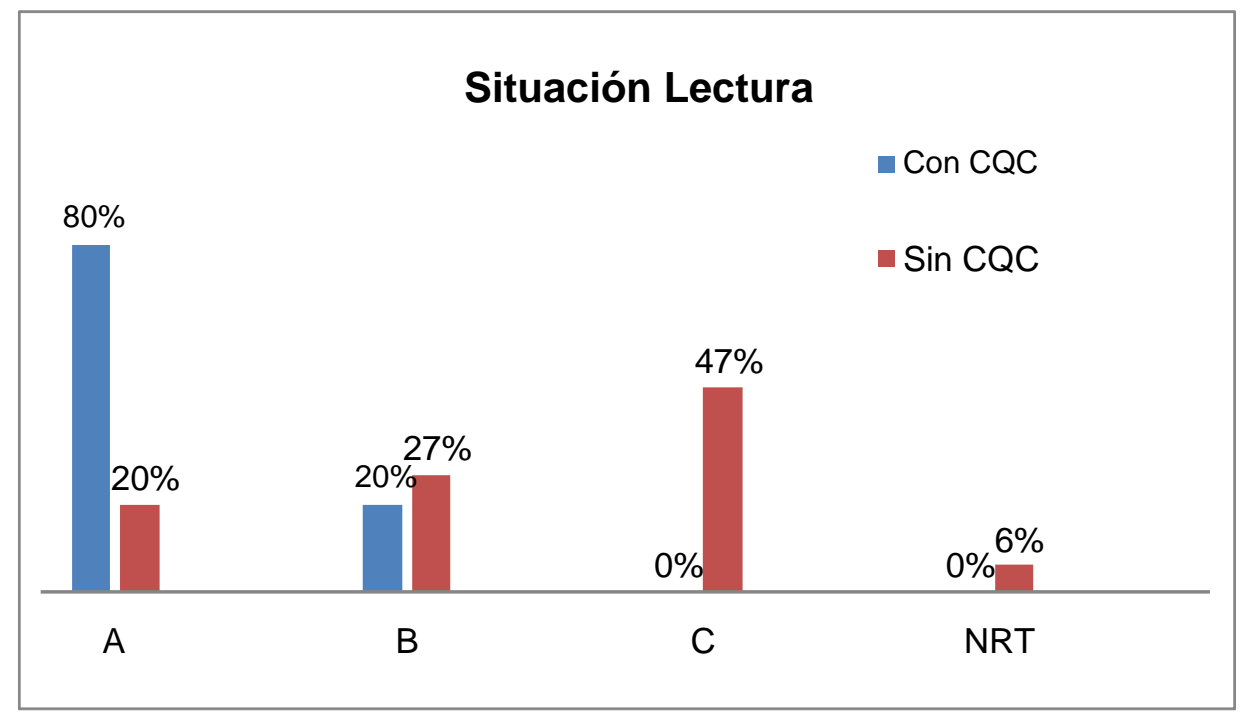

En esta situación también se evidencian diferencias significativas en los desempeños de los niños de ambos grupos. 
El 80\% de los niños que pertenecen al grupo con CQC puso en juego estrategias lectoras que les permitieron identificar todos los nombres de animales propuestos y el $20 \%$ restante logró reconocer algunos. En el otro grupo, el $20 \%$ accede a la identificación correcta de todas las palabras. Del $80 \%$ restante, cabe señalar que el $27 \%$ identifica solo algunas de las palabras, el $47 \%$ equivoca la identificación de la mayoría de los nombres y el $6 \%$ no realiza la tarea.

\subsection{Situación 7 - Breve encuesta a los niños}

La entrevistadora realiza al niño algunas preguntas para saber si en su casa hay libros, si alguien le lee fuera de la escuela e indaga sobre los cuentos que conoce. Se registra quién le lee y qué cuentos conoce. Esta situación pretende indagar la presencia física de materiales impresos en el hogar, así como identificar las oportunidades de participación de los niños en eventos de lectura y quiénes intervinieron en los primeros acercamientos de los mismos a la cultura escrita.

Las respuestas son consignadas en la siguiente planilla:

\begin{tabular}{|l|l|l|l|}
\hline \multicolumn{2}{|l|}{ NOMBRE DEL NIÑO } & \multicolumn{3}{|l|}{} \\
\hline CON CQC & \multicolumn{3}{|l|}{ Sin CQC } \\
\hline QUIÉN LE LEE & $\begin{array}{l}\text { CUÁLES TíTULOS } \\
\text { RECUERDA }\end{array}$ & CUÁNTOS \\
\hline & & \\
& & \\
& & \\
\hline
\end{tabular}

\subsubsection{Análisis comparativo de los lectores con que cuentan los niños}

Esta situación procuraba relevar, a partir de la propia voz de los niños, a quiénes reconoce como la/s persona/s que le ha/n leído y el caudal de cuentos a que ha podido acceder. 
En la tabla 13 se consigna la información vinculada con quienes fueron los actores fundamentales en el acercamiento temprano de los niños del grupo 1(Con CQC) y del grupo 2 (Sin CQC) a la cultura letrada.

TABLA 13

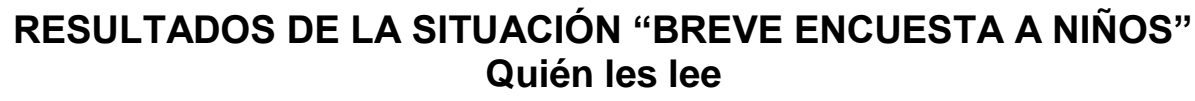

\begin{tabular}{|l|ll|ll|}
\hline \multicolumn{1}{|c|}{$\begin{array}{c}\text { ¿Quién les lee } \\
\text { frecuentemente? }\end{array}$} & Con CQC & Sin CQC & \\
\hline Un familiar & $67 \%$ & 10 & $27 \%$ & 4 \\
\hline La maestra & $27 \%$ & & $53 \%$ & \\
\hline Otros & & 4 & & 0 \\
\hline Nadie & $0 \%$ & 0 & $0 \%$ & 3 \\
\hline
\end{tabular}

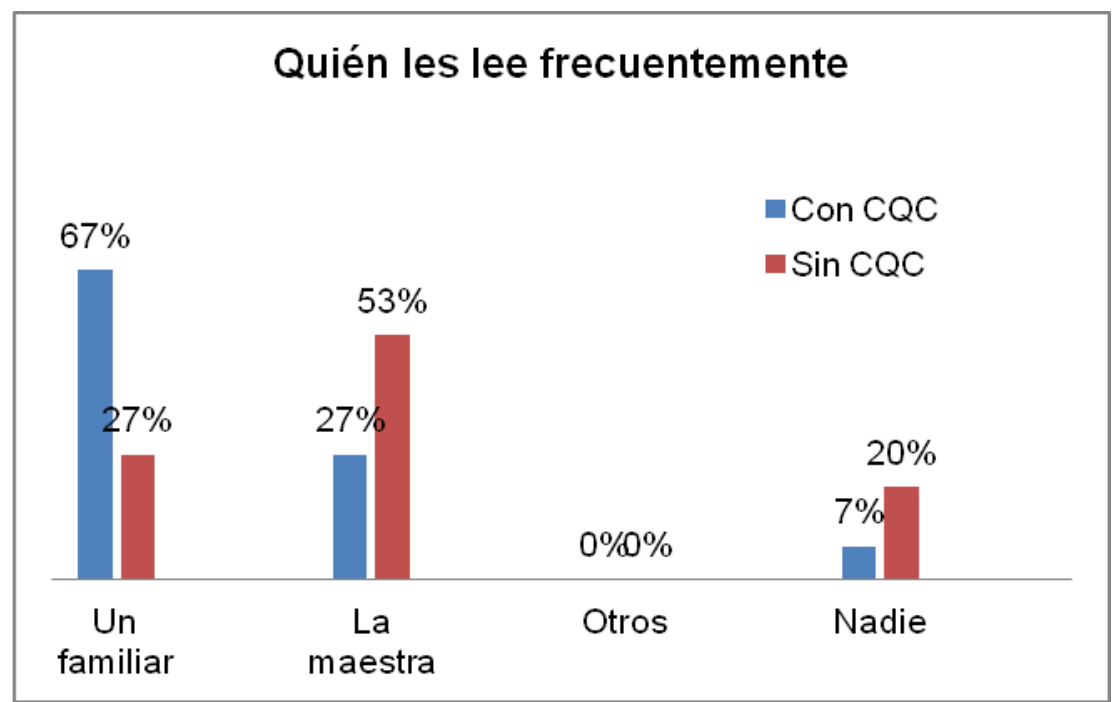

Como puede apreciarse en el Grupo 1, los principales agentes que participaron en la inclusión de los niños en el mundo letrado fueron miembros de sus familias. Por el contrario, esta misión recae de manera privilegiada, para el segundo grupo, en la institución educativa. 


\subsubsection{Análisis comparativo del caudal de cuentos conocidos}

En la Tabla 14 se consigna la cantidad de títulos conocidos por el Grupo 1 (CQC) y el Grupo 2.

TABLA 14

Caudal de libros conocidos

\begin{tabular}{|c|c|c|}
\hline & Con CQC & Sin CQC \\
\hline \multirow[t]{2}{*}{ Más de 10} & $13 \%$ & $0 \%$ \\
\hline & 2 & 0 \\
\hline \multirow[t]{2}{*}{ Entre 5 y 9} & $74 \%$ & $27 \%$ \\
\hline & 11 & 4 \\
\hline \multirow[t]{2}{*}{ Entre 1 y 4} & $13 \%$ & $60 \%$ \\
\hline & 2 & 9 \\
\hline \multirow[t]{2}{*}{ Ninguno } & $0 \%$ & $13 \%$ \\
\hline & 0 & 2 \\
\hline
\end{tabular}

El $74 \%$ de los niños pertenecientes al Grupo 1 conoce entre 5 y 9 cuentos, mientras que el $13 \%$ de los niños del segundo grupo no ha leído ninguno. El grupo mayoritario de niños de este segundo grupo se concentra y da como respuesta que ha leído entre 1 y 4 libros.

Los integrantes del grupo Con CQC mencionan ciento dos títulos y los niños del grupo Sin CQC el caudal asciende a cincuenta y uno.

También en este caso se evidencia una diferencia sustancial entre ambos grupos.

\begin{tabular}{|l|c|c|}
\hline & Con CQC & Sin CQC \\
\hline Promedio de cuentos aludidos por cada niño & 6,8 & 3,4 \\
\hline
\end{tabular}




\subsubsection{Análisis comparativo del conocimiento de los títulos de los cuentos}

En la Tabla 15 se consigna el conocimiento literal de los títulos de cuentos por el Grupo 1 (CQC) y el Grupo 2.

TABLA 15

Conocimiento literal de los títulos de cuentos

\begin{tabular}{|c|c|c|}
\hline Conocimiento de títulos de cuentos & Con CQC & Sin CQC \\
\hline Títulos recordados literalmente & $73 \%$ & $33 \%$ \\
\hline Títulos sustituidos por otros posibles & $20 \%$ & $47 \%$ \\
\hline Títulos que no guardan relación con la historia & $7 \%$ & $7 \%$ \\
\hline No recuerda ningún título & $0 \%$ & $13 \%$ \\
\hline
\end{tabular}

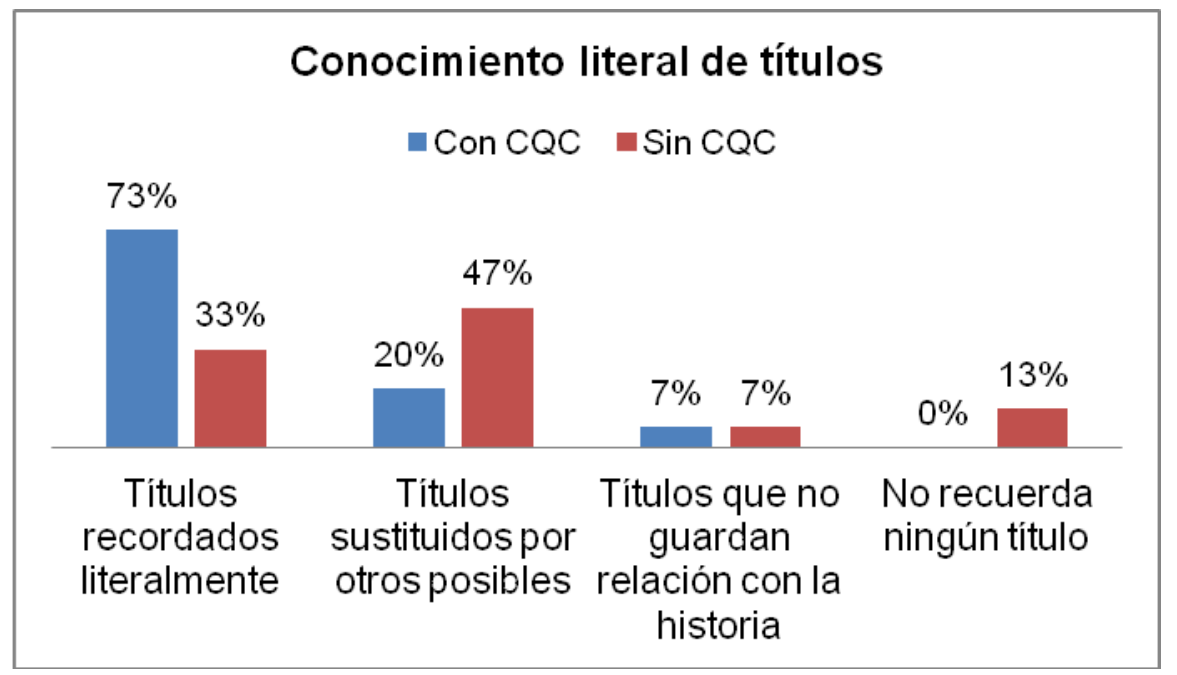

El 73\% de los niños del Grupo 1 han podido aludir literalmente a los títulos leídos. Esto da cuenta del conocimiento que poseen de la cultura escrita. Se contrapone a este dato un porcentaje menor de niños del Grupo 2: solo el 33\% logra hacerlo. El porcentaje mayoritario del segundo grupo se concentra en la categoría de análisis que evidencia la sustitución del título literal del cuento por otros posibles. En ambos grupos son muy pocos los niños que no recuerdan ningún título o que mencionan a los personajes de manera indefinida, como por ejemplo, "uno de bichos". 


\title{
Conclusiones
}

En este apartado se realiza una síntesis de los resultados obtenidos -confrontados con las tres preguntas orientadoras del presente trabajo- y se comparten algunas reflexiones finales.

\section{Síntesis de los resultados obtenidos}

La primera pregunta se vinculaba con las eventuales modificaciones que pudieran haberse generado en los adultos participantes del Programa de alfabetización:

\begin{abstract}
¿Qué modificaciones en las actitudes y prácticas lectoras de los adultos pueden identificarse después de participar en el Programa de Alfabetización Cuenta Quien Cuenta?
\end{abstract}

Las respuestas obtenidas en la Encuesta a adultos participantes del programa permiten relevar que su participación ha incidido positivamente en la generación de nuevos escenarios de lectura en el hogar. Por otra parte, todos manifestaron que, a partir de dicha participación, advirtieron cambios significativos en sus actitudes y prácticas relacionadas con la lectura: una revalorización de la lectura como una práctica cultural importante a ser desarrollada en los hogares; un aumento considerable en la frecuencia con que leen a sus hijos; un incremento en la disponibilidad de materiales de lectura en el hogar; una diversificación de las actividades que realizan con sus hijos para apoyar los aprendizajes y una disminución de las restricciones que manifestaban tener para leerles.

Haber participado en el Programa permitió a los adultos vivenciar la lectura como una experiencia que estrecha los vínculos familiares y tener la oportunidad de reflexionar sobre la vida cotidiana a través de los cuentos leídos.

En este sentido resultó fundamental el espacio social donde tenía lugar el despliegue de las prácticas. Un espacio destinado casi en exclusividad a los adultos para aprender entre adultos. Asimismo, manifestaron que la presencia de materiales que no tenían en sus hogares -libros, papelógrafos y materiales impresos- fue de gran importancia; la convivencia e interacción con 
otros lectores favoreció la construcción de significados y la circulación de saberes entre ellos. Es muy probable que, para algunos, la revinculación con prácticas de lectura y escritura abandonadas hacía tiempo haya sido potenciada por la motivación de apoyar a sus hijos en los aprendizajes necesarios para convertirse en usuarios idóneos de la cultura escrita.

Como este instrumento releva manifestaciones subjetivas de los participantes consideramos que era importante indagar los efectos que los cambios aludidos pudieran haber provocado en sus hijos.

Por esta razón, las dos últimas preguntas se refieren a la incidencia que la lectura frecuente de cuentos, por parte de los adultos participantes del programa, pudiera haber ejercido sobre ciertas actitudes, conocimientos y estrategias de los niños.

La segunda pregunta era la siguiente:

¿De qué manera incide la lectura frecuente en los hogares en las características que adopta el contacto de los niños con los libros?

La situación experimental de exploración y contacto con libros permitió advertir una diferencia cualitativa y cuantitativa interesante entre el grupo experimental y el grupo control: los del primer grupo manifestaron una mayor disposición a contactarse con los libros, asumiendo una postura como lectores y manifestando mayor interés por vincularse con estos objetos culturales.

En dicha situación se analizó el tiempo de contacto de los niños con los libros, la modalidad de ese contacto y la socialización de la lectura.

En las tres variables, el grupo experimental evidenció un mejor desempeño que el grupo cuyos padres no habían participado del programa.

En cuanto al tiempo de contacto, casi la totalidad del grupo Con CQC se vinculó con los libros todo el tiempo, mientras que el grupo Sin CQC la mitad de los integrantes se conectaba por lapsos breves o bien permanecía indiferente.

En relación con el segundo indicador -la modalidad con que se relacionan con los libros- todos los niños Con CQC tomaban adecuadamente los libros y los hojeaban mientras que la mitad del otro grupo cambiaba de libro permanentemente, retiraba con brusquedad los libros de la mesa o se los quitaba a algún compañero que estaba leyendo. 
Con referencia a la socialización de la lectura también se manifestaron diferencias entre los dos grupos. Doce de los quince niños Con CQC compartían el contenido del texto que estaban leyendo e intercambian opiniones. En el grupo Sin CQC, la mitad que se había conectado con los libros lo hizo de manera solitaria.

Jean Hèbrard, frente a la pregunta: ¿puede la escuela enseñar el placer de la lectura?, responde que la escuela puede inventar el placer de hablar juntos del mismo libro. Porque eso es lo que la escuela crea, como todas las instituciones de la cultura: esa capacidad de descubrir cosas que entendemos de la misma manera. La escuela puede crear una comunidad de interpretación. Lo importante no es dar libros a los niños, sino que aprendan que no hay lecturas fuera de las comunidades porque son ellas las que nos permiten ser lectores. $Y$ finaliza remarcando que el placer está dado por la palabra que se agrega al libro. (Hèbrard J. 2000).

Los resultados correspondientes al ítem de socialización de las lecturas, indican que el Programa "Cuenta Quien Cuenta" podría estar, de alguna manera, contribuyendo a crear una comunidad de interpretación antes de que los niños ingresen a la escuela.

La encuesta que se tomó a los niños fue adecuada para indagar un aspecto cuantitativo del contacto con los libros: el caudal de cuentos conocidos. Asimismo, permitió considerar otros aspectos cualitativos: a quiénes reconocen los niños como personas que les han leído cuentos y si conocen literalmente los títulos de los mismos. Este último dato tiene una estrecha vinculación con el conocimiento de la cultura escrita.

Si se analiza la parte cuantitativa de la pregunta, se encuentran diferencias significativas. En el grupo Con CQC, casi el 90\% manifiesta conocer entre cinco y diez cuentos, mientras que en el grupo Sin CQC este dato se da en un $27 \%$ de los niños, el $60 \%$ dice conocer entre uno y cuatro y el $13 \%$ expresa no conocer ninguno.

En este sentido, cabe señalar que el Programa procuró distribuir libros de literatura infantil y hacerlos accesibles a los participantes. Esta es condición necesaria para permitir, a través de la lectura de cuentos, la construcción de un capital cultural en tanto y en cuanto el lector se apropia de la riqueza formal del mundo literario, incluyendo el transitar por otros mundos posibles.

Retomando los aspectos cualitativos, indagamos a quiénes reconocían los niños como la o las personas que les habían leído. En el grupo Con CQC el 67\% mencionaba a los miembros de sus familias como los principales agentes lectores, mientras que en el grupo Sin CQC, esto sucedía en 
la cuarta parte de la población. La mitad señalaba a su maestra como la única persona que les leía y la cuarta parte restante manifestaba que nadie había cumplido ese rol.

Otro aspecto cualititativo interesante es el conocimiento de los títulos de los cuentos. Mientras que en el grupo Con CQC las tres cuartas partes de los niños pudieron mencionar literalmente los títulos, en el otro grupo solo lo logró un 33\% de los integrantes. Esto implica, lógicamente, una diferencia importante en lo que hace a la inclusión en el mundo letrado.

Se comentará a continuación la relación entre la última pregunta formulada y los datos obtenidos. Este interrogante era el siguiente:

¿De qué manera incide la lectura frecuente en los hogares en el conocimiento del sistema de escritura y del lenguaje escrito así como en el desarrollo de estrategias lectoras que el niño pondrá en juego al ingresar al primer año escolar?

Los resultados encontrados en las situaciones experimentales en las que se indagó el conocimiento del lenguaje escrito, del sistema de escritura y de las estrategias lectoras arrojaron información que permiten constatar diferencias interesantes entre los conocimientos de los niños cuyos padres habían participado del Programa de Alfabetización Cuenta Quien Cuenta al ingresar a primer año escolar y de aquellos cuyos padres no lo habían hecho.

En primer término, con respecto del conocimiento del lenguaje escrito evaluado en la situación de renarración de un cuento, se pusieron en evidencia mejores niveles en los niños del Grupo 1 que en los del Grupo 2, tanto en la reconstrucción de la estructura narrativa del cuento como en el uso de algunos recursos literarios: diálogos y léxico.

Como se comentara en el marco teórico, trabajos anteriores han demostrado que la práctica de lectura frecuente de cuentos en el hogar impacta positivamente en el aprendizaje de la lectura y de la escritura. Sin embargo, esos estudios no identifican precisamente en qué aspectos del lenguaje escrito los niños están mejor posicionados.

Esta tesis confirma en términos generales lo enunciado por estudios anteriores pero, además, analiza el conocimiento específico de tres aspectos del lenguaje escrito: la reconstrucción de la estructura narrativa de los cuentos y la inclusión de dos de los recursos propios de este género: el uso de un léxico literario, diferente del lenguaje oral y, desde la perspectiva discursiva, dar la voz a los personajes para enriquecer el relato. 
En base a las pautas de corrección establecidas, es interesante apreciar que más del $70 \%$ de los niños del Grupo 1 consigue reconstruir la estructura narrativa del cuento aunque distorsionen $u$ omitan algún episodio, situación que prácticamente se invierte en el grupo control. Con referencia al léxico empleado, el $40 \%$ del Grupo 1 utiliza expresiones propias del lenguaje literario y en el Grupo 2 esto ocurre solo con un niño. En cuanto a la inclusión de las voces de los personajes, casi la mitad de los niños cuyos padres participaron de CQC introducen diálogos en sus renarraciones, mientras que en el otro grupo solo un niño utiliza este recurso y el resto prescinde de él.

En segundo lugar también aparecieron diferencias importantes en cuanto al conocimiento del sistema de escritura.

La tarea de escritura de palabras permitió apreciar diferencias entre los desempeños de ambos grupos. En el grupo Con CQC, la totalidad de los niños relaciona su escritura con los aspectos sonoros del habla, mientras que en el grupo Sin CQC alcanza esta escritura el 66\% (diez niños). De los cinco niños restantes, tres escriben sin relación con la sonoridad y los otros dos no realizan la tarea.

Considerando que el descubrimiento de las relaciones entre nuestro sistema de escritura y los aspectos sonoros del habla es fundamental para garantizar el éxito de la alfabetización temprana, puede arriesgarse que todos los niños del grupo Con CQC tiene mejores expectativas de logro para el primer año escolar que varios de los niños cuyos padres no participaron del programa.

En tercer lugar también se puede concluir que la gran mayoría de los niños cuyos padres participaron del Programa, evidencian al inicio del año escolar estar en condiciones de utilizar ciertas estrategias lectoras, consistentes en tomar en cuenta algunas características de las escrituras, tales como ciertas letras conocidas o cantidad de letras, para ratificar o rechazar sus anticipaciones. En función de estos datos, es altamente probable que estos niños culminen primer año escolar leyendo palabras o textos muy breves con prescindencia de las imágenes. (Kaufman y otros, 2010; pp.241). 


\section{Reflexiones finales}

A partir de este trabajo se ha podido comprobar que el Programa Cuenta Quien Cuenta, a pesar de su corta duración, ha tenido efectos sobre los niños cuyos adultos de referencia participan del mismo, efectos que pueden ser observados incluso bastante tiempo después de haber sido desarrollado. Muchos participantes comentaron que, pasados tres años, todavía conservan y utilizan la colección de libros elaborados en los talleres y otros que fueron recibiendo.

Tal como fue señalado en la Justificación, esta tesis intenta aportar algunos insumos que tal vez puedan contribuir a la evaluación más sistemática de los efectos de los programas de alfabetización familiar en los conocimientos y actitudes de los niños.

Es probable que, en la medida en que se aporte a la evaluación de este tipo de programas, se esté aportando al aumento de la legitimidad y validación social de los mismos y, por lo tanto, a la toma de conciencia de los actores públicos y privados acerca de la importancia de la inclusión de las familias de contextos vulnerables en los procesos de mejoramiento de los niveles de aprendizaje de la lectura y la escritura como estrategia de democratización de la cultura.

Esta tesis intenta proporcionar algunos datos acerca de qué tipos de conocimientos logran construir los niños de sectores populares cuando sus adultos de referencia les leen cuentos con cierta frecuencia.

El cambio más importante que genera el Programa es la revalorización de la lectura que hacen los adultos participantes, desencadenante fundamental de nuevas actitudes y comportamientos frente a la misma y facilitadora de la relación del niño con el lenguaje escrito.

Asimismo, cabe señalar, que en el análisis de los datos del grupo cuyos padres no participaron del Programa CQC, se destaca un niño que obtiene buenos resultados en casi la totalidad de las situaciones experimentales aplicadas.

Las coordinadoras del Programa conocemos a esa familia y sabemos que, a pesar de contar con muy pocos recursos económicos, los padres se ocupan mucho de la escolaridad de sus hijos y comparten con ellos sus tareas y aprendizajes. Esta situación refuerza lo que muchos estudios ya han mencionado en cuanto a que las diferentes condiciones de los hogares establecen, desde el comienzo de la escolaridad, importantes desigualdades en lo que se refiere al aprendizaje del 
lenguaje escrito. El caso de este niño está marcando una sensible ventaja que lo equipara más con los hijos de los participantes del Programa que con los de su grupo.

En este sentido consideramos muy importante diseñar, implementar y evaluar programas como Cuenta Quien Cuenta, que estarían posibilitando oportunidades para todos los niños y no los dejarían librados a la suerte de tener adultos que puedan vincularlos con la cultura escrita desde edades tempranas.

También creemos en la conveniencia de que la problemática sobre la alfabetización se asuma desde un abordaje sistémico, donde el centro de todo esfuerzo continúe siendo el niño pero a través del potenciamiento del trabajo en conjunto de sus dos instituciones de referencia: la escuela y la familia.

Para concluir, si queremos desarrollar políticas públicas de promoción y desarrollo de la lectura, concebidas como herramientas de democratización de la cultura, consideramos de fundamental importancia enfatizar, en los sectores populares, el rol primordial de la familia en la alfabetización de sus hijos.

Es posible que el Programa Cuenta Quien Cuenta haya funcionado en esta dirección. 


\section{Referencias bibliográficas}

Aguerrondo, I. (1993). "Escuela, Fracaso y Pobreza: cómo salir del círculo vicioso". Washington, D.C.: OEA.

Alliende, F. (1984). "Los padres y el comportamiento lector de sus hijos" Fundación Germán Sánchez Ruipérez. Año 3- № 9.

Alvarado, M. y Vernon, S. (2004). "Leer y escribir con otros y para otros en los primeros años de escolaridad”, en Pelicer y Vernon (comps), Aprender y enseñar la lengua escrita en el aula, México: SM editores.

Álvarez, D. (2006). "Seis ensayos para una bibliotecología de la lectura". Medellín, Colombia. Trabajo presentado para optar a la categoría de Profesos Asociado. Escuela Interamericana de Bibliotecología Universidad de Antioquia.

(2010). Notas preliminares sobre la idea de comportamiento lector. Medellín, Colombia.

Bahloul, J. (2002). "Lectura precarias" Estudio sociológico sobre los pocos lectores. Fondo de Cultura Económica. México.

Beuchat, C. (1990). "Familia y Literatura: un encuentro significativo" revista Colibrí Año 3- № 7. Fundación Germán Sánchez Ruipérez.

Bourdieu, P. (1999). “La Miseria del Mundo”. Editorial Fondo de Cultura.

Bourdieu, P. (1986). "La producción y la reproducción de la lengua legítima", en: ¿Qué significa hablar? Economía de los intercambios lingüísticos, Akal., Madrid.

Bruner, J. (1991). “The narrative construction of reality”. Critical inquiry. Págs 1-21.

Brunner, J (2010). "Lenguaje del hogar, capital cultural y escuela". Pensamiento Educativo. Revista de Investigación Educacional Latinoamericana, Volumen 46. Número1.

Caamaño, C. (2003). “¿Evaluar o no evaluar el lenguaje en la escuela?” Revista de la Educación del Pueblo, № 89. Ed. Aula Montevideo.

CEPAL/UNESCO, (1992). "Educación y conocimiento: eje de la transformación productiva con equidad”. Santiago de Chile. CEPAL-UNESCO.

Certeau de, M. (1999). “La cultura en plural” Ed. Nueva Visión. Bs. As.

Certeau, de M. (2007). "La invensión de los cotidiano. Artes de hacer". Universidad Iberoamericana Biblioteca Francisco Xavier Clavigero. México

Cohen, E. y Franco, R. (1988). "Evaluación de proyectos sociales”. Siglo XXI. Buenos Aires. 
Charlot, B. (2008). "La relación con el saber, formación de maestros y profesores, educación y globalización. Cuestiones para la educación de hoy”. Ed. Trilce. Montevideo.

Charlot, B. (2006). "La relación con el saber. Elementos para una teoría”. Libros del Zorzal. Bs. As.

Chartier, A.M. (2004). "Enseñar a leer y escribir. Una aproximación histórica” Colección Espacios para la lectura. Fondo de Cultura Económica. México.

Chartier, A. M. y Hébrarrd, J. (1994). “Discursos sobre la lectura” (1880 - 1980) Ed. Gedisa. España.

Chommsky, N. (1979). “Reflexiones sobre el lenguaje”. Ed. Ariel. Barcelona.

Cucuzza, H.R. (1998). "Oír o leer: el poder y las escenas de lectura", en Revista Veritas, № 43, Diciembre de 1998, Porto Alegre.

Dabas, E. y D. Najmanivich (comp) (1995). Redes. "El lenguaje de los vínculos”. Ed. Paidós. Buenos Aires.

De Bruin-Parecki, A. y Krol-Sinclair, B. (2003). "Family Literacy: From Theory to Practice". Newark: IRA.

De Luna, M. (2009). "El hogar como contexto sociocultural de prácticas de lectoescritura de inmigrantes mexicanos en Canadá”. University College. Ontario. Canadá.

De Temple, J.M. (2001). "Parents and children reading books together". En D.K. Dickinson y P. O. Tabors (eds.) Beginning Literacy with language: Young Children learning al Home and School. Baltimore: Brookes.

Díaz, J.; Martínez, I.; López, K. (2006). "Componentes cognitivos de los padres en relación con las habilidades lectoras de sus hijos".

http://www.lecturayvida.fahce.unlp.edu.ar/numeros/a28n1/28 01 Diaz.pdf

Dickinson, D. (2003). "La alfabetización a través del lenguaje en la construcción de aulas preescolares". Tercer Encuentro internacional de educación inicial. Monterrey, México.

Dowley McNamee, G. (1993). "Aprender a leer y a escribir en un marco urbano: estudio longitudinal del cambio en una comunidad". Capítulo 12 del libro compilado por Luis C. Moll: "Vygotsky y la educación. Connotaciones y aplicaciones de la psicología sociohistórica en la educación” Ed. Aique.

Dubois, M. E. (1987). "Saber leer y ser lector". Conferencia presentada en la Jornada de Reflexión sobre Lectura y Escritura en Barranquilla, Colombia.

Echevarría K. (2007). "La lectura empieza por casa: trabajar con las familias la promoción de la lectura". Lectura y Vida: Revista latinoamericana de lectura. № 4, págs. 66 - 68.

Ferreiro, E. y Teberosky, A. (1979)"Los sistemas de escritura en el desarrollo del niño". Siglo XXI. México.

Ferreiro, E. (coord.). (1989). "Los hijos del Analfabetismo" Propuestas para la alfabetización escolar en América Latina. Siglo XXI Editores. México.

Ferreiro, E. (1997). “Alfabetización Teoría y Práctica” Siglo XXI Editores. México. 
Ferreiro, E. (1999). "Cultura escrita y educación" Conversaciones con Emilia Ferreiro. Fondo de Cultura Económica. México.

Ferreiro, E. (2002). "Relaciones de (in) dependencia entre oralidad y escritura" Ed. Gedisa. Barcelona.

Ferreiro, E. (2007). "Alfabetización de niños y adultos" Centro de Cooperación Regional para la Educación de Adultos en América latina y el Caribe. Paideia latinoamericana. México.

Ferreiro, E. (2008). "Pasado y presente de los verbos leer y escribir". 2da. Ed. Fondo de Cultura Económica. Bs. As. (pág. 25, 26, 27).

Freire, Paulo. (1984). "La importancia de leer". Siglo XXI Editores. México.

Feuerstein, A. (2000). "School Characteristics and Parent Involvement: Influences on participation in Children's Schools". The Journal of Educational Research. Vol.94 (1), pp.29-41.

Florez, R.; Restrepo, M.; Schwanenflugel, P. (2009). "Promoción del alfabetismo inicial y prevención de las dificultades en la lectura: una experiencia pedagógica en el aula preescolar". Avances en Psicología latinoamericana.

Flouri y Buchanan (2004). "Early father's and mother's involvement and child's later educational outcomes". British Journal of Educational Psychology. Vol. 74, pp. 141-153.

Goldenburg, C. (2002). "Making schools work for low-income families in the 21 st. century". En Neuman, S. y Dickinson, D. (editors): Handbook of early Literacy Research. New York: The Guilfort Press, pp. 211-231.

Gomes, A. y Masagão, V. (2004). "Cultura escrita no Brasil: modos e condições de inserção".

Goodman, K. (1986). “El lenguaje integral” Ed. Aique. Bs. As.

Guillaume, G. (1964). “Langage et science du langage”. París / Quebec: Presses de l'Université Laval.

Gumperz, J. (2005). "Estudios sobre contexto II" Universidad de Buenos Aires. Facultad de Filosofía y Letras.

Heath (1983). Citado en De Bruin-Parecki, A. y Krol-Sinclair, B. (2003) "Family Literacy: From Theory to Practice". Newark: IRA.

Hebrard, J. (2000). Conferencia "El aprendizaje de la lectura en la escuela: discusiones y nuevas perspectivas". Biblioteca Nacional. Buenos Aires.

Kalman, J. (2003). "El acceso a la cultura escrita: la participación social y la apropiación de conocimientos en eventos cotidianos de lectura y escritura". Revista Mexicana de Investigación Educativa, enero - abril, Vol. VIII, número 17 Consejo Mexicano de Investigación Educativa. México, pp 37 a 66.

Kasza, K. (2004). “Choco encuentra una mamá”. Ed. Norma. Colombia. 
Kasza, K. (2007). "El estofado del lobo". Ed. Norma. Colombia.

Kaufman, A. M. (1998). "Alfabetización temprana...¿y después?" Acerca de la continuidad de la enseñanza de la lectura y la escritura. Aula XXI. Santillana. Buenos Aires.

Kaufman, A. M. y Rodríguez, M. E. (2001). “¿Por qué cuentos en la escuela?” Lectura y Vida, 22 (1), 24-39.

Kaufman, A.M. (2009). “Leer y escribir: el día a día en las aulas”. Ed. Aique Buenos. Aires.

Kaufman, A.M. (2012). "El desafío de evaluar...procesos de lectura y escritura”. Una propuesta para primer ciclo de la escuela primaria. Ed. Aique. Buenos Aires.

Lahire B. (1995). "Transmisiones Familia escritura y el rendimiento académico de los estudiantes" CE2, GRS, p:338. Las investigaciones realizadas a petición de: PPSH Rhône-Alpes / Ministerio de Educación.

Lahire, B.(1997). "Sucesso escolar nos meios populares. As razoes do improvavel. Editora Ática. Sao Paulo. Brasil.

Lahire, B. (2004). "El hombre plural. Los resortes de la acción”. Ediciones Bellaterra. Barcelona. España.

Lahire, B. (2004). "Sociología de la lectura" Ed. Gedisa. Barcelona.

Lahire, B. (2005). "El trabajo sociológico de Pierre Bourdieu, dudas y críticas”. Siglo XXI Editores. Argentina.

Lahire, B. (2006). “El espíritu sociológico” Ed. Manantial SRL. Argentina.

Lahire, B. (2008). "Escrituras domésticas. La domesticación de lo doméstico". Lectura y Vida.

Lerner, D. (2001). "Leer y escribir en la escuela: lo real, lo posible, lo necesario". Fondo de Cultura Económica. México.

Lerner, D. (2004). "Lectura y escritura. Apuntes desde una perspectiva curricular". Textos en contextos 4- la escuela y la formación de lectores y escritores.

Lida, C. (1997). “¿Qué son las Clases populares? Los modelos europeos frente al caso español en el siglo XIX”, en Revista Historia Social, Nro. 27, Valencia.

Lonigan, C. J., \& Whitehurst, G. J. (1998). "Relative efficacy of parent and teacher involvement in a shared-reading intervention for preschool children from low-income backgrounds." Early Childhood Research Quarterly, 13, 263 - 290.

Mancebo, M. y Alonso, C. (2012). "Programa APRENDER de Uruguay. Las visiones y opiniones de los maestros directores”. Colección “Innovar en Educación” UNICEF. CEIP. Uruguay.

Mara, S. (1999). "Estudio de Evaluación de Impacto de la Educación inicial en el Uruguay". Dicho trabajo se realizó en el marco del componente del Proyecto de Mejoramiento de la Calidad de la Educación Primaria (MECAEP) perteneciente al Consejo Directivo Central (CODICEN) de la Administración Nacional de Educación Pública (ANEP). Cabe destacar que en ese momento el 
Uruguay procuraba la universalización y obligatoriedad de Educación inicial a partir del estudio mencionado.

Martínez M. (1994) “La investigación cualitativa etnográfica en educación”. México: Trillas.

Martiniello, M. (1999). "Participación de los padres en la educación: Hacia una taxonomía para América Latina". Development Discussion Paper, 709, June, Harvard Institute for International Development

Masagao Ribeiro, Vera. (2003). “Letramento no Brasil”. Reflexiones a partir do INAF 2001.

Matsuura, K (2005). "Hacia las sociedades del conocimiento". UNESCO

Moll, L. (1993). "Vygostky y la educación”. Connotaciones y aplicaciones de la psicología sociohistórica en la educación. Ed. Aique Bs. As. Aprender a leer y a escribir en un marco urbano.

Molina, A. (1999). "Adriana y los recuentos independientes de sus cuentos favoritos". Lectura y Vida: Revista Latinoamericana de lectura.

Molina, A. (1999). "Leer y conversar sobre los cuentos favoritos: la lectura dialógica en la alfabetización temprana". Lectura y Vida: Revista Latinoamericana de lectura.

Morrison, F.J. y Cooney, R. R. (2001). "Parenting and academic achievement: Multiple paths to early literacy. Parenting and Child's World: Influences on Academic, Intellectual, and Socioemotional Development". Mahwah, NJ: Lawrence Erlbaum.

Namo de Mello, G. (1985). "Las clases populares y la institución escolar: una interacción contradictoria". Educación y clases populares en América Latina. Eds. M. Ibarrola y E. Rockwell (comp). México: Dpto. de Investigaciones Educativas, Centro de Investigaciones y Estudios Avanzados del I.P.N.

Neirotti, N. (2005). "Elementos conceptuales y metodológicos para la evaluación de políticas y programas sociales". $8^{\circ}$ Curso Regional Planificación y Formulación de políticas Educativas. UNESCO - IIPE. Buenos Aires.

Olivera Galvao de, A. M. (2003). "Letramento no Brasil". Reflexiones a partir do INAF 2001. Leitura: algo que se transmite entre as gerações? Ed. Global. Sao Paulo.

Olson. D. (1994). "El mundo sobre el papel. El impacto de la escritura y la lectura en la estructura del conocimiento". Ed. Gedisa. Colección LEA. España.

Olson, D. y Torrance, N. (comps) (1995). "La cultura escrita y la oralidad". Ed. Gedisa. Colección LEA. Barcelona. España.

Parolo, M. (2001). "Ocupaciones y oficios. Los sectores populares en la ciudad de Tucumán, 18001870". Universidad Nacional de Tucumán. CONICET. Argentina.

Pena, D.C. (2000). "Parent Involvement: Influencing Factors and Implications". Journal of Educational Research. Vol.94 (1), p.42. 
Petit, M. (1999). "Nuevos acercamientos a los jóvenes y la lectura" Fondo de Cultura Económica. México.

Petit, M. (2005). "Lectura y familia, Lecturas sobre lecturas”. Dirección General de Publicaciones del Conaculta, México.

Piacente, T.; Tittarelli, A.M. (2009). "La lectura de cuentos dialógica y las características de la interacción según estrato social de procedencia”. Universidad Nacional de La Plata. Facultad de Psicología. Buenos Aires. Argentina.

Pinto, J y Salazar, G. (1999). "Historia Contemporánea de Chile II. Actores, identidad y movimientos". LOM, Santiago.

Plana, D.; Borzone, A.M. y Silva, M.L. (2010). "Representaciones mentales, sistemas de memoria y discurso narrativo: efectos del tópico en la recuperación y relato de eventos en niños pequeños". Revista Argentina de Neuropsicología, 15, 34-54. Buenos Aires, Neuropsicológica. En http://www.revneuropsi.com.ar.

Primavera, J. (2000). "Enhancing family competence through literacy activities". Journal of Prevention and Intervention in the Community, 20, pp.85-101.

Raiter, A. (1995). “Lenguaje en uso. Enfoque sociolingüístico”. A - Z Editora. Buenos Aires.

Hudson, R. (2000). “La sociolingüística”. Editorial Anagrama. Barcelona.

Redondo, P. (2004). "Escuelas y pobreza” Entre el desasosiego y la obstinación. Ed. Paidós. Bs. As.

Román, M. (2009). "La influencia de los padres y la comunidad en el aprendizaje de la lectura y la escritura". Tesis aprobada. Universidad Metropolitana Recinto de Cupey. Facultad de Educación. Departamento de Estudios Graduados. México.

Romero, L. (1990). "Los sectores populares urbanos como sujeto histórico", en Proposiciones 19, SUR, Santiago, Chile.

Rosemberg, C.; Stein, A.; Terry, M.; Benítez, M. (2007). “Aprender a leer y escribir en el hogar: un programa de alfabetización temprana para niños de barrios urbano marginados". Lectura y Vida: Revista latinoamericana de lectura. № 4, págs. 66 - 68.

Rosemberg, C., Silva, M. L. y Stein, A. (2009). "Narrativas infantiles en contexto: un estudio en hogares de barrios urbano marginados de Buenos Aires". Revista del Instituto de Ciencias de la Educación, Fac. de Fil. y Letras, Univ. de Buenos Aires. Bs As.: Miño y Dávila.

Rosemberg, C. y Silva, M. L. (2009). "Teacher Children Interaction and Concept-Development in Kindergarten". Discourse Processes, 46 (5), 572-591 Philadelphia, Routledge.

Sánchez Abchi, V., Silva, M. L. y Borzone, A. (2009). "El empleo de los tiempos verbales en la renarración. Un estudio de las producciones orales y escritas de niños pequeños". Boletín de Lingüística, 32 (XXI), 32-50. Caracas: Instituto de Filología "Andrés Bello".

Scarborough, H. (2002). Connecting early language and literacy to later readinf (dis)abilities: Evidence, theory and practice. En: Neuman S. y Dickinson D. Handbook of early literacy research. London: The Guilford Press, pp. 97-110. 
Schlemenson, S. (2007). “Leer y escribir en contextos sociales complejos”. Ed. Paidós. Bs.As.

Sepúlveda, L. (2005). "El aprendizaje inicial de la escritura de textos como (re) escritura". Tesis doctoral Interuniversitario de psicología de la Educación - Cultura, Educación y Sistemas Semióticos. Barcelona.

Siro, A. (2005). "Leer entre la escuela y la familia, una posibilidad abierta por los niños". Argentina.

Smirnov, A., Leontiev, S. (1962). "Psicología" Capítulo XIV Los Hábitos, las habilidades y las costumbres. Editorial Grijalbo. S.A. México.

Soler, M. (2003). "Lectura dialógica. La comunidad como entorno alfabetizador". En Contextos de alfabetización inicial. Teberosky, A. y Soler, M. Horsori. Barcelona.

Taylor, B. M. y Pearson, P. D. (2004). "Research on learning to read-at school, at home, and in the community". The Elementary School Journal. Vol.105 (2), pp. 167-182. Descargado en junio de 2005. http://proquest.umi.com

Teberosky, A. \& Soler, A. (Eds). (2003). “Contextos de alfabetización inicial”. Horsori. Barcelona.

Tolchinsky, L. (1990). "La reproducción de relatos en niños entre cinco y siete años: organización sintáctica y funciones narrativas". Anuario de Psicología, 47 (4), 65 -88.

Torres, R. M. (2006). "Alfabetización y aprendizaje a lo largo de toda la vida". Instituto Fronesis http://www.fronesis.org/immagen/rmt/documentosrmt/texto Dime\%20como\%20te\%20relacionas\%2 0con\%20el\%20lenguaje.pdf

Torres, R.M. (2002). "Educación básica de la calidad para todos: Agenda básica implica agenda de cambio". Publicado en EducAcción, suplemento del diario El Comercio, Quito, №130.

Torres, R.M. (2007). "No basta con enseñar a leer y escribir. Hay que acercar la lectura y la escritura a la gente". Entrevista con Rosa María Torres por la Campaña Latinoamericana por el Derecho a la Educación (CLADE).

Train, B. (2006). "Investigación sobre la lectura familiar: una perspectiva internacional". World Library and Information Congress: 72 IFLA General Conference and Council, Seoul, Korea.

Unamuno, V. (2003). "Lengua, escuela y diversidad sociocultural” Hacia una educación lingüística crítica. Ed. Graó. Barcelona. España.

UNESCO (1993). "Glosario de términos de tecnología de la evaluación". http://www.unesco.org.uy/politicacientifica/budapest+10

Valls, R.; Soler, M.; Flecha, R. (2008). "Lectura dialógica: interacciones que mejoran y aceleran la lectura”. Revista Iberoamericana para la Educación, la Ciencia y la Cultura. España.

Vance, C, Smith Patrick; Murillo, L. (2005). "Prácticas de lectoescritura en padres de familia. Influencias en el desarrollo de la lectoescritura de sus hijos". Esta investigación se llevó a cabo en la comunidad de San Andrés Cholula, Puebla en el marco del programa de Construcción Social de los Lectores de México. 
Vernon-Feagans, Scheffiner, Miccio y Manlove, (2002). Early language and literacy skills in lowincome African-American and Hispanic Children. En: S.B. Neuman y Dk. Dickinson (Eds), Handbook of Early Literacy Research. New York: The Guilford Press.

Vygostky, L. (1999). "Pensamiento y Lenguaje" teoría del desarrollo cultural de las funciones psíquicas. Comentarios críticos de Jean Piaget. Ed. La Pleya.

Vygostky, L. (1996). "Pensamiento y lenguaje". Buenos Aires, Ediciones Fausto - 22

Weisz, T. (2004). Operativo realizado Sao Paulo, Brasil, por el SARESP (Sistema de Avaliacao de Rendimento Escolar do Estado de Sao Paulo - Secretaria da educacao do Estado de Sao Paulo).

Wasik, Dobbins y Herrmann, (2002). "Intergenerational Family Literacy”. En: S.D. Neuman y D.K. Dickinson (Eds.), Handbook of Early Literacy Research. London: The Guilford Press.

Wells, G. (1985). "Desarrollo del Lenguaje en los años pre-escolares" Idioma en casa y en la escuela, Vol. 2. Cambridge: Cambridge University Press.

Yubero Jiménez, S. y Larrañaga Rubio, E. (2010). "El valor de la lectura en relación con el comportamiento lector. Un estudio sobre los hábitos lectores y el estilo de vida en niños", en Revista OCNOS no 6 p. 7-20. ISSN 1885-446X. Universidad de Castilla-La Mancha. España.

Zamudio C. (2008), "Influencia de la escritura alfabética en la segmentación de sonidos vocálicos y consonánticos”, en Lectura y Vida, Buenos Aires, año 29, №1. 


\section{ANEXOS}

\section{ANEXO 1}

Situación 2. Cuentos seleccionados para la: Renarración de cuentos

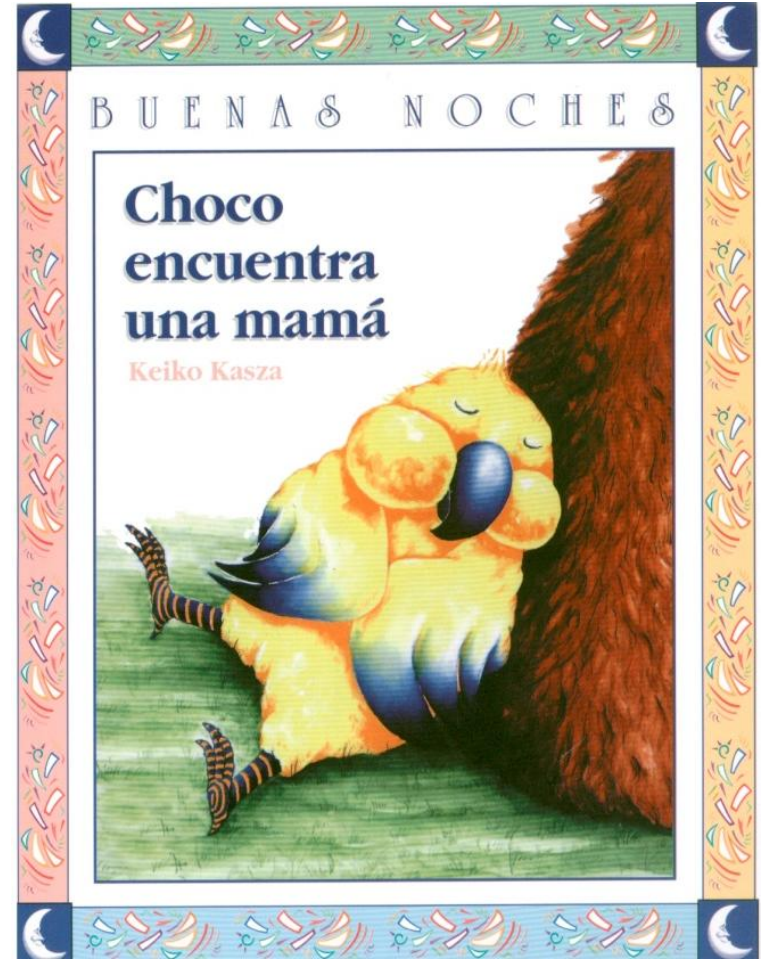

\section{Choco encuentra}

\section{una mamá}

Keiko Kasza

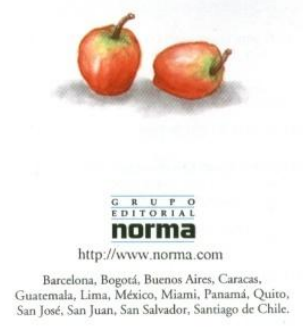




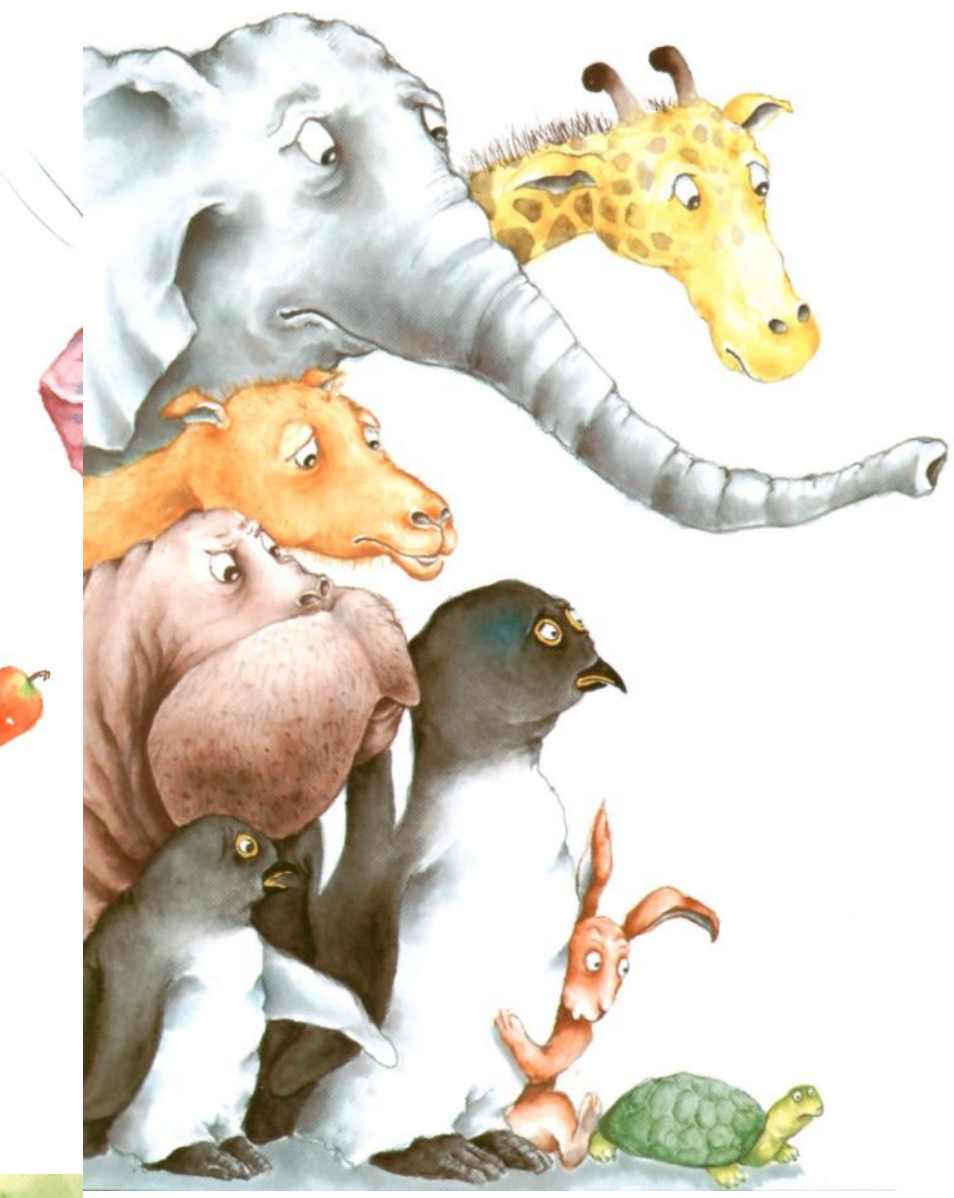

Choco buscó por todas partes, pero no pudo encontrar una madre que se le pareciera.

6

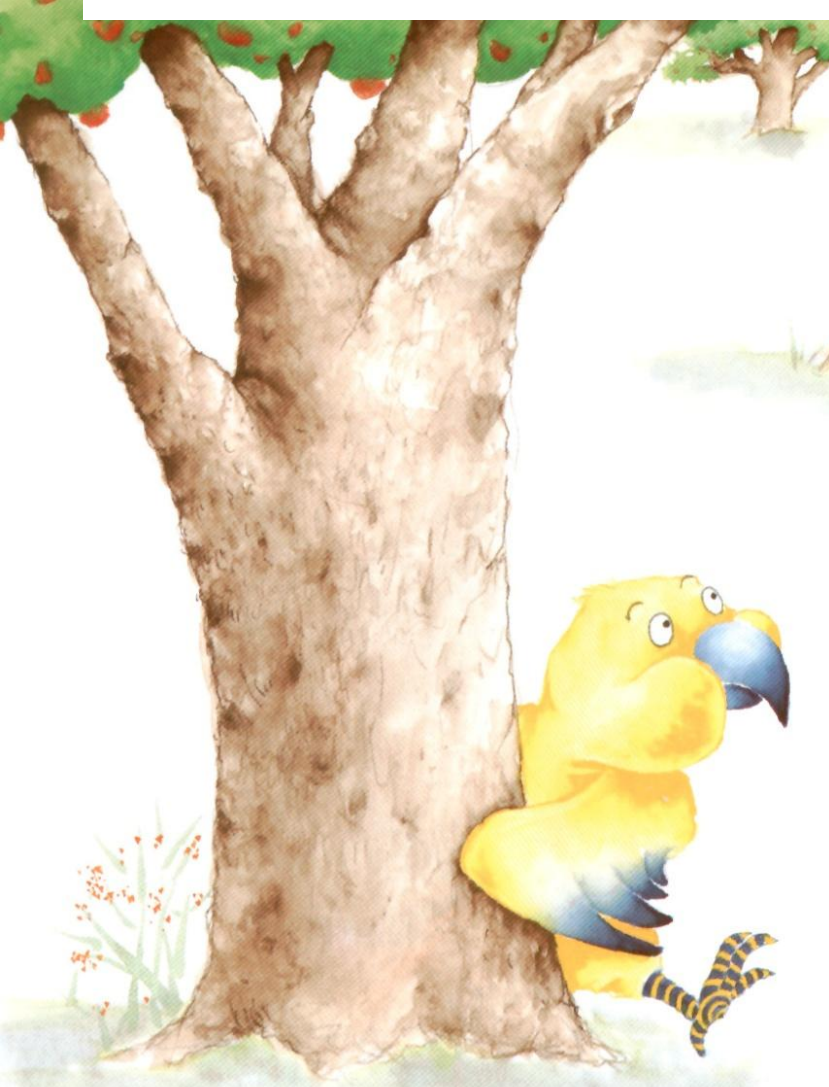

Cuando Choco vio a la señora Oso recogiendo manzanas, supo que ella no podía ser su madre. No había ningún parecido entre él y la señora Oso. 

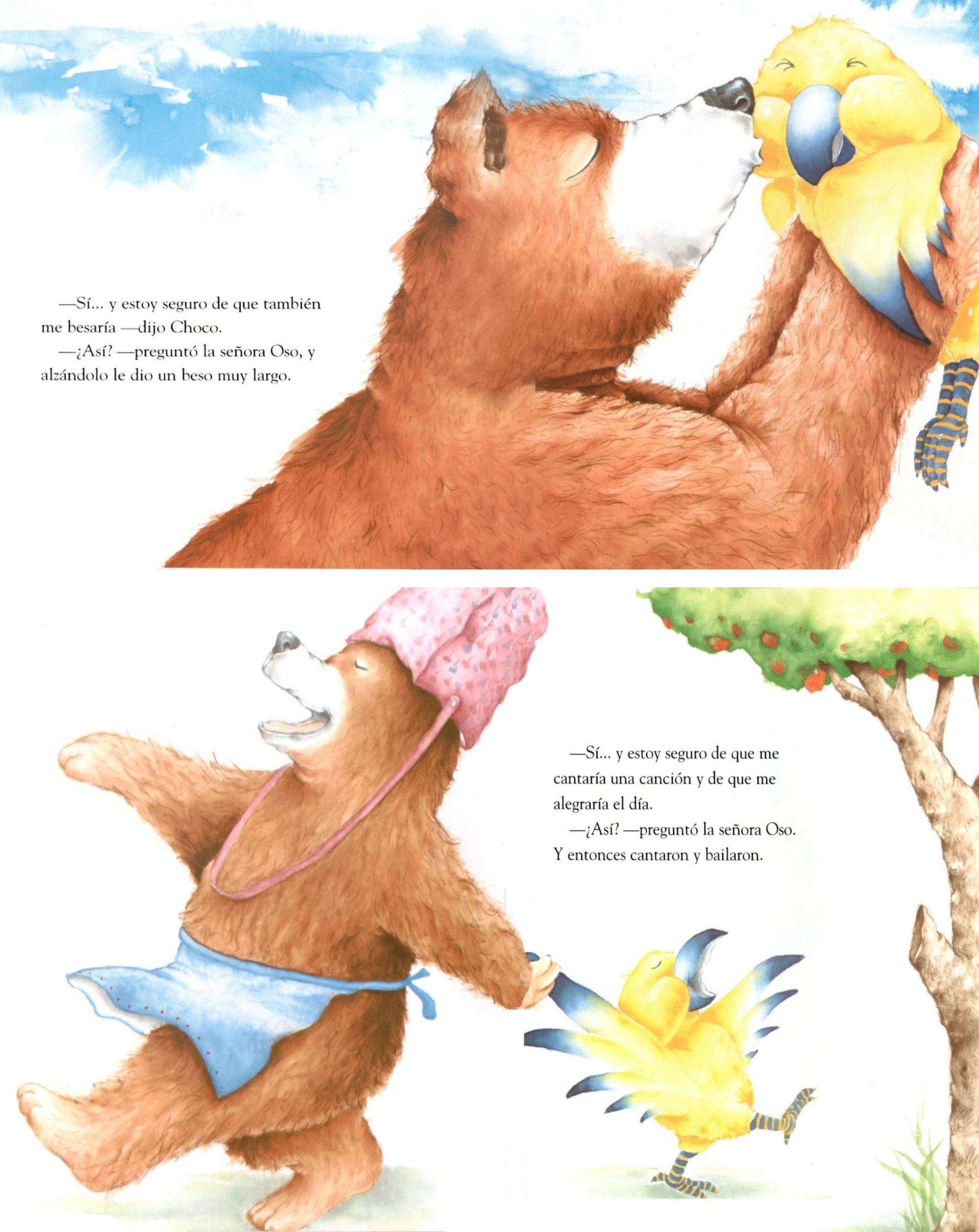


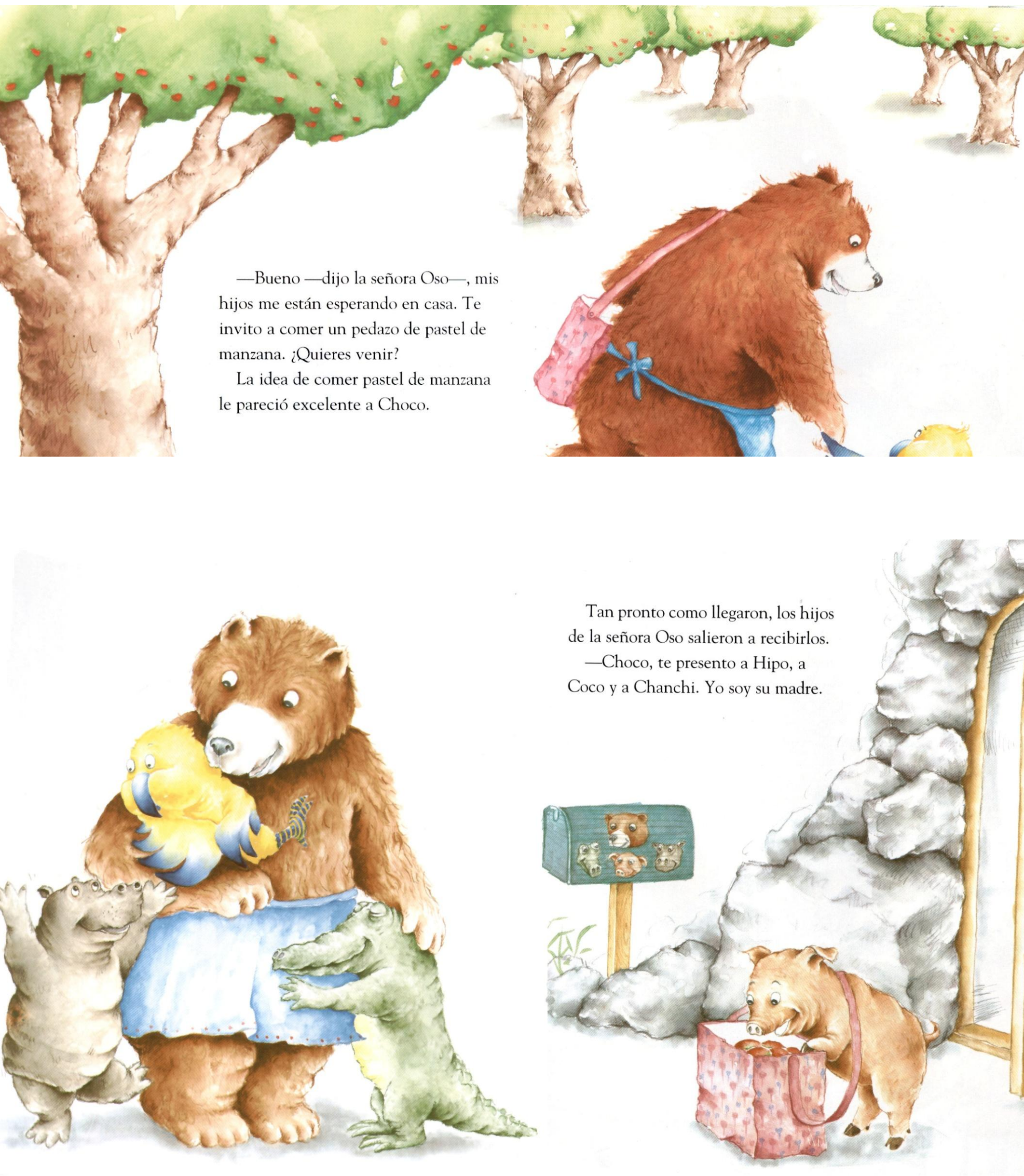




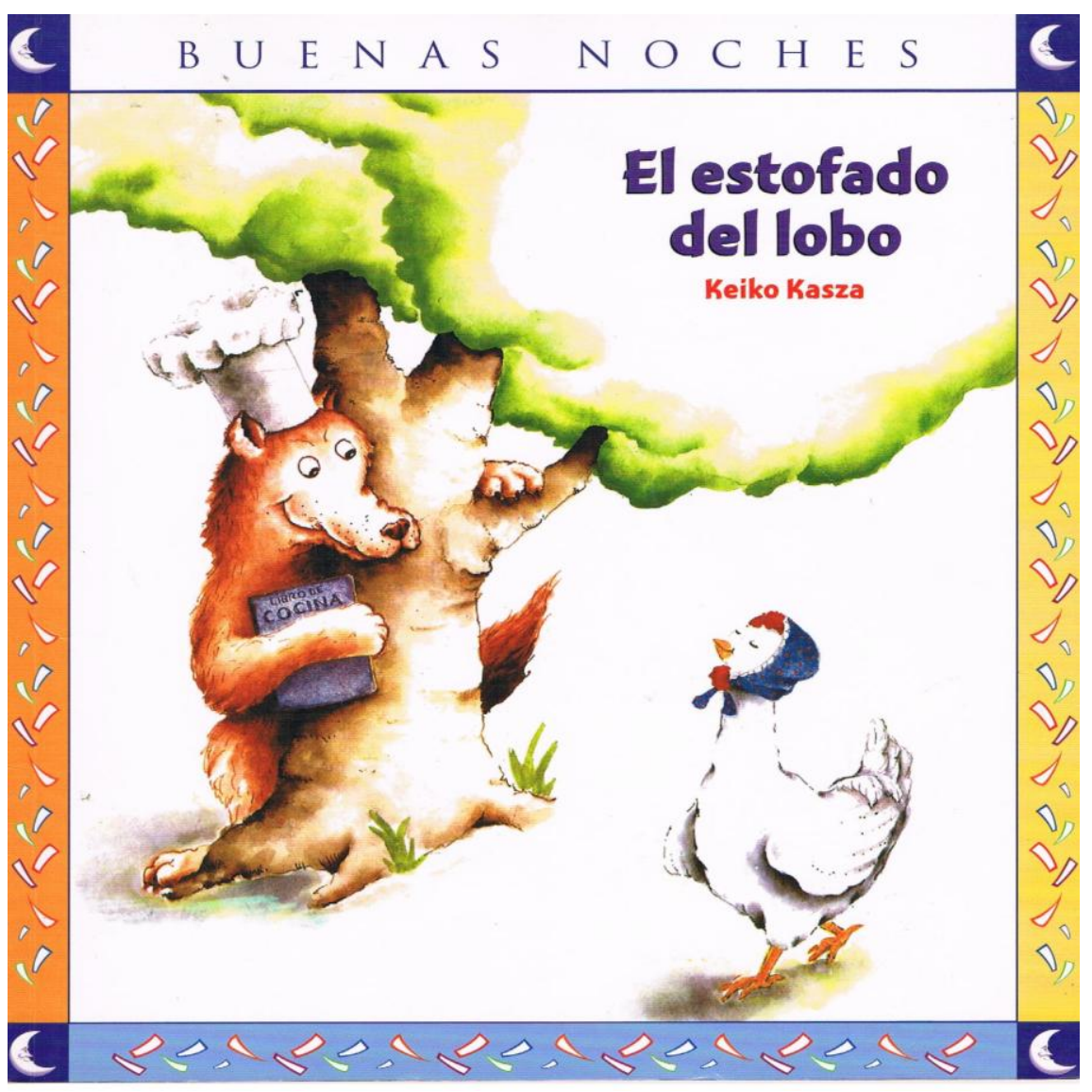

\section{del lobo}

\section{Keiko Kasza}

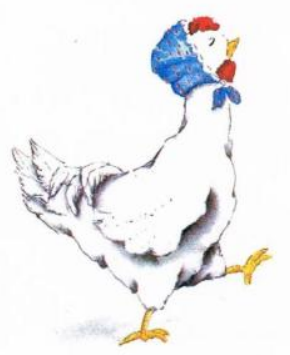



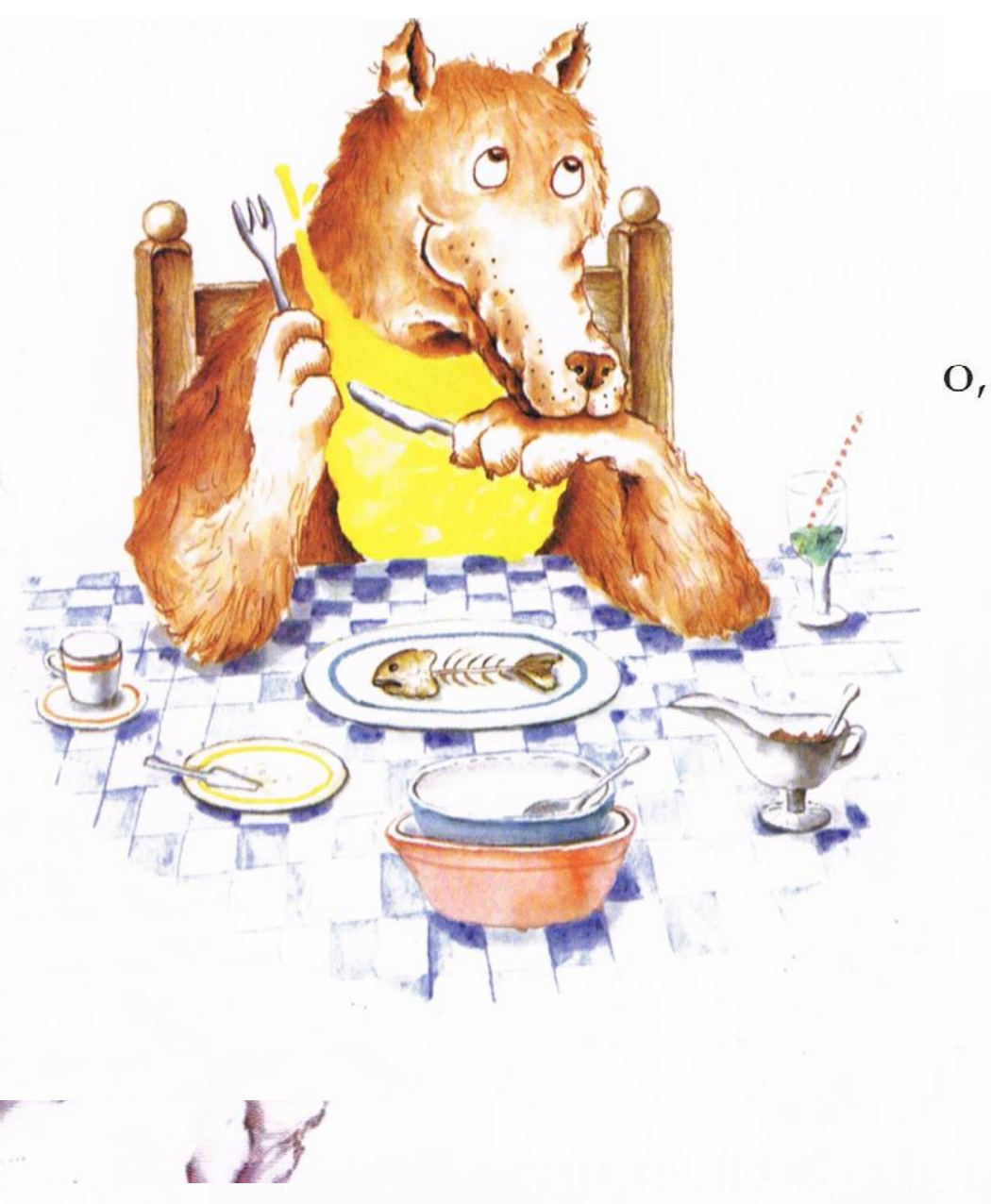

Había una vez un lobo al que comer le gustaba más que cualquier otra cosa en el mundo. Apenas terminaba una comida empezaba a pensar en la próxima. 


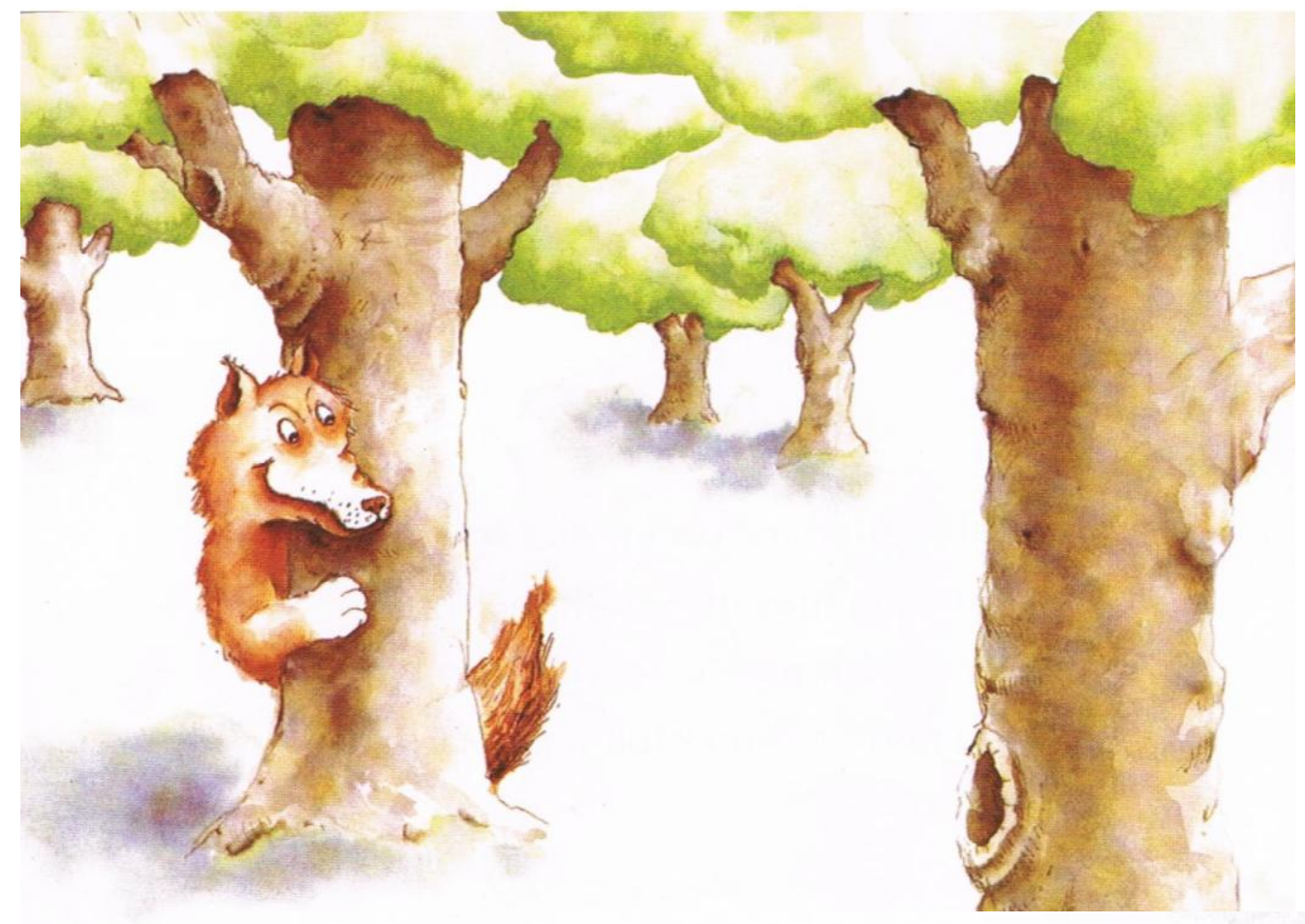

El lobo acechó a su presa hasta que la tuvo cerca, pero cuando ya la iba a agarrar...

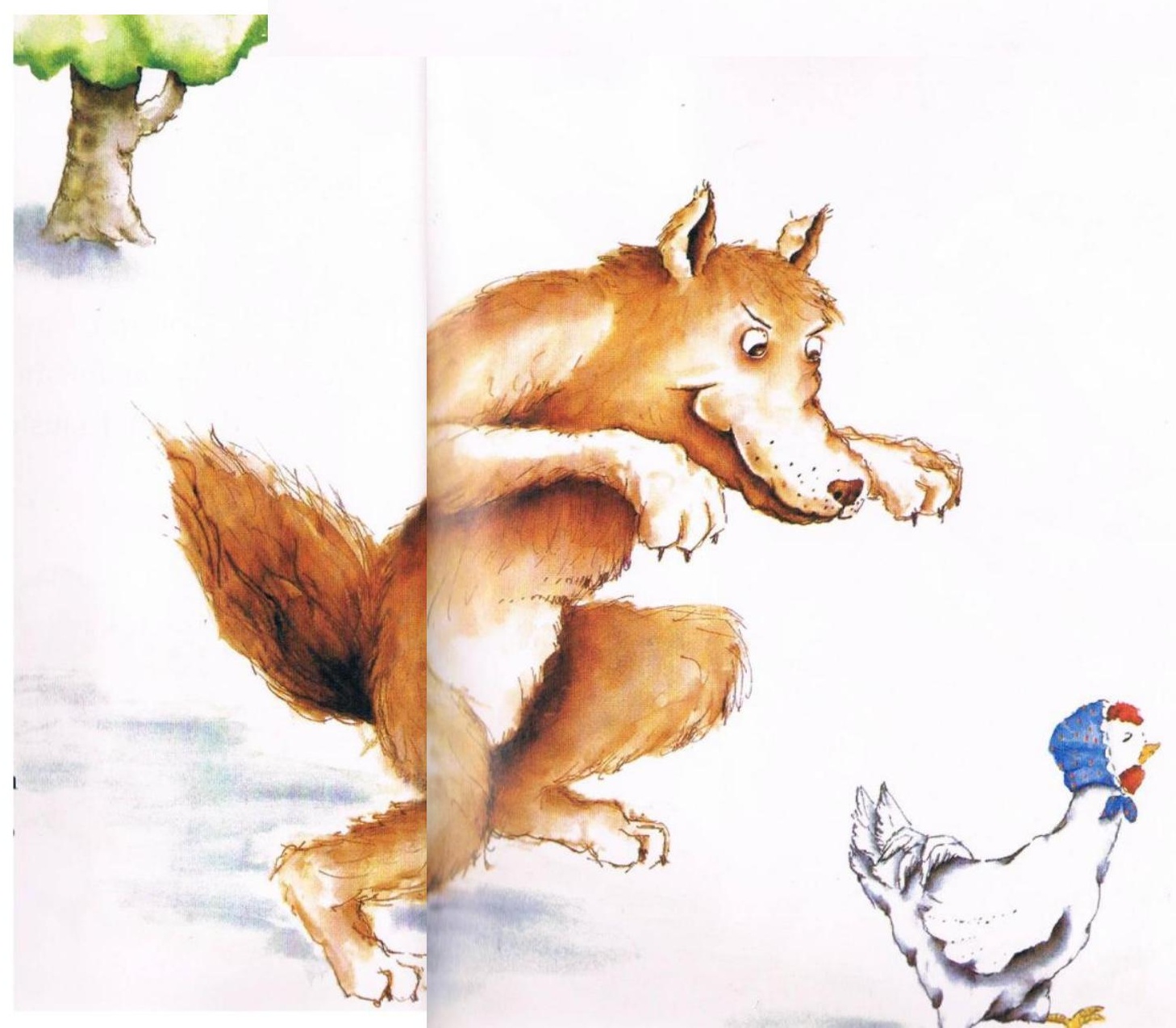



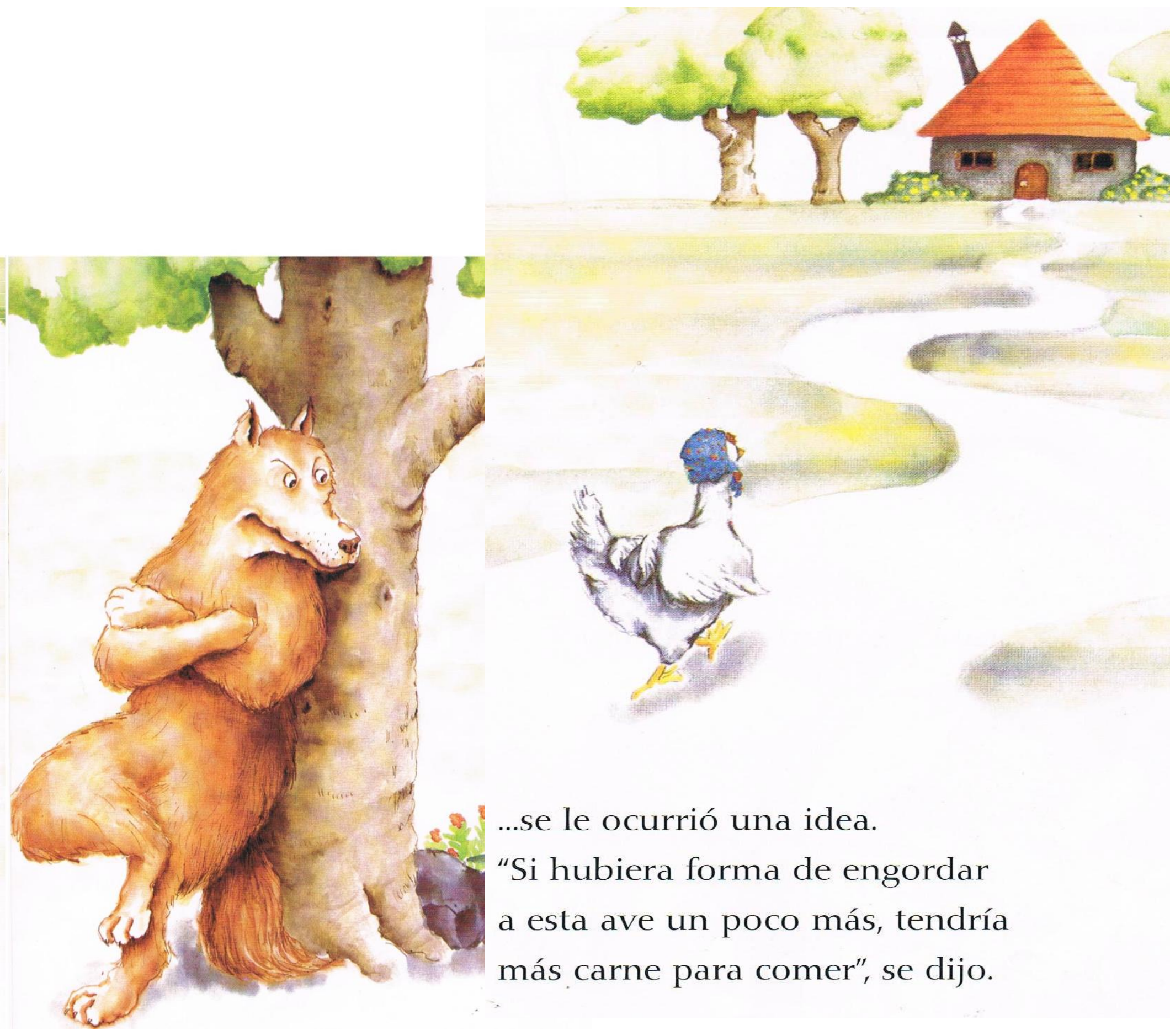

...se le ocurrió una idea.

"Si hubiera forma de engordar a esta ave un poco más, tendría más carne para comer", se dijo. 


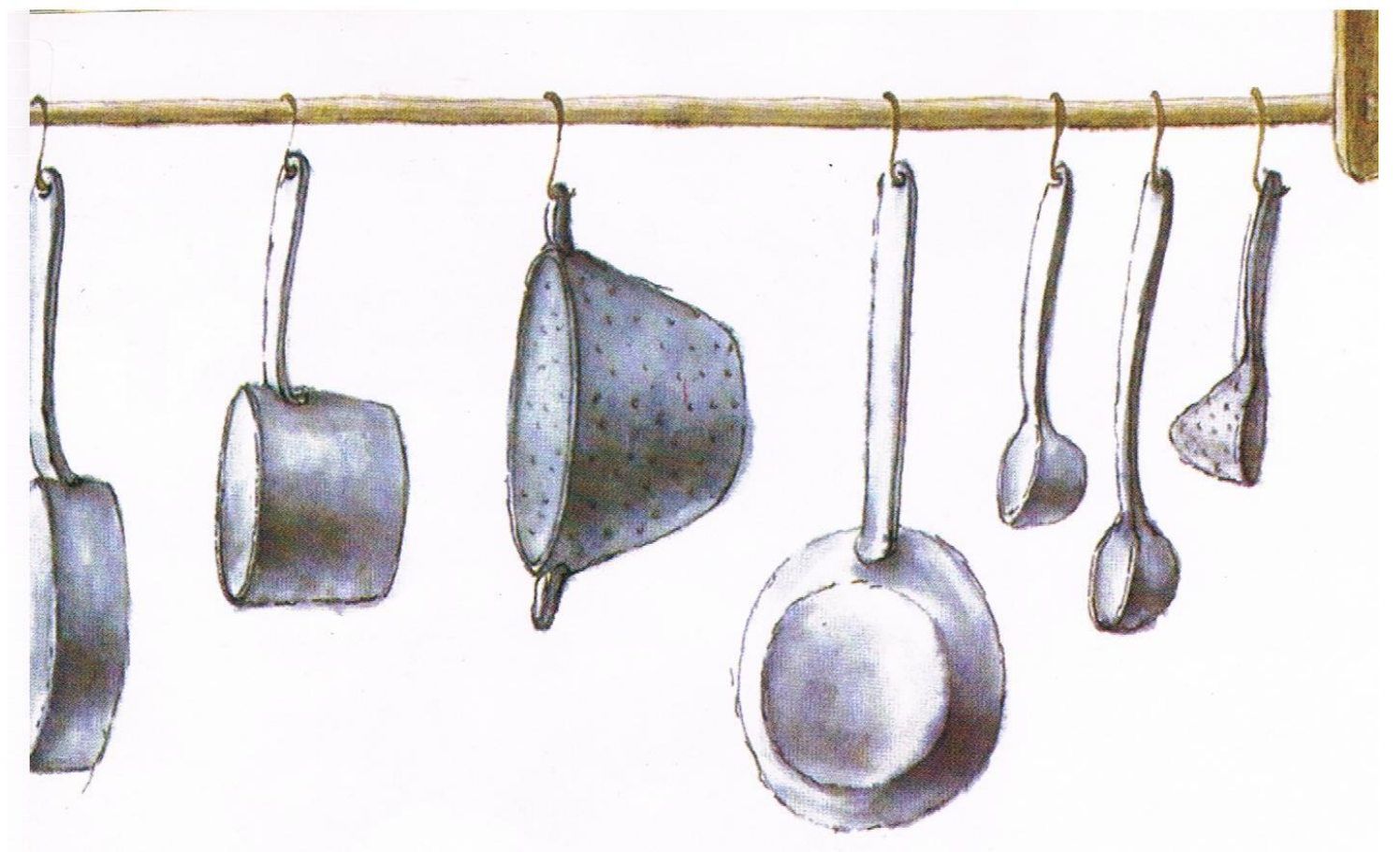

El lobo corrió a casa y se puso a cocinar.

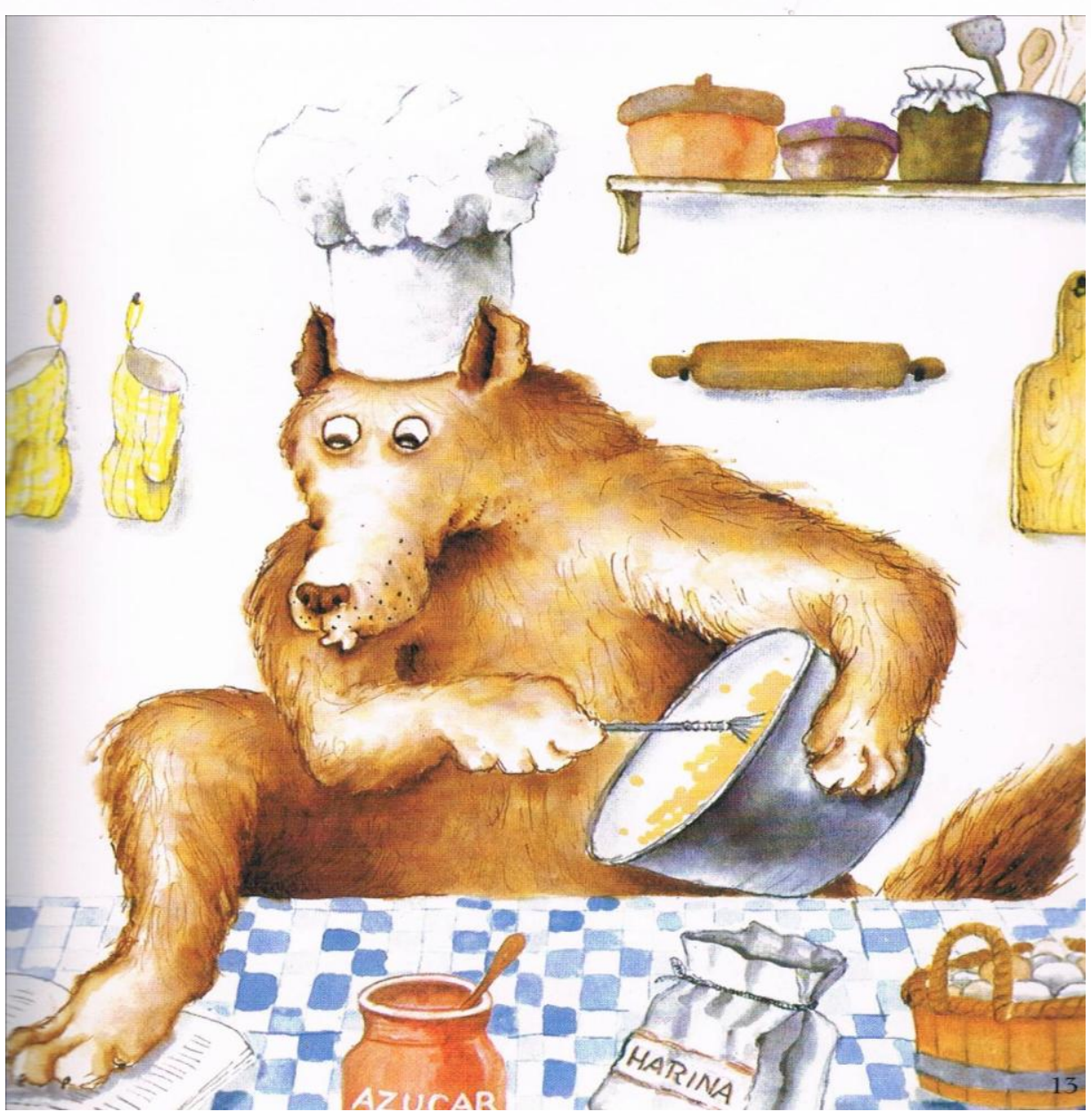



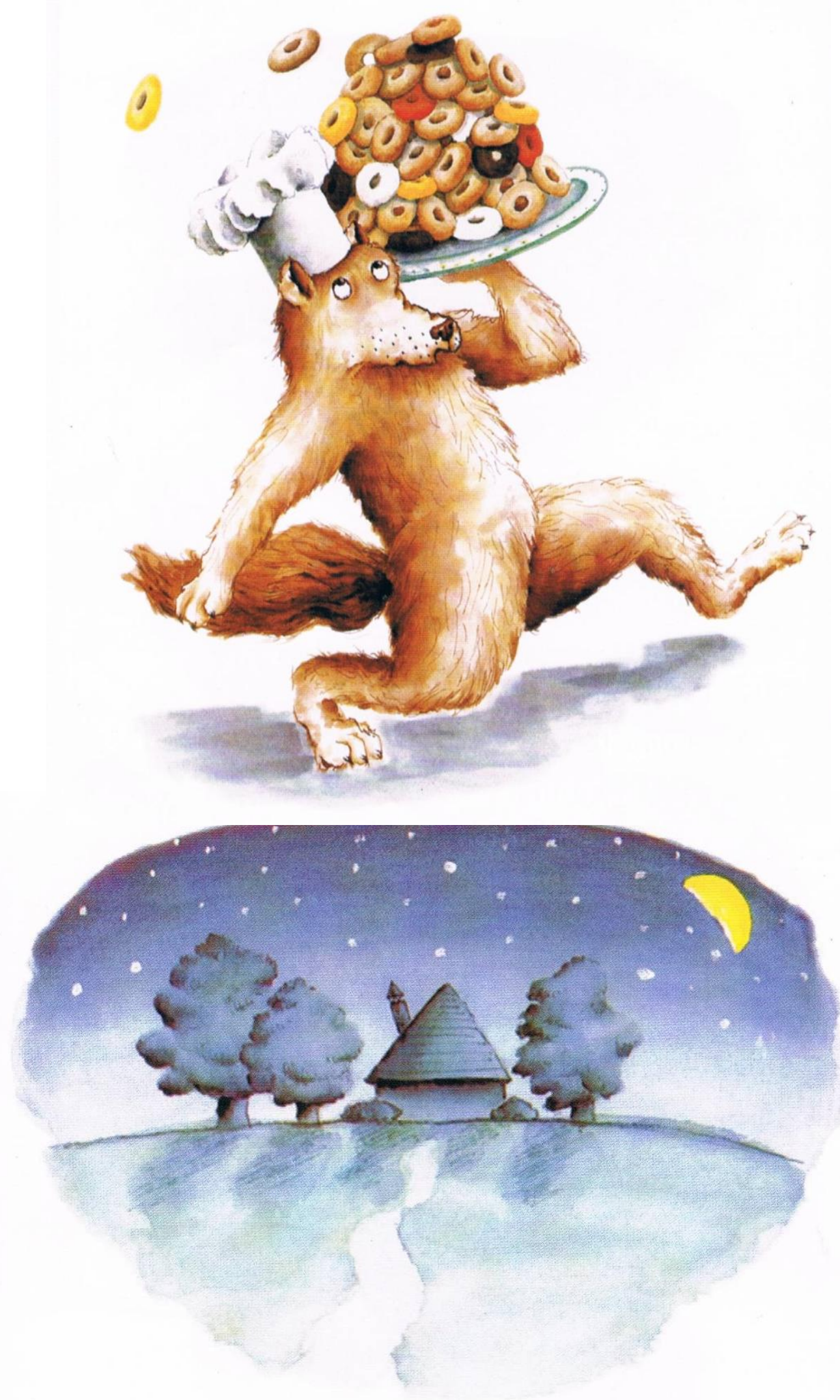

La noche siguiente le llevó a la gallina cien apetitosas rosquillas.

-Come bien, gallinita mía. iPonte gorda y

sabrosa para mi estofado! -dijo. 


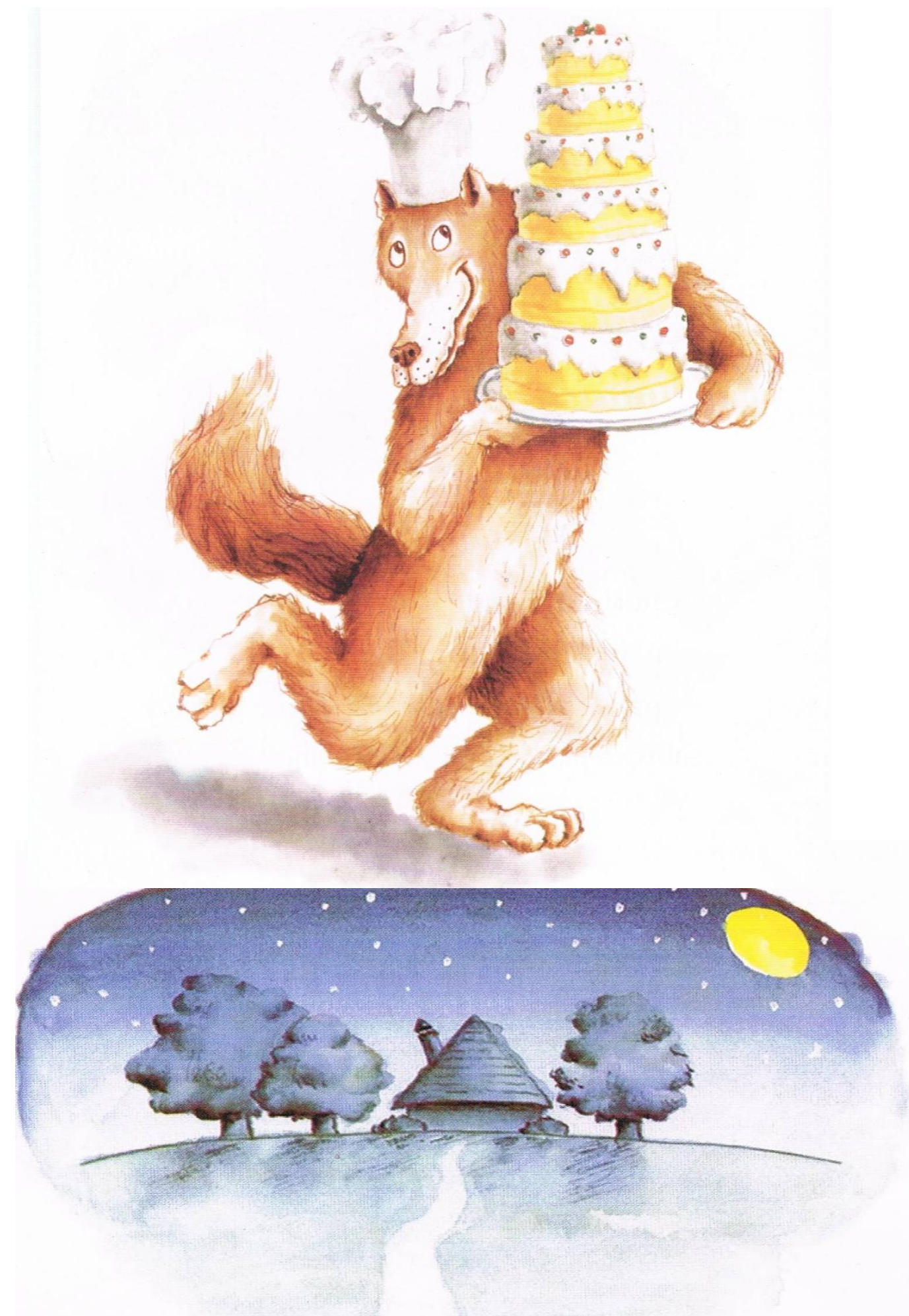

Al día siguiente le llevó un apetitoso

pastel que pesaba más de cien kilos, y relamiéndose dijo:

-Come bien, gallinita linda. iPonte gorda y 
Por fin llegó la noche que el lobo había estado esperando.

Puso una olla enorme al fuego y salió alegremente a buscar su comida.

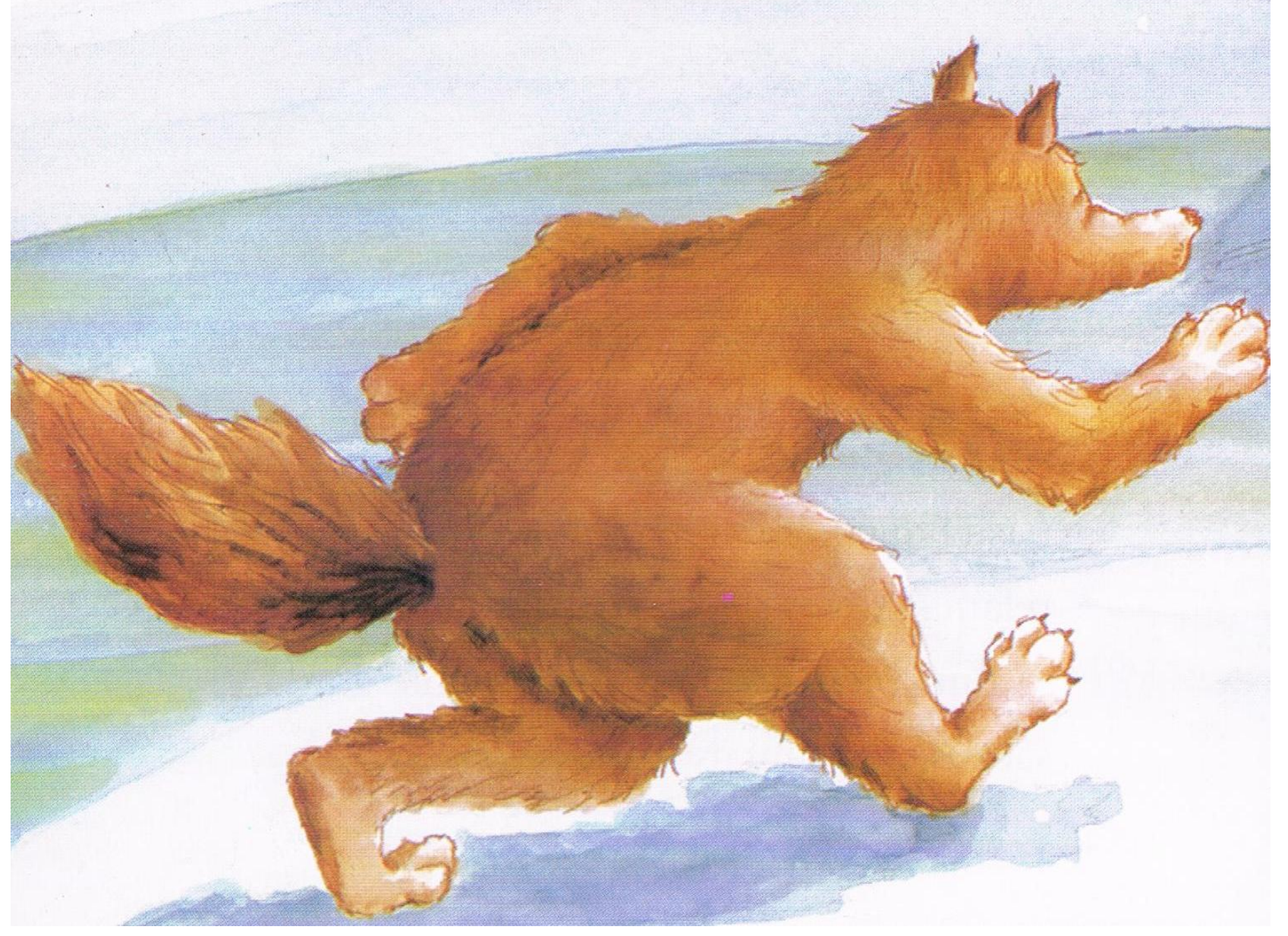




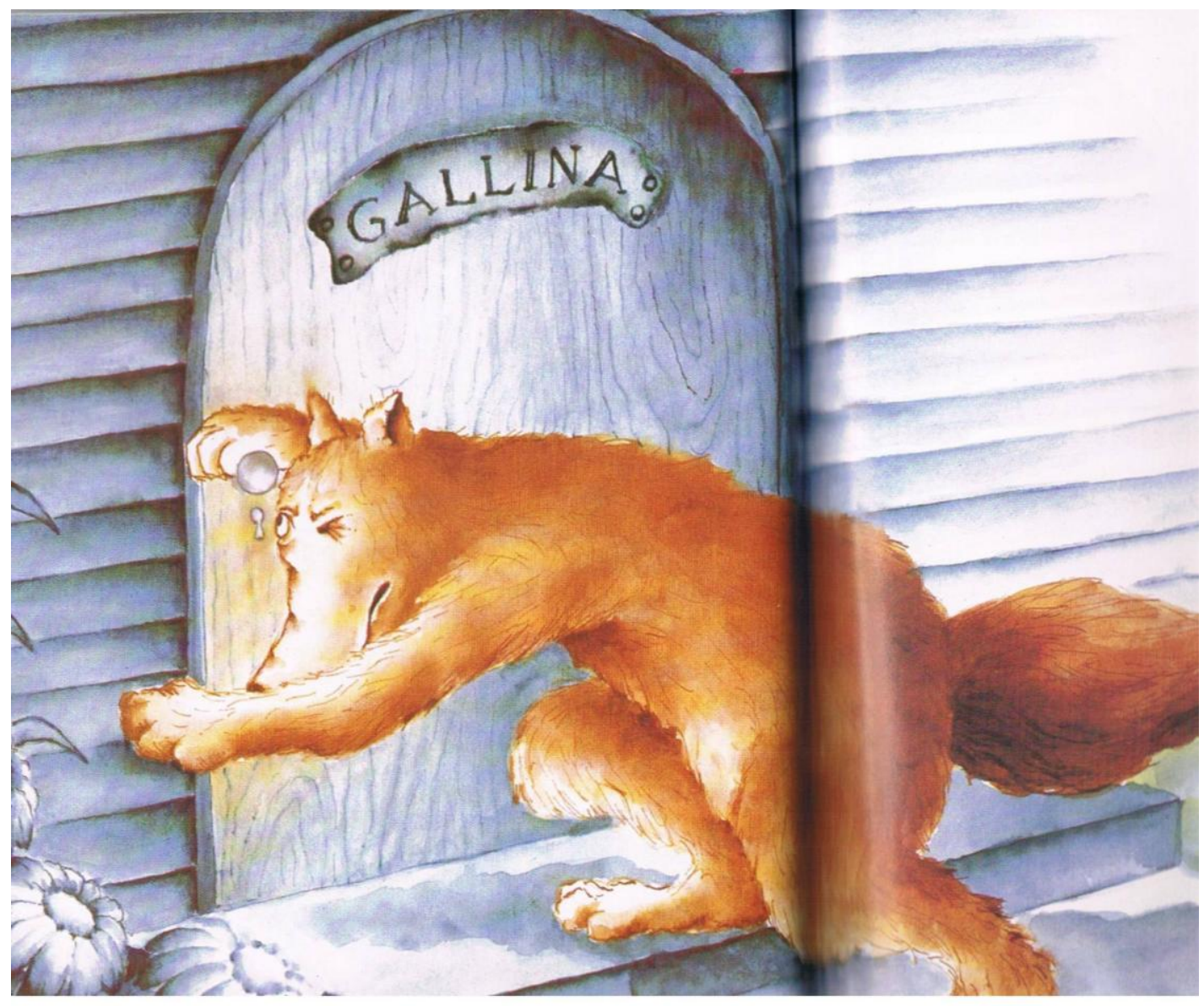

"Esa gallinita debe estar gorda como un balón", pensó. "Voy a verla". Pero apenas se asomó a espiar por el ojo de la cerradura... 

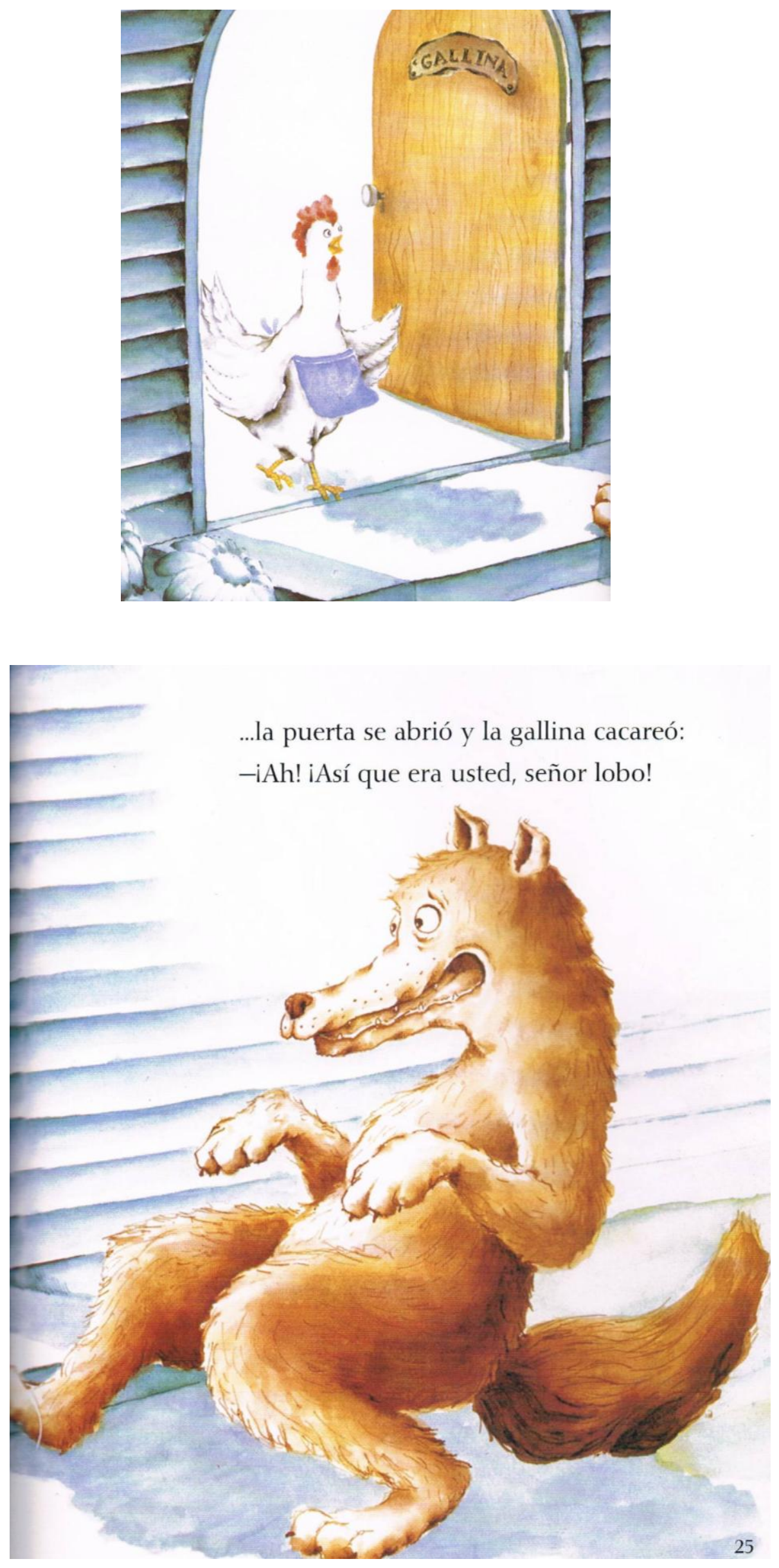


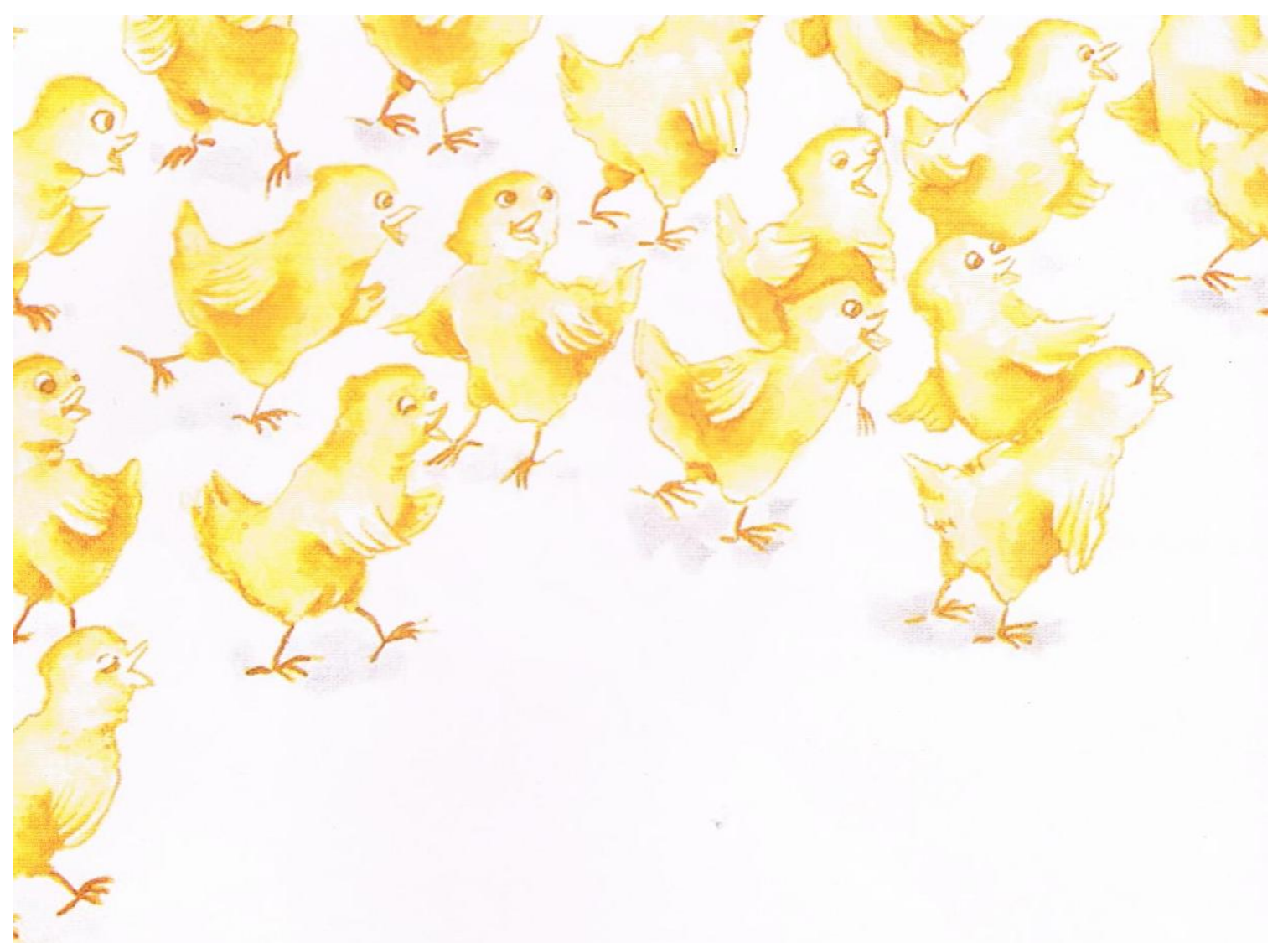

-iNiños, niños! Los panqueques, las rosquillas y ese exquisito pastel no eran regalo del Niño Dios. Los trajo el tío lobo.

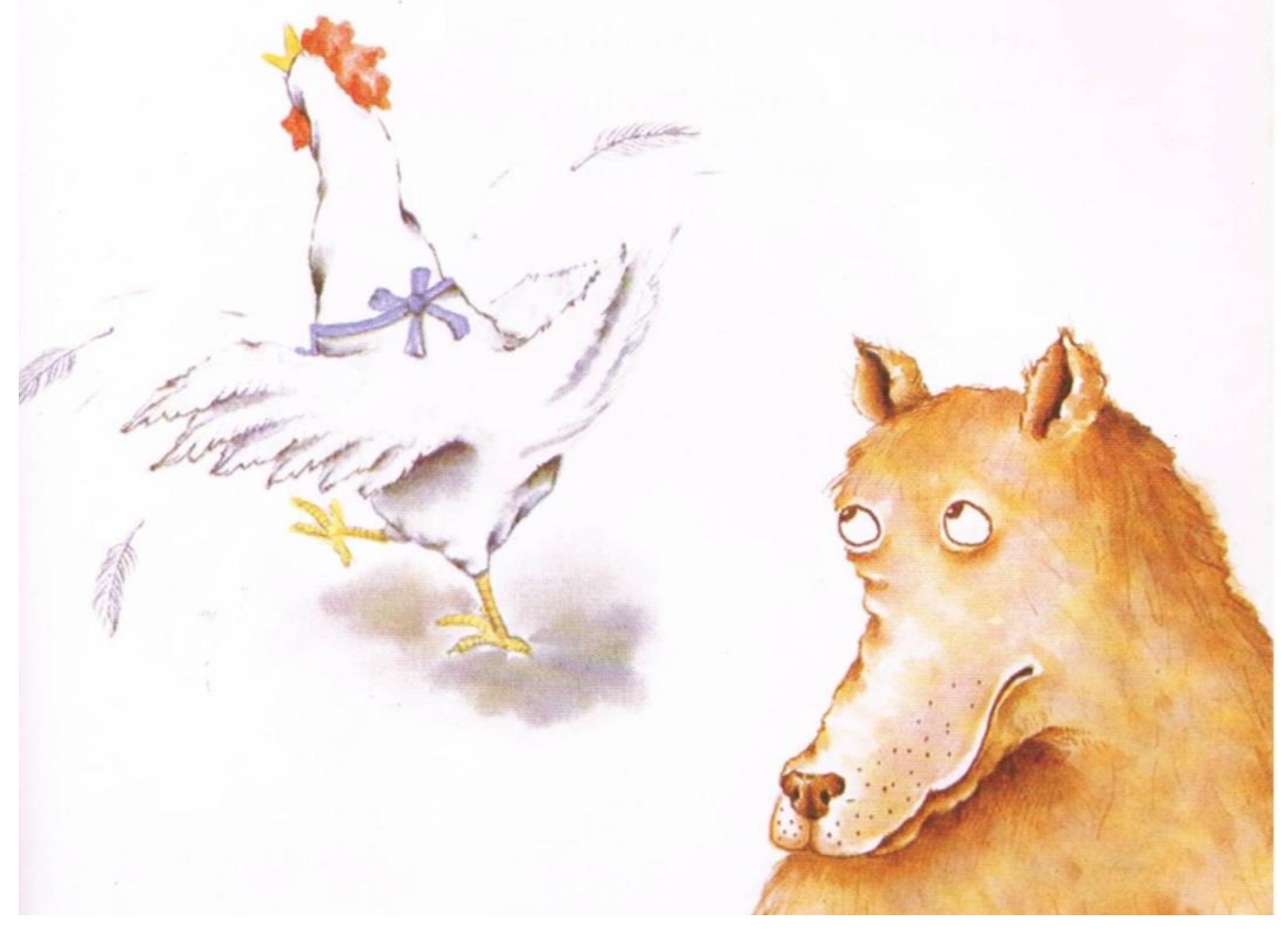




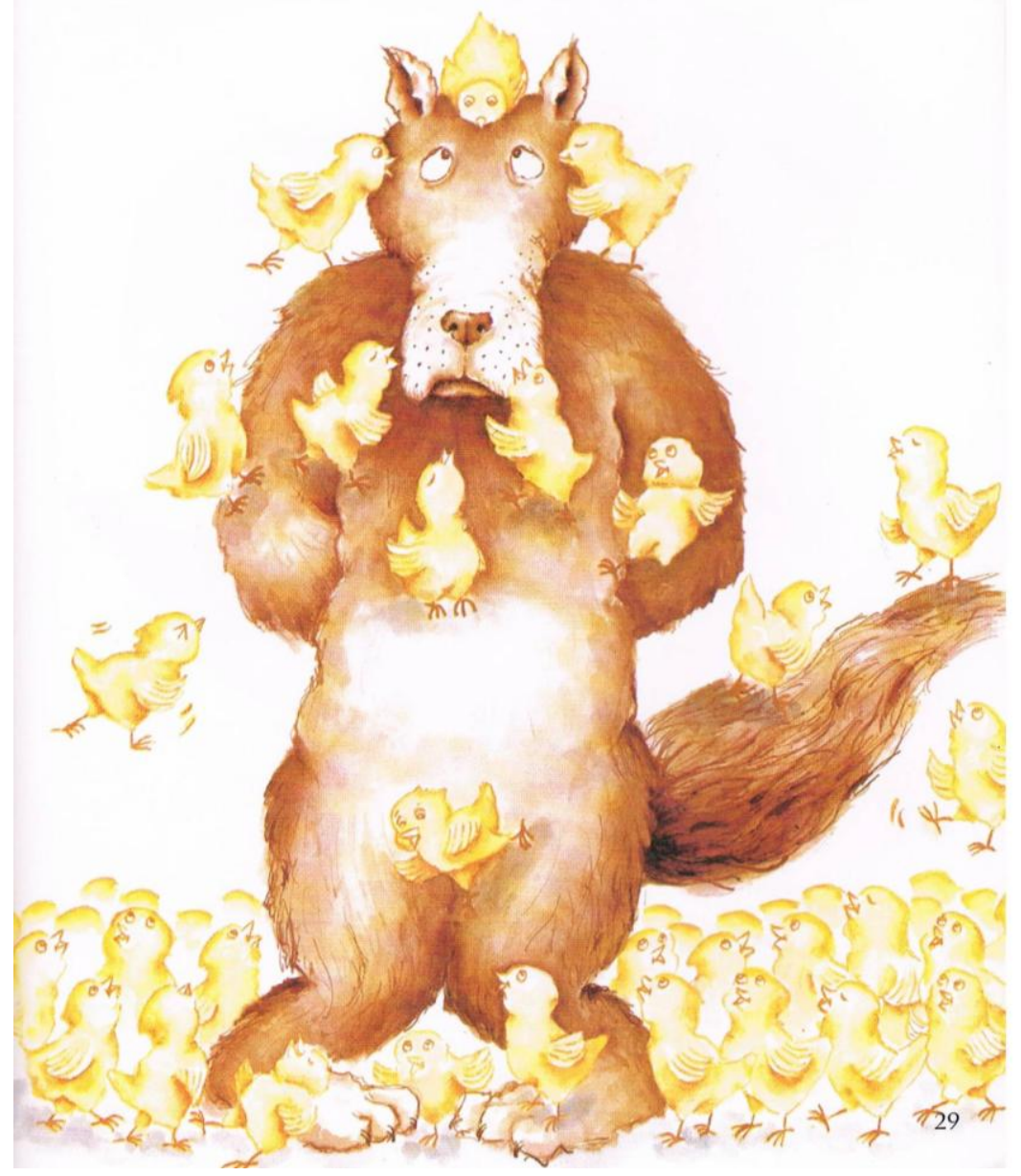

Los pollitos agradecidos, saltaron sobre el lobo y le dieron cien besitos.

-iGracias, gracias, tío lobo! iEres el mejor cocinero del mundo!

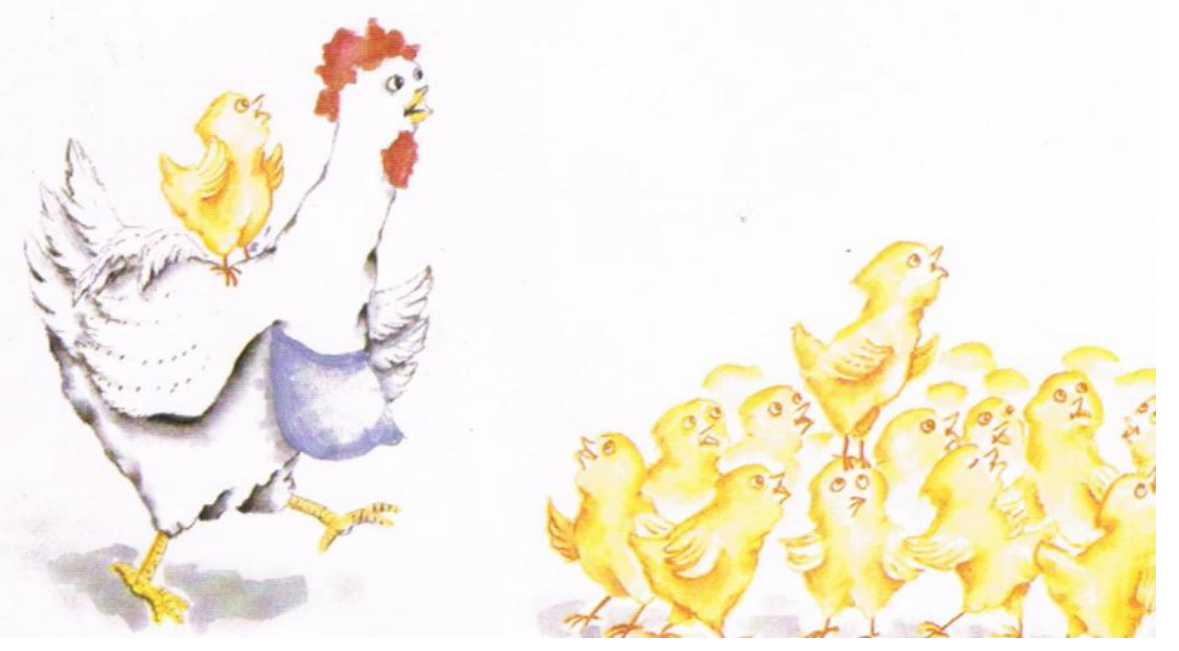




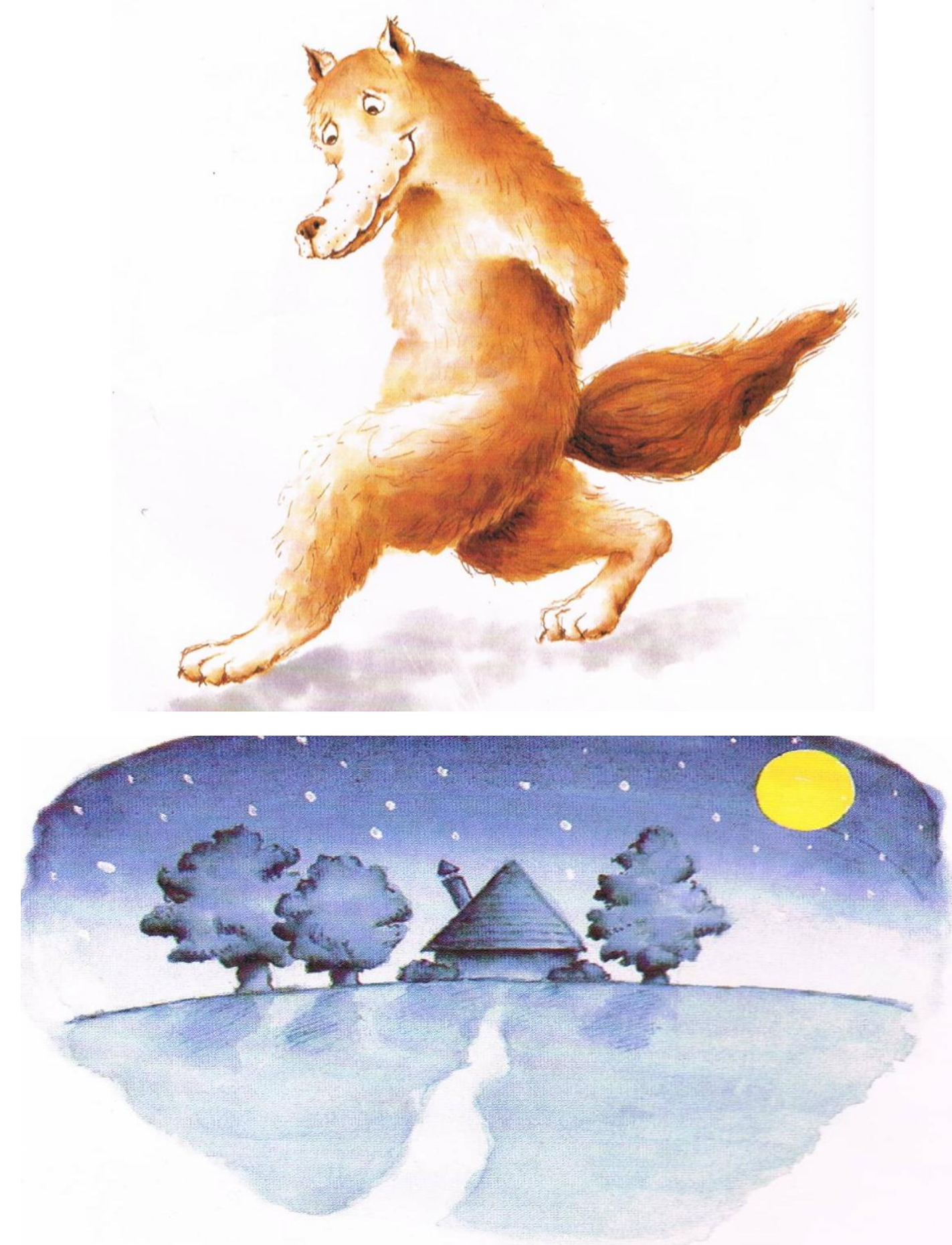

El tío lobo no comió estofado esa noche, pero mamá gallina le preparó una cena deliciosa.

"No he comido estofado de pollo, pero he hecho felices a los pequeñuelos", pensó mientras volvía a casa. "Tal vez mañana les prepare cien apetitosas galletitas". 


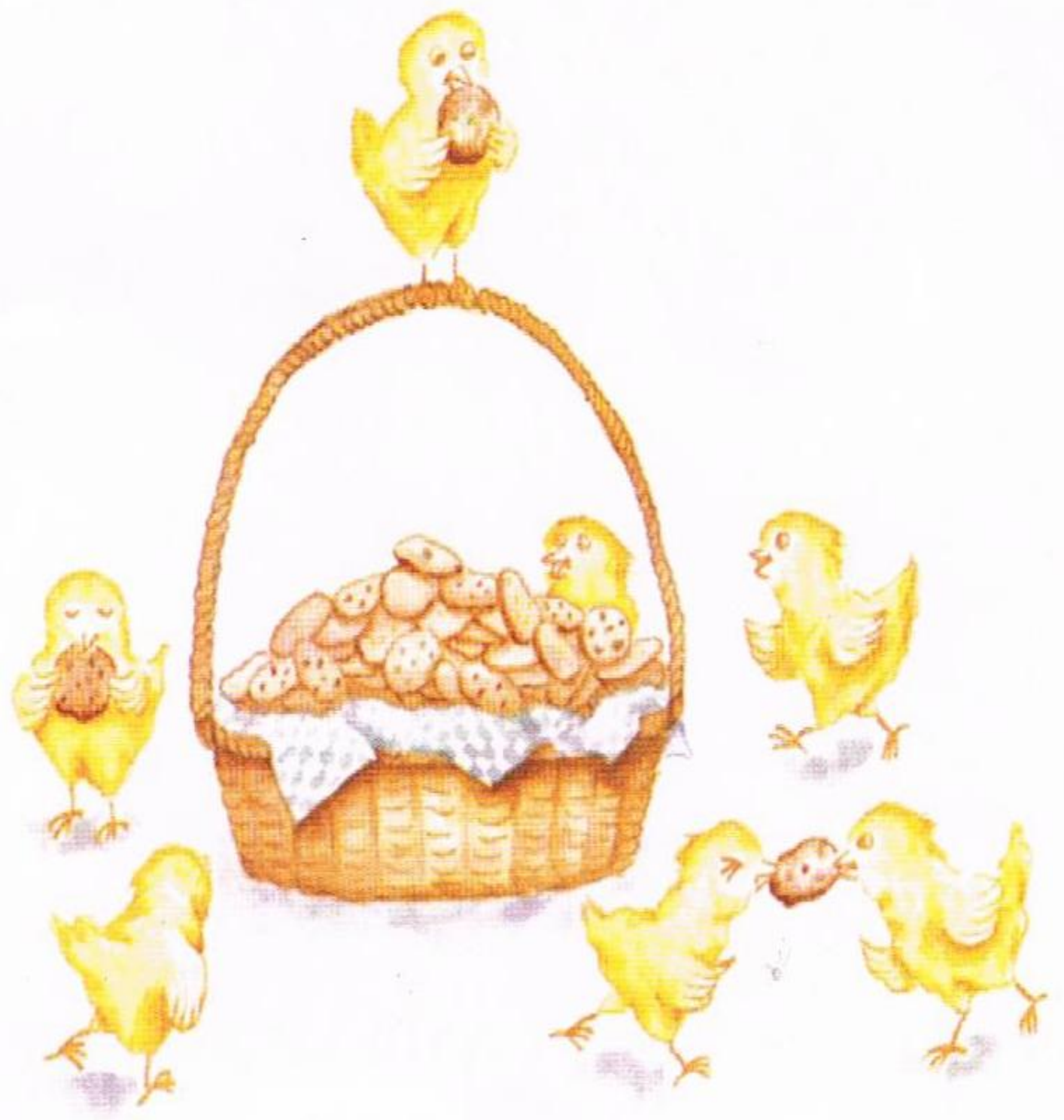




\section{ANEXO 2}

Desgrabaciones de los relatos orales de cuentos

Grupo 1: Con CQC (niños cuyos padres participaron del programa).

\section{Situación 2 - Renarración de un cuento}

Contexto de renarración:

La entrevistadora invita a uno de los niños seleccionados a sentarse y le muestra los tres cuentos que la maestra leyó previamente.

- ¿Conocés estos cuentos? Me los dio tu maestra y me dijo que se los había leído. Yo no los conozco, ¿qué tal son?, ¿te gustaron?

Luego le pide que elija uno y se lo cuente. Es importante que logre estimularlo para que el niño se anime a narrarlo. Incluso se puede abrir el libro en la primera página y preguntarle cómo comienza.

\section{1- Federico: "Choco encuentra una mamá"}

Choco no tenía una mamá y salió a buscar una. Y le preguntó a la señora jirafa:

- Señora Jirafa, ¿usted es mi mamá?

- $\quad$ No, yo no tengo alas como tú, para volar, ni cachetes gordos... tan gordos.

Le preguntó a la señora jirafa... a la señora pingüino... y le dijo:

- $\quad$ Sí, usted tiene alas como yo.

- $\quad$ No, le dijo.

Le preguntó a la señora morsa:

- $\quad$ Usted puede ser mi mamá. Tiene los cachetes gordos como yo.

No la encontró.

Se encontró con la señora oso... estaba juntando manzanas... Choco entonces se puso a llorar porque no tenía una mamá.

La madre los abrazó a todos los hijos. Un cocodrilo, un chancho y un hipopótamo.

2- David: "Choco encuentra una mamá"

Es del lorito que no tiene mamá. Busca una mamá.

- Yo no tengo cachetes como tú....

Uuuuh! Estaba enojada. Después estaba éste. El lorito fue a la casa de la mamá y la osa le dio la torta de manzanas y un abrazo. 
3- Facundo: "Choco encuentra una mamá"

María: Y ¿cuál te acordás más de la historia? ¿De qué se trata?

No sé... se trata de un lorito que busca una mamá. Encuentra sólo un oso nomás. Y que el oso no es la madre.

Digo, el oso tiene hijos, pero es un... un... un... un cocodrilo, un chanchito y un, a ver...Y un hipopótamo.

Le dice a ella que es amarilla también si ella es su madre. Y le dice que no, porque no tiene alas.

Acá le dice:

- Porque "usted tiene alas".

Y le dice:

- No, tampoco.

Acá le dice si es la madre porque tiene cachetes grandes.

Pero le dice que no. Y acá no sé qué pasa; está triste; después acá está llorando. Y acá encuentra una osa, le da un abrazo.

Y acá van a bailar. Y acá se disfraza para que se parezca a ella. Y acá dice que vayan a comer un pastel de manzanas. Y acá le presenta a los hijos. Y acá... y acá... están jugando... y acá termina.

4- Andy: "Choco encuentra una mamá"

Mirá acá le dijo:

- ¿Es usted mi mamá?

- No.

Y se fue llorando.

Y se encontró con la oso.

Y después lloró.

Y la osa vino a ver qué pasó.

Y después lo abrazó.

Y después le dio un bruto beso.

Y después acá cantó una canción.

Y después se ponía contra un palo.

Y después no era la mamá. No tenía cachetes como él.

Y después fue a la casa.

Y después... éste se llamaba.... Son hijos de ella. Este es el Chanchito. Este el cocodrilo y ésta es la osa y éste es hijo también. Y jugó con él y lo abrazó.

5- Sophíe: "Choco encuentra una mamá"

Se trata de éste que no tenía una mamá.

Que... que... le preguntó a todos los animales y... tuvo una mamá Oso que los hermanos... que los hijos no eran osos.

El loro. El lorito que le pregunta a la jirafa, y acá con los pingüinos. Yo no sé leer. 
6- Luisina: "El estofado del lobo"

Este es "el del pajarito."

Un pajarito... un pajarito... que estaba buscando madre...

Y encontró a una señora jirafa y le dijo a la señora jirafa:

- Señora Jirafa, usted ¿es mi mamá? Porque tiene color amarillo como yo.

Y la señora Jirafa dijo:

- No.

- ¡Hola Pingüino! ¿Tú eres mi mamá? Porque tienes, porque tienes... algunas cosas para volar como yo.

Y la mamá Pingüino dijo:

- No.

- ¡ ¡Hola señora ...¡Hola señora Morsa! ¿Usted es mi mamá? Porque tiene... tiene colita como yo.

Y la señora le dijo que no. Y entonces no encontró una madre que sea de él.

Después vio a una señora oso agarrando manzanas. Y entonces, le dijo:

- No llores. ¿Por qué estás llorando?

- Porque no tengo mamá.

- Mejor, así te cuidaré.

- Quiero un gran abrazo de mi madre.

Y él le dio un... Y la mamá oso le dio un abrazo. Y después lo llevó a su casa donde había otros hijos diferentes. $Y$ entonces, fueron y iban cantando por el bosque. Entonces, la mamá... el pajarito y la mamá oso... Y el pajarito le dijo:

- ¿Me contás un cuento?

Y le contó un cuento. Y entonces, la mamá Oso le puso "algo" como un oso. Y después se acariciaron los dos. Entonces, fueron a la casa de la mamá oso. Después se encontraron con los demás hijos. Eran un hipopótamo, un cocodrilo y un chanchito. Y entonces, después, la mamá oso estaba haciendo una torta y los niños jugaban y vivieron felices para siempre.

7- Mateo: "El estofado del lobo"

Que el lobo la quería comer a la gallina.

Y después pensó y dijo coman bien gallinita mía que eran sabrosas y primero le llevó panqueques y le dijo:

- $\quad$ Come bien, gallinita. 
Y después le llevó unas roscas y le dijo:

- Come bien, gallinita mía.

Y después fue a ver a la casa, por la puerta y la gallinita lo descubrió y dijo:

- $\quad$ Ahí está, el tío Lobo.

Y después los pollitos vinieron, saltaron y le dieron besitos.

Y después terminó.

\section{8- Néstor: "Choco encuentra una mamá"}

El pájaro que busca la mamá.

Y les pregunta a todos los animales quién es la mamá pero ninguno es. Después encuentra una madre oso... y le pregunta si es la madre y le dice que ella lo puede cuidar; que puede ser la madre. $Y$ ella no tiene un hijo solo. Tiene un cocodrilo, un cerdo y un... no me acuerdo...y un hipopótamo. Lo invitó a comer pastel de manzanas...Y terminó. No era parecida.

9- Santiago: "El estofado del lobo"

El lobo tiene hambre...y quería comerse una apetitosa gallina... tuvo un plan para comerla, se fue asomando para agarrarla y después tuvo una gran idea y se fue p'atrás. Estaba esperando para cortar la gallina para comerla; se iba llevando los panqueques para darle qué comer y después una rica torta y después fue a ver cómo estaba. Y la gallinita se asomó para ver quién era. Y el lobo se escondía detrás de la puerta. Y dijo:

- Pase señor lobo. ¡Pase!

Y entró. Y dice la gallina:

- $\quad$ No fue el tío que nos dio la comida fue el señor Lobo.

Después el señor que era el lobo se fue contento caminando por la callecita y dijo:

- $\quad$ Aprontaré unas ricas galletitas para que coman los pollitos y la gallina.

10- Milagros: "Choco encuentra una mamá"

Chocó se sentía triste porque no tenía una mamá. Y un día decidió ir a preguntarles a los otros animales si podrían ser su mamá. Primero se comunicó con la señora Jirafa y la señora Jirafa dijo:

- Perdón Choco, pero yo no soy tu mamá; no tengo las mejillas tan gordas como las tuyas.

Después con la señora Pingüino. Le dijo si podía ser su mamá. Le dijo que perdone, pero no tenía los pies rayados como él.

Después se encontró con la señora Elefante y la señora Elefante le dijo:

- Perdón Choco, yo no tengo alas como tú. 
Después, Choco vio a la señora Oso, y supo que ella no podía ser porque no tenía nada en la cara, nada igual. Entonces cuando él empezó a llorar:

- Quiero una mamá, quiero una mamá.

La señora Oso se arrimó corriendo a ver qué le sucedía. Entonces lo invitó a comer un pastel de manzanas y vio que todos los hijos de ella eran todos diferentes que ella.

Choco es feliz. O sea la mamá se disfrazó de pájaro...Para ver si tenían algo de iguales.

\section{1- Abigail "El estofado del lobo"}

El lobo quiere comer a la gallina.

La estaba persiguiendo pero después, no. Se fue a pensar en otra idea.

Hizo unos platillos para la señora gallina. Acá también y acá también. Acá llevó pasteles.

Y ahí fue a ver si estaba.

Acá la señora Gallina abrió la puerta y después los pollitos salieron. Y acá preparó galletitas. Para los pollitos.

\section{2- Priscilla "El estofado del lobo"}

El lobo quiere comer la gallina.

Y le da todo con lo que él pueda hacer con lo que él lee en el libro y le hace para que ella se vaya engordando y así la atrapa el lobo y la agarra.

Y como la gallina tenía tantos pollitos, salieron los pollitos y era él. Y él estaba vigilando ahí por el agujero de la casa de la gallina y así salieron todos los pollitos y se subieron arriba del lobo. Porque le estaban diciendo:

- Gracias, gracias.

Porque él era el tío Lobo. Porque les daba de todo de comer.

Le daba, le daba, galletitas, le daba, le daba, pasteles...

El lobo le hace cantidad de galletitas. Se va caminando para la casa y dice:

- No pude comer asado de gallina, pero otro día podré hacerle... otro día podré hacerle galletitas a los pollitos.

\section{3- Marcelo "El estofado del lobo"}

De un lobo, pila de pollitos y la gallina.

Mirá, el lobo se quiere comer la gallina ¿no? y siempre la mira y la mira, y está muy flaca.

- Mejor, la engordo.

Y fue a la cocina y cocinó bollos y panqueques y... y de todo y se lo llevaba a la gallina y a los hijos y después el lobo era el tío de los pollitos y fin.

14- Pablo "El estofado del lobo"

El lobo está con hambre y ve una gallina y la quiere agarrar y no la agarra. 
Porque él la va a engordar, quiere que coma y que se haga gorda.

Le hace torta, roscas, y panes y galletitas y se las da.

No la come porque tenía que dar de comer como a mil pajaritos y se hicieron amigos.

Y terminó, colorín, colorado este cuento terminó.

15- Luis: "El estofado del lobo"

De un pajarito que lloraba y lloraba porque no tenía mamá y estaba triste y lloraba...entonces le preguntó a la jirafa:

- ¿Vos sos mi mamá?

- No, no soy tu mamá.

Y...le dijo a la morsa y no era.

Y el pollito lloraba y después le dijo a un pingüino y tenía alas y entonces:

- ¿Vos sos mi mamá?

Pero no era y vio la osa...

La osa estaba en el bosque sacando manzanas para hacer un pastel y le iba a dar a sus hijos y entonces el pajarito también era su hijo y fue para la casa y estaba un cocodrilo, un chancho, un...otro más... y el pollito y vivieron felices en la casa de la osa. 
Grupo 2: Sin CQC (niños cuyos padres no participaron del Programa).

\section{Situación 2 - Renarración de un cuento}

La entrevistadora invita a uno de los niños seleccionados a sentarse y le muestra los tres cuentos que la maestra leyó previamente.

- ¿Conocés estos cuentos? Me los dio tu maestra y me dijo que se los había leído. Yo no los conozco, ¿qué tal son?, ¿te gustaron?

Luego le pide que elija uno y se lo cuente. Es importante que logre estimularlo para que el niño se anime a narrarlo. Incluso se puede abrir el libro en la primera página y preguntarle cómo comienza.

1- Valeria: "El estofado del lobo"

De una gallina... el lobo quería... iba tras de ellas... le hizo comida para ellos... y de noche se la llevó... estaba mirando por el agujerito...

Y después la gallina abrió y se asustó el lobo. Y después la gallina salió a contar los Pollitos. Y después los pollitos le dieron un besito al lobo.

\section{2- Denise "El estofado del lobo"}

Había un lobo...ahí estaba por agarrarla... y la gallina...

Le llevaba galletitas a los pollitos... acá la torta... y acá estaba golpeando la puerta. Y la gallina entró y estaba con los pollitos...

Se abraza con los pollitos.

\section{3- Eduardo: "El estofado del lobo"}

Iba al bosque y se convertía en lobo. Después la cola... las tortas...Este queda mal. Va a la casa de la abuelita... y fue a la casa de la abuelita y llegó feliz.

\section{4- Oscar "El estofado del lobo"}

El lobo que se quería comer una gallina.

La loba fue a agarrar los pajaritos y después se fue corriendo los pajaritos. Estaba contento con los pajaritos. La madre y el pajarito. Porque quería tener una madre y bailó. Estaba bailando contento nomás.

5- Víctor: "El estofado del lobo"

Es de un lobo.

Le llevaba pasteles, estaba corriendo, corriendo. Ahora va a la casita... un lobo...

El lobo vuelve. 
6- Gabriel "Choco encuentra una mamá"

Choco es un pajarito. No me acuerdo más.

7- Ismael: "El estofado del lobo"

El del lobo que quería comer la gallina. Acá le está dando tortas y ahí...pila de chocolate...Acá llevaba galletitas y se los llevaba a los pollitos... Acá lleva el Pastel a la casa de la gallina. Esta era la casa de la gallina...Abrió la puerta la gallina y se asustó... Ahí están todos los pollitos.

- ¡Mirá! ¡Mirá! acá hay una torta.

Y colorín colorado este cuento se ha terminado.

8- Santiago: "El estofado del lobo"

Un lobo que quería atrapar a la gallina y le quería dar comida para que engorde más, pero le daba a los pollitos. El lobo termina siendo el tío de los pollitos.

El estofado de pollo.

9- Giuliano: "Choco encuentra una mamá"

Choco estaba triste porque no tenía mamá. Le preguntó a la señora Jirafa:

- Tú eres amarilla como yo. ¿Vos sos mi madre?

- No - dijo la señora Jirafa -. Perdóname.

Otro día se encontró con una pingüino y le dijo:

- Tú tienes alitas como yo, ¿vos sos mi madre?

- $\quad$ No, yo no tengo mejillas como vos.

Después le dijo a la señora Foca:

- Vos tenés mejillas como yo - y le dijo - ¿vos sos mi madre?

- No. Perdón, Choco.

En un ratito se encontró con la señora Oso.

- No eres igualita a mí.

- No soy igualita a vos.

- Entonces no podrías ser mi madre.

Se continuó llorando. Salió corriendo la Osa a decirle qué le pasa.

- No tengo a mi madre.

- ¿Una madre podría darte un abrazo como yo?

- Sí. - Y le dio un tremendo abrazo-.

- ¿Me darías un besito como a todos los demás?

- Sí. - Y le dio un tremendo beso.

Entonces le dijo:

- ¿Me abrazarías muy fuerte?

Y entonces lo abrazó muy fuerte. Después se fue yendo para su casa para convidarlo con un pastel de manzanas. El señor Cerdito, el señor Cocodrilo también el hijo Hipopótamo se reunieron a venir a visitar al otro...

Y la madre estaba muy feliz. Estaba bien feliz la madre porque se divirtieron. Y colorín colorado este cuento se ha terminado. 


\section{0- Dahiana: "Choco encuentra una mamá"}

Al lorito se le murió la mamá. El lorito le preguntó si era la madre. Dice que no. Y le dice a ella que si es la madre y le dice que no. Y éste le dice que esta es la madre y tampoco, le dice que no.

Y se fue triste. Acá está llorando. Ninguna era la madre y empezó a llorar. Y el pajarito, el lorito, si ésa era la madre y le dijo que sí. Acá le dio besitos. Acá está comiendo. Éste se iba con éste. Y acá están con los padres. Y acá éste era el padre y éste era la madre. Acá está la madre. Y éste es la madre de éste. Y el lorito le dijo que si era la madre y le dijo que sí. Y acá está chocha. Acá estaba haciendo... $Y$ todos éstos eran los hijos.

\section{1- Facundo: "Choco encuentra una mamá"}

Choco encuentra una mamá. Era una osa. Le dijeron a una cantidad de animales, que le dijeron, a una morsa...

Una jirafa, aaah... el pingüino, la morsa, y después no conozco a nadie. A tres no más. Y después se fue. Se fue caminando triste y vio que una osa que estaba sacando manzanas y después él empieza a llorar y la osa lo agarra y le dijo si quería ser su mamá.

Después le dio un abrazo y después la mamá Osa lo llevó y le dio un beso. Lo llevó. Bailaron y después, estaban juntos hablando y... ¡Mirá cómo quedó!

Mirá tenía el cocodrilo, el rinoceronte y el chanchito.

Hijos de ella. Y acá ella estaba haciendo un pastel de manzanas.

Y ahí termina.

12- María: "El estofado del lobo"

Que el lobo iba a comer a la gallina. Le llevaba comida para que, pa que engorde la gallina y después se la coma.

\section{3- Mariela: "Choco encuentra una mamá"}

Era de un pajarito amarillo que buscaba su madre y buscaba...después la encuentra.

Le habló a la jirafa el pajarito, le habló al chancho, y..., y... le habló a otro pájaro pero no era su madre...la osa era la madre y terminó.

\section{4- Jhony: "El estofado del lobo"}

El del lobo... No me acuerdo mucho, el lobo...se va a comer la gallina...y la va a agarrar y...no no la agarra... Se la va a comer y ...le da de comer a los hijitos y le da torta y galletas y ....después está el del pajarito que encuentra la mamá.

Me acuerdo que está triste y que encuentra la mamá y que come la torta y terminó.

\section{5- Gabriela: "El estofado del lobo"}

El del lobo que se ponía las cosas de los amigos, las cosas...la cola, los pelos del león...la cola del...del...de otro lobo y quedaba todo horrible.

La gallina era... no me acuerdo, me parece que el lobo se fue corriendo porque estaba con hambre. 
ANEXO 3

Situación 3. Distribución de los datos sobre estructura narrativa y recursos literarios correspondientes al Grupo 1 y 2.

\section{DISTRIBUCIÓN DE LOS DATOS DEL GRUPO 1}

\begin{tabular}{|c|c|c|c|c|}
\hline & \multirow{2}{*}{$\begin{array}{l}\text { NOMBRE DEL } \\
\text { ALUMNO } \\
\text { (Con CQC) }\end{array}$} & \multirow{2}{*}{$\begin{array}{l}\text { a) } \\
\text { ESTRUCTURA } \\
\text { NARRATIVA }\end{array}$} & \multicolumn{2}{|c|}{$\begin{array}{l}\text { b) RECURSOS } \\
\text { LITERARIOS }\end{array}$} \\
\hline & & & Diálogos & Léxico \\
\hline 1 & Federico & $B$ & $A$ & $B$ \\
\hline 2 & David & C & C & $\mathrm{C}$ \\
\hline 3 & Facundo & $B$ & C & C \\
\hline 4 & Andy & $\mathrm{C}$ & $\mathrm{C}$ & $\mathrm{C}$ \\
\hline 5 & Sophie & $B$ & C & $C$ \\
\hline 6 & Luisina & $A$ & $A$ & $B$ \\
\hline 7 & Mateo & $B$ & $A$ & $B$ \\
\hline 8 & Néstor & C & C & $C$ \\
\hline 9 & Santiago & $B$ & $A$ & $A$ \\
\hline 10 & Milagros & B & $A$ & $A$ \\
\hline 11 & Abigail & C & C & $\mathrm{C}$ \\
\hline 12 & Priscila & $A$ & $B$ & $B$ \\
\hline 13 & Marcelo & $B$ & $\mathrm{C}$ & C \\
\hline 14 & Pablo & $A$ & $\mathrm{C}$ & $C$ \\
\hline 15 & Luis & $A$ & B & C \\
\hline
\end{tabular}




\section{DISTRIBUCIÓN DE LOS DATOS DEL GRUPO 2}

\begin{tabular}{|c|l|l|l|l|}
\hline & \multirow{2}{*}{$\begin{array}{l}\text { NOMBRE DEL } \\
\text { ALUMNO }\end{array}$} & $\begin{array}{l}\text { a) } \\
\text { ESTRUCTURA } \\
\text { NARRATIVA }\end{array}$ & \multicolumn{2}{|c|}{$\begin{array}{l}\text { b) RECURSOS } \\
\text { LITERARIOS }\end{array}$} \\
\cline { 4 - 6 } & & & Diálogos & Léxico \\
\hline $\mathbf{1}$ & Valeria & C & C & C \\
\hline $\mathbf{2}$ & Denisse & C & C & C \\
\hline $\mathbf{3}$ & Eduardo & C & C & C \\
\hline $\mathbf{4}$ & Oscar & C & C & C \\
\hline $\mathbf{5}$ & Víctor & C & C & C \\
\hline $\mathbf{6}$ & Gabriel & C & C & C \\
\hline $\mathbf{7}$ & Ismael & C & C & C \\
\hline $\mathbf{8}$ & Santiago & B & C & C \\
\hline $\mathbf{9}$ & Giuliano & B & B & A \\
\hline $\mathbf{1 0}$ & Dahiana & C & C & C \\
\hline $\mathbf{1 1}$ & Facundo & C & C & C \\
\hline $\mathbf{1 2}$ & María & C & C & C \\
\hline $\mathbf{1 3}$ & Marianela & C & C \\
\hline $\mathbf{1 4}$ & Jhony & Gabriela & C & C \\
\hline $\mathbf{1 5}$ & G & & \\
\hline
\end{tabular}


ANEXO 4

Situación 4. Distribución de los datos sobre escrituras correspondientes al Grupo 1 y 2.

\begin{tabular}{|c|c|c|c|c|c|}
\hline $\begin{array}{l}0 \\
\frac{0}{2} \\
\frac{\pi}{0}\end{array}-$ & $\begin{array}{l}\text { NOMBRE DEL } \\
\text { ALUMNO } \\
\text { (Con CQC) }\end{array}$ & $\begin{array}{l}\text { Escrituras } \\
\text { alfabéticas }\end{array}$ & $\begin{array}{l}\text { Escrituras } \\
\text { relacionadas } \\
\text { con la } \\
\text { sonoridad }\end{array}$ & $\begin{array}{c}\text { Escrituras que } \\
\text { no se } \\
\text { relacionan con } \\
\text { la sonoridad }\end{array}$ & NRT \\
\hline 1 & Federico & $X$ & & & \\
\hline 2 & David & & $X$ & & \\
\hline 3 & Facundo & & $X$ & & \\
\hline 4 & Andy & & $x$ & & \\
\hline 5 & Sophie & & $x$ & & \\
\hline 6 & Luisina & $X$ & & & \\
\hline 7 & Mateo & & $x$ & & \\
\hline 8 & Néstor & & $X$ & & \\
\hline 9 & Santiago & $x$ & & & \\
\hline 10 & Milagros & $x$ & & & \\
\hline 11 & Abigail & & $x$ & & \\
\hline 12 & Priscila & & $x$ & & \\
\hline 13 & Marcelo & & $x$ & & \\
\hline 14 & Pablo & & $x$ & & \\
\hline 15 & Luis & $x$ & & & \\
\hline
\end{tabular}




\begin{tabular}{|c|c|c|c|c|c|}
\hline 禽 N & $\begin{array}{l}\text { NOMBRE DEL } \\
\text { ALUMNO } \\
\text { (Sin CQC) }\end{array}$ & $\begin{array}{c}\text { A } \\
\text { Escrituras } \\
\text { alfabéticas }\end{array}$ & $\begin{array}{c}\text { B } \\
\text { Escrituras } \\
\text { relacionadas } \\
\text { con la } \\
\text { sonoridad }\end{array}$ & $\begin{array}{c}\text { C } \\
\text { Escrituras que } \\
\text { no se } \\
\text { relacionan con } \\
\text { la sonoridad }\end{array}$ & NRT \\
\hline 1 & Valeria & & $x$ & & \\
\hline 2 & Denisse & & & & $x$ \\
\hline 3 & Eduardo & & & $X$ & \\
\hline 4 & Oscar & & $x$ & & \\
\hline 5 & Víctor & & $\mathrm{X}$ & & $x$ \\
\hline 6 & Gabriel & & & & \\
\hline 7 & Ismael & & & $\mathrm{X}$ & \\
\hline 8 & Santiago & $x$ & & & \\
\hline 9 & Giuliano & $X$ & & & \\
\hline 10 & Dahiana & & & $x$ & \\
\hline 11 & Facundo & & $x$ & & \\
\hline 12 & María & & $X$ & & \\
\hline 13 & Marianela & & $x$ & & \\
\hline 14 & Jhony & & $X$ & & \\
\hline 15 & Gabriela & & $x$ & & \\
\hline
\end{tabular}




\section{ANEXO 5}

Distribución de los datos sobre Quién lee al niño; qué títulos recuerda y cuántos correspondientes al Grupo 1 y 2.

\begin{tabular}{|c|c|c|c|c|}
\hline 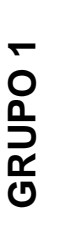 & $\begin{array}{l}\text { NOMBRE } \\
\text { DEL } \\
\text { ALUMNO } \\
\text { (con } \\
\text { CQC) }\end{array}$ & $\begin{array}{l}\text { QUIÉN } \\
\text { LE LEE }\end{array}$ & TÍTULOS QUE RECUERDA & CANTIDAD \\
\hline 1 & Federico & madre & $\begin{array}{l}\text { Caperucita Roja, La cenicienta, Pinocho, } \\
\text { Blancanieves, El patito feo, El gato con botas, el del } \\
\text { chancho (por El día de campo de Don chancho), El } \\
\text { estofado del lobo, Choco encuentra una mamá, El } \\
\text { regalo de Miguelito (por El regalo), La siesta del papá } \\
\text { elefante, La familia de los chanchos. }\end{array}$ & 12 \\
\hline 2 & David & madre & $\begin{array}{l}\text { Pinocho, El soldadito de plomo, El gato con botas, La } \\
\text { sirenita, Niña linda (por Niña Bonita), El del lobo (por } \\
\text { el estofado del lobo). }\end{array}$ & 6 \\
\hline 3 & Facundo & madre & $\begin{array}{l}\text { Los tres chanchitos, La bruja Berta, Una Pindó, La } \\
\text { liebre y la tortuga, Choco busca una mamá (por } \\
\text { Choco encuentra una mamá), El estofado de gallina } \\
\text { (por El estofado del lobo), Pulgarcito, Las princesitas, } \\
\text { Shrek. }\end{array}$ & 9 \\
\hline 4 & Andy & madre & $\begin{array}{l}\text { Caperucita Roja, Los enanitos (por Blancanieves), de } \\
\text { una bruja (no se pudo identificar título), Choco (por } \\
\text { Choco encuentra una mamá), El chancho Comilón } \\
\text { (por Camilón, Comilón). }\end{array}$ & 5 \\
\hline 5 & Sophie & nadie & $\begin{array}{l}\text { La otra orilla, La vaca Sofía (por Sofía, la vaca que } \\
\text { amaba la música), El de Marc (por De verdad que no } \\
\text { podía), Pinocho, Choco busca una mamá (por Choco } \\
\text { encuentra una mamá), El flautista (por El Flautista de } \\
\text { Hamelin), Pulgarcito, La casita de Chocolate. }\end{array}$ & 8 \\
\hline 6 & Luisina & madre & $\begin{array}{l}\text { Pinocho, No te rías Pepe, Julieta qué plantaste, } \\
\text { Olegario (por Olegario, el bicho de luz apagado), } \\
\text { Mariquita, Los tres cerditos, Federico dice No, El } \\
\text { estofado del lobo, Caperucita (por Caperucita Roja), } \\
\text { Sapo enamorado, de un ñandú (no se pudo identificar } \\
\text { título). }\end{array}$ & 11 \\
\hline 7 & Mateo & padre & $\begin{array}{l}\text { Harriet baila, Las habichuelas mágicas, Los gatos } \\
\text { (por Gato blanco, gato negro), Caperucita Roja, La } \\
\text { cenicienta, Pinocho, Hansel y Gretel, Olegario el } \\
\text { bicho de luz, El día de campo de Don Chancho. }\end{array}$ & 9 \\
\hline 8 & Néstor & maestra & $\begin{array}{l}\text { El del pajarito que busca la mamá (por Choco } \\
\text { encuentra una mamá), Caperucita, Patito feo (por El } \\
\text { patito feo). }\end{array}$ & ${ }^{3} 132$ \\
\hline
\end{tabular}




\begin{tabular}{|c|c|c|c|c|}
\hline 9 & Santiago & maestra & $\begin{array}{l}\text { Blancanieves, Ricitos de oro, Caperucita (por } \\
\text { Caperucita Roja), Pinocho, El patito feo, Sapo está } \\
\text { enamorado (por Sapo enamorado), El lobo que se } \\
\text { quería comer la gallina (por El estofado del lobo), el } \\
\text { de un pajarito que buscaba a su madre (por Choco } \\
\text { encuentra a su mamá). }\end{array}$ & 8 \\
\hline 10 & Milagros & hermana & $\begin{array}{l}\text { El pato que andaba en bici (no se pudo identificar } \\
\text { título), el del lobo y la gallina y los pollitos (por El } \\
\text { estofado del lobo), Choco (por Choco encuentra una } \\
\text { mamá), uno de los animales que duermen } \\
\text { (información leída por la maestra sobre los animales } \\
\text { que hibernan), los soldaditos (no se pudo identificar } \\
\text { título). }\end{array}$ & 5 \\
\hline 11 & Abigail & maestra & $\begin{array}{l}\text { Caperucita (por Caperucita Roja), el del lobo (por El } \\
\text { estofado del lobo). }\end{array}$ & 2 \\
\hline 12 & Priscila & hermana & $\begin{array}{l}\text { La casita de chocolate, Blancanieves, El estofado del } \\
\text { lobo, El chanchito comilón (por Camilón, comilón), } \\
\text { Una Pindó. }\end{array}$ & 5 \\
\hline 13 & Marcelo & abuela & $\begin{array}{l}\text { El patito feo, Los siete lobitos (por Los siete cabritos), } \\
\text { Dora la exploradora, Paula (revista), El lobo (por El } \\
\text { estofado del lobo). }\end{array}$ & 5 \\
\hline 14 & Pablo & madre & $\begin{array}{l}\text { Julieta qué plantaste, La sirenita, Pulgarcito, Los } \\
\text { backyardigans (serie de TV.), El estofado del lobo, La } \\
\text { otra orilla. }\end{array}$ & 6 \\
\hline 15 & Luis & maestra & $\begin{array}{l}\text { Choco (por Choco encuentra una mamá), La casita } \\
\text { de chocolate, Los dinosaurios (enciclopedia), de los } \\
\text { insectos (enciclopedia), Pinocho, Los cazavampiros } \\
\text { (serie de TV), La sirenita, Madagascar (película), el } \\
\text { del lobo (por El estofado del lobo). }\end{array}$ & 8 \\
\hline
\end{tabular}




\begin{tabular}{|c|c|c|c|c|}
\hline 禺 & $\begin{array}{l}\text { NOMBRE } \\
\text { DEL } \\
\text { ALUMNO } \\
\text { (sin CQC) }\end{array}$ & $\begin{array}{l}\text { QUIÉN } \\
\text { LE LEE }\end{array}$ & TíTULOS QUE RECUERDA & CUÁNTOS \\
\hline 1 & Valeria & maestra & $\begin{array}{l}\text { El estofado de la gallina (por El estofado del lobo), } \\
\text { Caperucita (por Caperucita Roja). }\end{array}$ & 2 \\
\hline 2 & Denisse & maestra & Caperucita Roja & 1 \\
\hline 3 & Eduardo & nadie & $\begin{array}{l}\text { El de un chancho y un lobo (no se pudo identificar el } \\
\text { título a que corresponde la referencia). }\end{array}$ & 0 \\
\hline 4 & Oscar & madre & $\begin{array}{l}\text { Los tres chanchitos, Pulgarcito, La tortuga Manuelita, } \\
\text { Los hermanos de la casita de chocolate (por Hansel } \\
\text { y Gretel o La Casita de chocolate), La hormiga y la } \\
\text { cigarra, el del lobo que tenía hambre (El estofado del } \\
\text { lobo). }\end{array}$ & 5 \\
\hline 5 & Víctor & maestra & $\begin{array}{l}\text { Pulgarcito, el de un pajarito amarillo (por Choco } \\
\text { encuentra una mamá), El lobo y la gallina (por El } \\
\text { estofado del lobo). }\end{array}$ & 3 \\
\hline 6 & Gabriel & nadie & Choco (por Choco encuentra una mamá). & 1 \\
\hline 7 & Ismael & madre & $\begin{array}{l}\text { Choco (por Choco encuentra una mamá), Las } \\
\text { plantas mágicas (por Las habichuelas mágicas), La } \\
\text { cenicienta, El gato con botas, Aladino (por Aladino y } \\
\text { la lámpara maravillosa). }\end{array}$ & 5 \\
\hline 8 & Santiago & maestra & $\begin{array}{l}\text { Una Pindó, El bicho Olegario (por Olegario el bicho } \\
\text { de luz apagado), El patito feo, El estofado del lobo. }\end{array}$ & 4 \\
\hline 9 & Giuliano & madre & $\begin{array}{l}\text { Pinocho, El patito feo, Julieta qué plantaste, Las } \\
\text { hormigas (enciclopedia), Chistes (revista), Miguelito } \\
\text { (por El regalo), El elefante que duerme (por La siesta } \\
\text { de papá elefante), Choco (por Choco que encuentra } \\
\text { una mamá), El estofado de pollo (por El estofado del } \\
\text { lobo). }\end{array}$ & 9 \\
\hline 10 & Dahiana & maestra & $\begin{array}{l}\text { Coco el cocodrilo (por Cirilo el cocodrilo), El ratón } \\
\text { valiente, El lorito Choco (por Choco encuentra una } \\
\text { mamá), de la palmera y la hormiga (por Una Pindó). }\end{array}$ & 4 \\
\hline 11 & Facundo & maestra & $\begin{array}{l}\text { El chanchito comilón (por Camilón comilón), el del } \\
\text { lobo que daba de comer a los pollitos (por El } \\
\text { estofado del lobo), Choco (por Choco encuentra una } \\
\text { mamá), Los tres cerditos, Sapo y Pata (por Sapo } \\
\text { enamorado), El patito feo, El soldado y la bailarina } \\
\text { (por El soldadito de plomo). }\end{array}$ & 7 \\
\hline 12 & María & abuela & $\begin{array}{l}\text { Blancanieves y los enanitos (por Blancanieves y los } \\
\text { siete enanitos), Caperucita Roja, El lobo y la gallina }\end{array}$ & 4 \\
\hline
\end{tabular}




\begin{tabular}{|c|l|c|l|c|}
\hline & & & (por El estofado del lobo), La abuela pirata. & \\
\hline $\mathbf{1 3}$ & Marianela & maestra & $\begin{array}{l}\text { Choco busca una mamá (por Choco encuentra una } \\
\text { mamá), Julieta (por Julieta qué plantaste), Caperucita } \\
\text { (por Caperucita Roja). }\end{array}$ & 3 \\
\hline $\mathbf{1 4}$ & Jhony & nadie & $\begin{array}{l}\text { Del lobo y un pajarito (no pudo identificar el título a } \\
\text { partir de los referentes dados, pudo referirse a uno, } \\
\text { dos cuentos o ninguno). }\end{array}$ & 0 \\
\hline $\mathbf{1 5}$ & Gabriela & maestra & De dinosaurios, de piratas, Pinocho. & 3 \\
\hline
\end{tabular}


ANEXO 6

\section{Programa de Alfabetización con la Familia}

Contenidos del MÓDULO 4

Metodología participativa: conceptos y técnicas. La interacción

lingüística como estrategia de aprendizajes permanentes.

Motivación para generar la participación de la comunidad en el

acercamiento al libro como objeto cultural y a otros materiales de

lectura. El momento a momento de un taller del Programa.

Hasta aquí hemos argumentado, desde la perspectiva teórica y experiencial, los contenidos conceptuales que subyacen en el programa Cuenta Quien Cuenta. Identificar una metodología coherente con ellos implicó todo un desafío. Esta debía dar respuestas a algunos aspectos pragmáticos y, por sobre todo, debía respetar los saberes y el proceso de cada padre de familia que participara de él.

En este sentido la búsqueda de la mejor forma de trabajar, a partir de la convicción de la importancia del involucramiento de las familias en el proceso de inclusión de los niños en la cultura escrita, estuvo orientada por los siguientes interrogantes:

¿Cómo reorientar la dinámica del trabajo con las familias y la lectura?

¿Cómo intervenir para que éstas recuperen su rol

en la formación inicial del niño como lector?

¿Cómo hacer de ésta una experiencia feliz?

\section{Las interacciones lingüísticas como generadoras de aprendizaje}

Desde el inicio del proceso de diseño y puesta en marcha del Programa, se ha destacado la importancia de las interacciones sociales como condición indispensable para que se genere todo aprendizaje lingüístico. A nivel de los adultos entre sí, en los talleres, y a nivel de las interacciones de los niños con sus adultos referentes, en el hogar.

Los niños están sujetos a aprender el modo en que está notificada la información culturalmente significativa que encuentran en todos los contextos sociales donde están presentes. Cuando los niños ingresan a la escuela han estado expuestos a la escritura y a la lectura en mayor o en menor medida. Esta variación, como lo hemos conversado en módulos anteriores, estará determinada por 
la valoración que la comunidad hace de estas prácticas. En síntesis, cada niño que ingresa a la escuela traerá consigo un capital cultural riquísimo y diferente pero en relación al conocimiento del mundo letrado este es, muchas veces, insuficiente para enfrentar la enseñanza formal en la escuela. Es necesario entonces crear las condiciones para exponer al niño al mundo escrito lo antes posible. Esta exposición informal a la escritura y la lectura no garantiza obviamente que el niño aprenderá a leer y escribir, pero será útil cuando el maestro le enseñe mediante actividades planificadas que aprovechen todos los aspectos significativos de los contextos sociales vividos por el niño.

Dentro de este enfoque se destacan autores como Jerome Bruner y Lev Vygotski, quienes consideran que el aprendizaje comienza en contextos sociales no formales, por ejemplo en su comunidad, en el hogar, y que la interacción con adultos a través de la participación en la cultura de lo escrito, como se registra en la práctica de los cuentos leídos por ejemplo, resulta fundamental.

\section{La metodología participativa}

La educación no formal, la educación popular, la pedagogía de la comunicación, la educación participativa refieren a procesos de trabajo con grupos que- aunque distintos- tienen como elemento común la utilización de metodologías participativas como ejes principales de la acción. Esta metodología se fundamenta en la concepción de que los participantes son actores o co-gestores de su propia realidad y de sus propios aprendizajes y propone vías horizontales que estimulan el potencial crítico y creador de los involucrados. A través de ella se pretende que el individuo se transforme en sujeto activo del proceso, apropiándose conscientemente de su realidad y elabore creativamente, en colaboración con otros, mecanismos para transformarla.

En este caso en particular, dicha realidad refiere a la complejidad del aprendizaje de la lectura y la escritura sumado a la ausencia de la intervención familiar en el acercamiento a la cultura escrita. A través de un proceso vivencial y reflexivo Cuenta Quien Cuenta pretende que las familias desarrollen acciones que potencialicen su rol como primer agente alfabetizador de sus hijos.

Convengamos que la participación de alguien en algo, no puede ser compulsiva. La participación implica poder expresarse creativamente, espontáneamente y por sobre todo críticamente; es imprescindible que la persona no se sienta presionada, y actúe en un ambiente de libertad y de confianza. La metodología participativa lleva implícita la idea de proceso integrado, armónico y coherente. Aunque integrado, este proceso es flexible y permite la adecuación a diversas situaciones y contextos; aunque armónico, provoca la confrontación de ideas y aunque coherente, tiende a introducir elementos que parecen romper esa coherencia.

El trabajo participativo e inclusivo, impone entonces un cambio de actitudes en lo que se refiere a las interrelaciones y formas de comunicación por parte de los educadores que se hallen coordinando cada taller.

Nos parece oportuno destacar que esta metodología, en su intencionalidad pedagógica, tiene una intencionalidad transformadora, entendiendo que la participación supone el acceso por parte de las familias, a un espacio de valorización de la palabra y de respeto por ella. Optar por una metodología participativa es optar por la búsqueda de alternativas metodológicas que se fundamentan en el fomento de la plena participación de los actores de esos procesos y conllevan 
una práctica consciente y transformadora de la realidad, que colabore en superar los problemas identificados.

Una metodología orientada hacia la participación activa debe utilizar técnicas que promuevan el intercambio de experiencias e información entre los participantes, haciendo uso de aquellas situaciones de aprendizaje que permitan favorecer la interrelación vivencial. Esto significa orientarse hacia un cambio de actitud autónomo y responsable, enriquecido a través del conocimiento y análisis de situaciones y experiencias vividas. Por lo antedicho proponemos, como uno de los elementos sustanciales de la metodología del Programa, el juego, el que supone, gozo, alegría y encuentro.

\section{Principios básicos de la metodología}

$\checkmark$ Partir de la realidad

Del bagaje de las experiencias lectoras, propias y cotidianas de los grupos, es que extraemos elementos conceptuales que a su vez generan una nueva práctica enriquecida. Se trata de facilitar procesos para que las mismas familias definan y redescubran la realidad partiendo de la vivencia cotidiana y de la experiencia acumulada. Por ejemplo, si el tema que se tratará, a través de la lectura de un cuento, es sobre la condición de género quizás se introduzca al mismo jugando o generando conversaciones sobre qué acciones cotidianas vivencian los participantes según sean ellos mujeres u hombres.

\section{$\checkmark$ Momento de reflexión}

El contenido del cuento o la historia narrada en el mismo es el pretexto que ayuda a poner de manifiesto algún elemento que configura a la familia en este tiempo histórico. La selección de los cuentos está orientada a facilitar la reflexión acerca de valores y actitudes relevantes socialmente (tales como la necesidad de tolerancia familiar y comunitaria; la comprensión de la diversidad cultural; la reflexión sobre la discriminación negativa hacia lo diferente y sobre el rol de cada integrante de la familia; los cambios y permanencias; la construcción de la identidad; etc).

Luego del análisis de esta realidad se promueve la reflexión sobre aquellos elementos que son expuestos; es un momento de reflexión colectiva donde cada participante comunica sus ideas, supuestos y experiencias. Si bien la interacción entre los participantes genera aprendizajes debemos conservar nuestro rol como educadores e intervenir en este momento para optimizar el proceso.

Nuestra intervención -en el marco de esta metodología- exige de nosotros el uso de una de las herramientas pedagógicas más válidas: la pregunta. El educador no interviene diciendo, aclarando, explicando, estableciendo su verdad, sino que dirige los comentarios vertidos en formas de preguntas. Por ejemplo:

¿Qué les parece a los demás lo que opina el papá de Pablo?

¿Han vivido ustedes una situación parecida a la del cuento? 
¿Se podría haber resuelto la situación de otra manera? ¿Cómo?

$\checkmark$ De la reflexión a una nueva práctica enriquecida.

En este proceso que propone el Programa, identificamos en un primer momento la importancia de la toma de conciencia por parte de la familia de objetivar la realidad a cuál nos referimos: la dificultad de los niños en el aprendizaje de la lectura y la escritura durante el primer año escolar. Luego de reflexionar y profundizar sobre la práctica, la familia construye aprendizajes que le permiten formular acciones en el seno de su hogar o con las demás familias, procesos que contribuyen a mejorar cualitativamente esa práctica y transformarla en una nueva y mejor.

\section{Condiciones que mejoran la participación.}

La participación no es un concepto único, estable y referido sólo a lo político. Es una dinámica mediante la cual los ciudadanos se involucran en forma consciente y voluntaria en todos los procesos que les afectan directa o indirectamente. Se habla de participación cuando la gente asiste a reuniones; cuando sale a la calle a manifestarse a favor o en contra de algo; cuando de manera pacífica se niega pública y notoriamente a comprar, hacer o decir algo que la mayoría considera correcto, cuando vota en los procesos electorales, cuando ejecuta determinadas tareas: campañas de alfabetización, de vacunación, etcétera. Todas estas son, sin duda, formas de participación pero, en relación al propósito del programa Cuenta Quien Cuenta, la principal forma es la participación en la toma de decisiones que le afecten a sí mismo e involucren a sus hijos.

Tengamos en cuenta que para participar es necesario tres condiciones básicas:

Querer hacerlo, tener un motivo, sentir una necesidad, estar motivado.

Saber hacerlo, haber tenido oportunidad de aprender a participar.

Poder hacerlo, que estén dadas las condiciones físicas, psicológicas, de tiempo y espacio.

También es importante que en cada encuentro se intente:

- dar respuesta a las necesidades, intereses y capacidades de los participantes

- integrar al participante como persona

- identificar y valorar los logros grupales

- realizar una propuesta atractiva y novedosa

- realizar un trabajo ordenado y regular

- proponer actividades graduando la complejidad

\section{Características de la metodología participativa}

Debe promover:

- Un ambiente lúdico: se trata de rescatar lo recreativo para ser instrumentalizado con propósitos didácticos, desformalizando el proceso educativo, permitiendo momentos de esparcimiento donde los participantes aprenden y se comunican. 
- El diálogo y la discusión: se pretende desarrollar la confrontación de ideas y llegar a conclusiones de consenso.

- La conciencia de grupo: el proceso metodológico debe estimular el sentimiento de pertenencia al grupo, para tender a la consolidación orgánica del mismo.

- La creatividad y la flexibilidad: Los procesos participativos obligan, por su dinámica, a un margen de flexibilidad para permitir adecuaciones creativas a las diferentes circunstancias.

- El compromiso de los participantes: No se aspira sólo a la participación de los individuos, sino además y fundamentalmente a que esa participación sea consciente y comprometida. Ese compromiso no sólo será verbal sino que tendrá que reflejarse en acciones concretas a favor de intereses colectivos.

- La formación: Se debe buscar la formación integral del individuo, que éste razone, opine, escuche, se manifieste y aporte al grupo.

\begin{tabular}{|l|}
\hline Momentos de cada taller \\
\hline 1. Dinámica de encuentro con el cuento. \\
\hline 2. Desarrollo de estrategias de comprensión de la lectura. \\
\hline 3. Los adultos leen a través del educador. \\
\hline 4. Espacio de descontextualización y reflexión sobre la temática o hechos \\
relevantes del cuento. \\
\hline 5. Taller de compaginación del libro. \\
\hline 6. Instalación de escenarios de lectura en el hogar.
\end{tabular}

\section{El momento a momento de un taller del Programa}

Como recordarán adelantamos la presentación de este esquema en el módulo 1. En esa oportunidad pretendimos describir el desarrollo de cada taller y destacar que la secuencia de actividades se mantiene estable aunque el contenido de las dinámicas, las estrategias de animación a la lectura y los cuentos varíen, encuentro a encuentro.

Ahora comentaremos en detalle cada momento. 


\section{Dinámica de encuentro con el cuento.}

Centrada en la estrategia lúdica, promueve la construcción de vínculos de confianza entre las familias y con los educadores. El juego o dinámica seleccionada está estrechamente vinculada con la temática del cuento que se leerá en el taller.

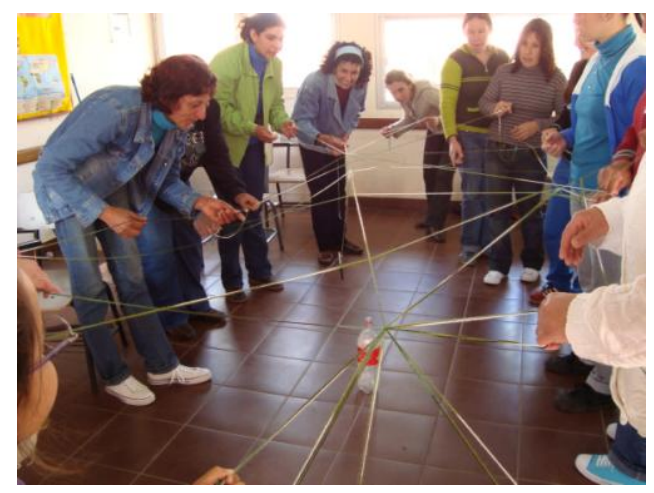

\section{Desarrollo de estrategias de comprensión de la lectura.}

Puesta en marcha de estrategias de lectura. En esta instancia los participantes realizan un aprendizaje integral del lenguaje en situaciones integrales. Las actividades de lectura se centran en el significado y no en el lenguaje en sí mismo, considera hechos auténticos del habla y de la lectoescritura. Se estimula para que se arriesguen a utilizar el lenguaje en todas sus variedades y teniendo en cuenta sus propios propósitos.

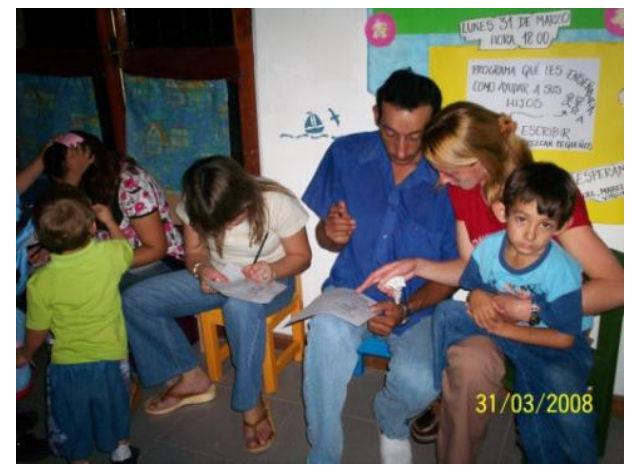

\section{Los adultos leen a través del educador}

Lectura del cuento seleccionado por parte del docente. El padre de familia que vive el acto aparentemente pasivo de escuchar -nos recuerda Roser Ros- confronta constantemente lo que oye y lo que podría haberle ocurrido a él. En esos instantes, se está produciendo un verdadero acto de comunicación durante el cual el adulto va captando intensamente el argumento, el que más tarde transmitirá a sus hijos, cuando les lea o narre el cuento.

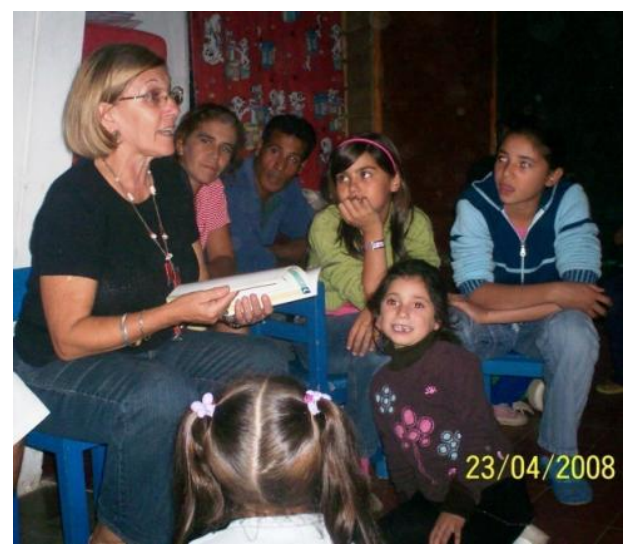

\section{Espacio de descontextualización y reflexión sobre la temática o hechos relevantes del cuento.}

Espacio de descontextualización y reflexión sobre los valores y mensajes del cuento. En este momento se generan preguntas sobre la temática del cuento y se indaga sobre si algunos de los participantes han vivido la historia como el personaje del cuento o han resuelto la situación de otra manera. Una vez culminada la lectura del cuento se abre un espacio a preguntas con el propósito de

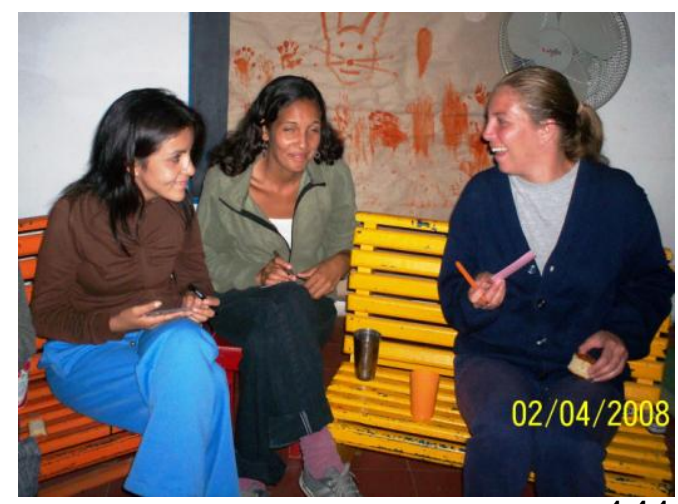


que cada adulto comente qué impactó del cuento en él. En general las temáticas seleccionadas son la condición de género, la identidad, la diversidad, los vínculos afectivos, la tolerancia, la resolución de conflictos, la amistad, la discriminación, los derechos humanos, etc.

Por ejemplo: si el tema central del cuento aborda la condición de género es probable que utilicemos algunas de las siguientes preguntas:

¿De dónde pensamos que proviene la creencia de que es la madre la que debe "planchar", "cocinar", "ordenar la casa", "ir a buscar el agua"...?

¿De qué manera son adjudicados los roles en la familia?

¿Cuánto incide en nosotros el modelo machista que predomina en nuestra sociedad?

¿Cómo se generan en cada familia las actitudes de colaboración y ayuda?

\section{Taller de compaginación del libro.}

Elaboración del libro. A cada participante se le entrega la transcripción del cuento leído, la tapa, contratapa e ilustración del personaje principal. Los padres de familia decoran el libro con diversas técnicas plásticas. Es una instancia donde conversan, estrechan vínculos y ponen de manifiesto su creatividad.

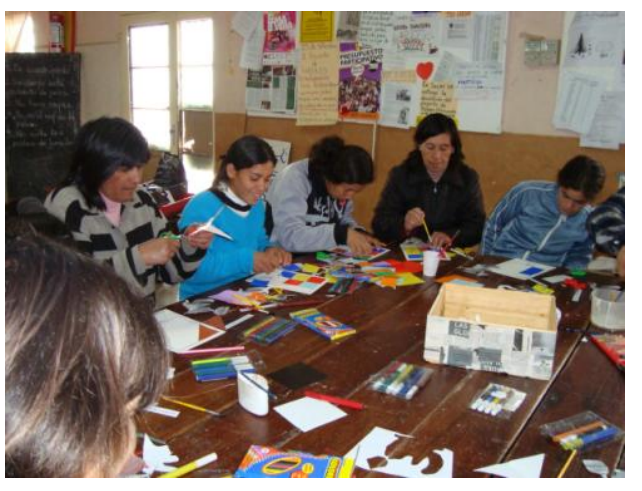

\section{Instalación de escenarios de lectura en el hogar.}

Ya hemos comentado que cuando los niños escuchan cuentos, historias y poemas, aprenden a identificar y relacionar la palabra hablada con lo escrito y su significado, se preguntan sobre la relación de las grafías y las palabras emitidas, de esta manera se construye el camino para que las niñas y los niños aprendan a leer de manera convencional. Las familias asumen el compromiso de leer (o narrar) el cuento que llevan para su casa antes del próximo encuentro.

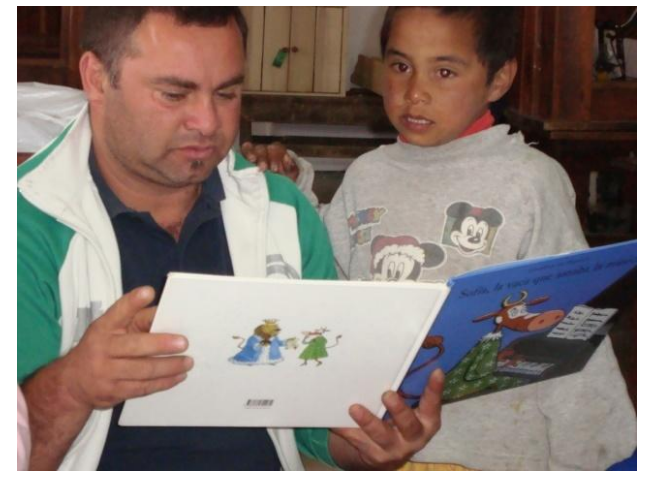




\section{Extensión a la comunidad}

El cierre del Programa es una instancia en que se concretan algunas acciones que ponen de manifiesto la importancia del proceso vivido por todos los padres de familia. En este momento hay que organizar en forma conjunta una actividad de festejo y de socialización de los aprendizajes. Por un lado las familias se organizan para realizar una actividad de extensión a la comunidad como por ejemplo: una maratón de cuentos (lectura de muchos cuentos durante un tiempo determinado y en un lugar acordado: escuela, plaza, mercado, etc),

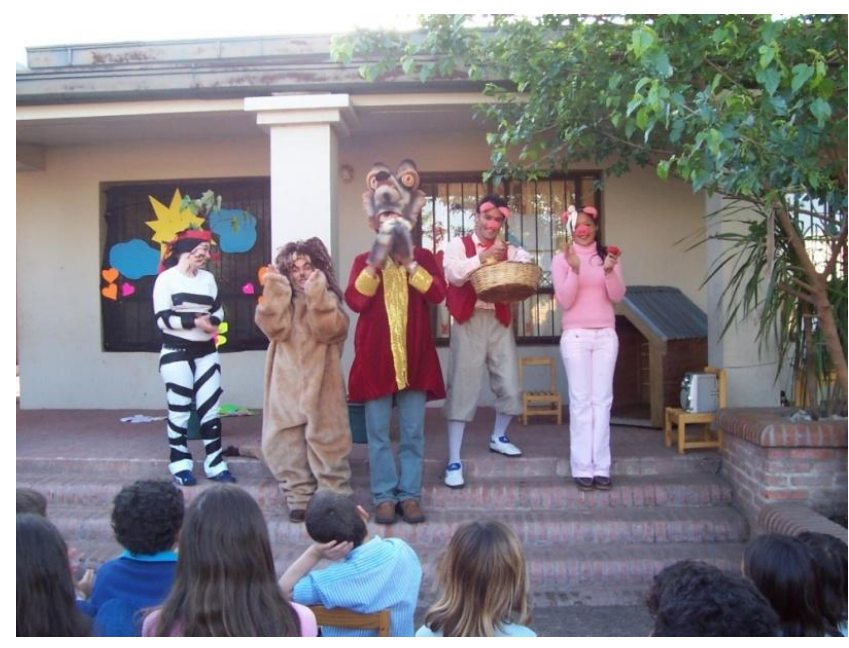
la dramatización, la donación de una colección de los libros del programa a la policlínica del barrio, otras escuelas, etc; ronda de lectura en las escuelas de la zona, etc. Por otro, los educadores que tuvieron a su cargo el desarrollo del Programa organizan una ceremonia donde se entregarán los certificados a los participantes.

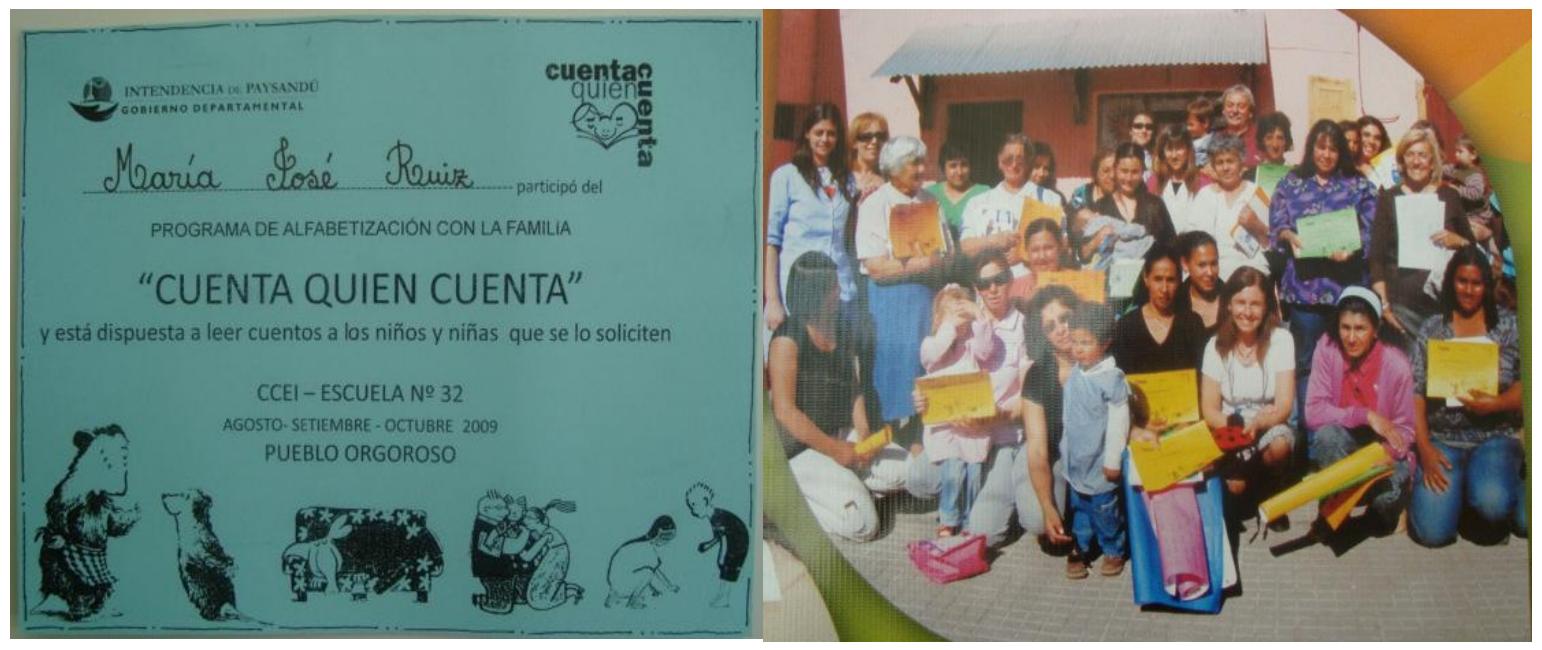

URUGUAY mariaguidali@gmail.com 